\title{
Die Cholera in Deutschland während des Winters 1892 bis $\left.1893 .{ }^{1}\right)$
}

\author{
(Aus dem Institut für Infektionskrankheiten zu Berlin.)
}

Von

Prof. R. Koch.

In der zweiten Hälfte des Oktober 1892 schien die große Choleraepidemie, welche in Hamburg seit dem 16. August gewütet hatte, ihr Ende erreicht zu haben. Da auch inzwischen alle von Hamburg ausgegangenen Ansteckungsherde erloschen waren, so durfte man sich der Hoffnung hingeben, daß die Choleragefahr vorläufig für Deutschland beseitigt sei. Diese Hoffnung erwies sich aber insofern irrig, als schon bald darauf in Hamburg eine Nachepidemie entstand, welche sich zwar innerhalb sehr geringer Dimensionen hielt, aber doch wieder zu einigen Verschleppungen der Seuche Veranlassung gab, welche mehr oder weniger heftige Ausbrüche der Cholera in Altona und in der Trrenanstalt Nietleben bei Halle bewirkten. Auf Veranlassung des Königl. Preußischen Kultusministeriums sind diese beiden letzterwähnten Epidemien vom Institut für Infektionskrankheiten unter meiner Leitung zum Gegenstand möglichst eingehender Untersuchungen gemacht, welche zu mehrfachen, nicht unwichtigen Ergebnissen geführt haben und deswegen hier eine eingehende Darstellung finden sollen.

Der Choleraausbruch in Altona steht mit der Hamburger Nachepidemie in einem so innigen Zusammenhang, und letztere bietet außerdem einige für meine Auseinandersetzungen so charakteristische Züge, daß ich eine ganz kurze Besprechung dieser Nachepidemie vorausschicken muß. Eine eingehende Schilderung derselben dürfen wir wohl von dem offiziellen Bericht, welchen im Auftrage der Reichsbehörden Prof. Ga f f $k$ y in Gießen bearbeitet, erwarten.

\section{Die Nachepidemie in Hamburg.}

Die erste Epidemie hatte in Hamburg am 16. August 1892 begonnen und konnte am 23. Oktober als beendigt angesehen werden. Am 9. und 11. November folgten noch vereinzelte Fälle ${ }^{2}$ ). Während dieser Epidemie betrug die Zahl der Erkrankungen 18000 mit 8200 Todesfällen. Den Beginn der Nachepidemie kann man vom 6. Dezember ab rechnen. Die letzte Erkrankưntg, welche derselben angehört, wurde am 4. März konstatiert, die vorletzte am 11. Februar. Auf diese zweite Epidemie kommen nur 64 Erkrankungen mit 18 Todesfällen. Läßt man die beiden vereinzelten Nachzügler der ersten und den letzten Fall der zweiten Epidemie unberücksichtigt, dann haben beide eine úngefähr gleichlange Dauer von etwas mehr als zwei Monaten. Aber welch ein gewaltiger

1) Aus Zeitschrift für Hygiene und Infektionskrankheiten, 1893, Bd. XV. - Eingegangen am 24. Juli 1893.

2) Reincke, Die Cholera in Hamburg. Deutsche Medizinische Wochenschrift, 1893, Nr. 3 u. 4. 
Unterschied in der Intensität dieser beiden Epidemien trotz der Übereinstimmung in bezug auf die Zeit, welche sie in Anspruch nehmen!

Man könnte meinen, daß die Jahreszeit von Einfluß gewesen sei und daß die Epidemie des Sommers durch die hohe Temperatur begünstigt wurde und deswegen so bedeutende Dimensionen erreichte, während die Winterepidemie bei der herrschenden Kälte sich nur kümmerlich entwickeln konnte. Diese Erklärung läßt sich aber nicht aufrechterhalten, wenn man berücksichtigt, daß in demselben Winter und zwar in der kältesten Periode desselben die niedrige Temperatur nicht imstande war, in Nietleben einen Choleraausbruch zu verhüten, welcher eine im Verhältnis zur Bevölkerungsziffer viel höhere Morbidiät aufweist als die Hamburger Sommerepidemie. Aus früheren Choleraepidemien sind auch anderweitige Vorkommnisse bekannt, welche beweisen, daß im Winter die heftigsten Ausbrüche gelegentlich entstehen können. Den Temperaturunterschieden kann man in diesem Falle also keine wesentliche Rolle beimessen. Ebensowenig läßt sich behaupten, daß Hamburg durch die erste Epidemie durchseucht wurde und wegen einer Art von Immunisierung nur noch Stoff für eine geringe Nachepidemie bot. Obwohl ich einer derartigen Auffassungsweise im allgemeinen beistimme, so möchte ich im vorliegenden Falle doch darauf hinweisen, daß Hamburg bei früheren Gelegenheiten mehrfach innerhalb Jahresfrist größere Epidemien hintereinander gehabt hat, was auch nicht zu verwundern ist, weil die Bevölkerung Hamburgs stark fluktuiert. Dazu kommt, daß eine große Zahl der Einwohner beim Beginn der Epidemie die Stadt verlassen hatte und daß diese Flüchtlinge bei ihrer Rückkehr im Oktober der Stadt eine nicht unbedeutende Menge von nicht durchseuchtem Material zuführten, ohne daß ein dadurch bedingtes Anschwellen der Epidemie beobachtet wurde.

Wir müssen uns also nach einer anderen Erklärung jener auffallenden Erscheinung umsehen und ich glaube dieselbe in folgender Weise geben zu können.

Bereits früher habe ich darauf aufmerksam gemacht, daß die Cholera bei ihren Ausbrüchen zwei ganz verschiedene Typen zeigt. Der eine besteht in einem explosionsartigen Verlaufe. Die graphische Darstellung eines solchen Ausbruchs gibt eine Kurve mit steil ansteigendem, hoch hinaufgehendem ersten Schenkel und fast ebenso steil abfallendem zweiten Schenkel. Der zweite Typus erscheint graphisch dargestellt dagegen wie eine nur wenig über die Grundlinie sich erhebende Kurve. Hamburg zeigt diese beiden Typen in seinen letzten Epidemien in einer geradezu extremen Form. Die Kurve der Sommerepidemie erscheint wie ein sehr hohes und spitzes Dreieck mit ganz schmaler Basis, die Kurve der Nachepidemie erhebt sich so wenig über die Basis hinaus, daß sie mit letzterer fast zusammenfällt.

Der erste Typus kommt dadurch zustande, daß der Infektionsstoff auf einmal und gleichmäßig über den befallenen Ort ausgestreut wird. Es muß dann eine Epidemie entstehen, welche explosionsartig verläuft und in graphischer Darstellung eine um so höhere und steilere Kurve bildet, je größer die Menge des gleichsam ausgesäten Infektionsstoffes war. Bedingung für diesen Typus der Epidemie ist aber, daß die örtliche Verteilung der Erkrankungsfälle eine einigermaßen gleichmäßige ist und daß die einzelnen Fälle keinen unmittelbaren Zusammenhang untereinander erkennen lassen. Allerdings darf man sich, selbst wenn dieser Typus am reinsten auftritt, die Verteilung nicht zu gleichmäßig und zu schematisch vorstellen. Denn die Aussaat wird wohl kaum jemals eine ganz gleichmäßige sein und auch der Boden, auf welchen sie fällt, ist nicht in allen seinen Teilen in gleicher Weise geeignet, den Keim zur Entwicklung zu bringen. Es werden individuelle Disposition, Reinlichkeit, Ernährung, Bevölkerungsdichtigkeit, mancherlei Lebensgewohnheiten usw. einen nicht zu unterschätzenden Einfluß ausüben. Eine gleichmäßige Aussaat, wie sie bei diesem Typus vorausgesetzt wird, kann nur durch etwas 
zustande kommen, was auf alle oder doch die meisten Bewohner eines Ortes zu gleicher Zeit wirken kann, wie Luft, Wasser, Boden, Nahrungsmittel. Aber weder Luft, noch Boden, noch Nahrungsmittel konnten bisher als Vermittler explosionsartiger Choleraausbrüche nachgewiesen werden. Auch Inselkten, an welche man mit Recht gedacht hat, können hier nicht in Frage kommen; da Choleraexplosionen gar nicht so selten in der kalten Jahreszeit vorkommen, wo die Übertragung durch Insekten bestimmt ausgeschlossen ist. Kleinere Gruppenerkrankungen mögen durch infizierte Nahrungsmittel wohl vorkommen und es ist auch nicht zu bestreiten, daß Insekten durch Verschleppung des Infektionsstoffes auf Nahrungsmittel hierbei eine Rolle spielen können; aber die plötzliche Infektion ganzer Ortschaften, wie wir sie bei der Cholera so oft erleben, lassen sich auf diese Weise nicht erklären. Es bleibt also nur das Wasser; und daß dieses in der Tat der Träger des Cholerakeimes nicht nur für einzelne Gruppen in der Bevölkerung einer Ortschaft, sondern für ganze Ortschaften und selbst große Städte sein kann, haben frühere Epidemien und ganz besonders wieder die jetzige an den Chöleraausbrüchen in Hamburg, Altona und Nietleben bewiesen. Aber gerade gegen die Annahme, daß der Infektionsstoff durch das Wasser verschleppt wird, hat man den Einwand gemacht, daß die Verteilung der Krankheit in solchen Epidemien eine zu ungleichmäßige gewesen. sei; das infizierte Wasser gelange doch in alle Haushaltungen und trotzdem finde man Häuser und ganze Straßen in dem mit solchem Wasser versorgten Gebiet, welche wenig oder gar nicht von Cholera ergriffen wurden; es müßten doch eigentlich, wenn das Wasser die Ursache sei, alle Menschen, welche damit in Berührung kommen, nach einem gewissen Prozentsatz ergriffen sein. Diese Voraussetzung würde allerdings dann richtig sein, wenn das Choleragift ein im Wasser aufgelöster, ganz gleichmäßig verteilter Stoff wäre, wenn alle erkrankten. Menschen genau gleiche Mengen davon zu sich genommen hätten und die Empfänglichkeit für das Gift bei allen Menschen gleich groß wäre. Aber wir wissen doch zur Genüge, daß nicht eine einzige dieser Bedingungen zutrifft. Es besteht unzweifelhaft, wie auch ganz besonders von bakteriologischer Seite von jeher hervorgehoben ist, eine große Verschiedenheit in der individuellen Disposition für Choleraerkrankung. Ferner braucht wohl kaum darauf hingewiesen zu werden, daß die Möglichkeit der Infektion durch Wasser für verschiedene Menschen eine sehr verschiedene sein muß, je nach ihren Beziehungen zum Wasser. Der eine genießt überhaupt kein Wasser, er kommt nur indirekt durch die Verwendung des Wassers im Haushalt damit in Berührung und er ist somit der Gefahr der Infektion entsprechend weniger ausgesetzt, als ein anderer, welcher das Wasser trinkt. Aber auch in bezug auf den letzteren wird es nicht gleichgültig sein, ob er viel oder wenig Wasser trinkt, zu welcher Zeit er es trinkt, ob bei leerem oder gefülltem Magen, ob seine Magen- und Darmfunktionen gleichzeitig in Ordnung sind oder nicht, ob Exzesse begangen wurden usw. Auch die Verteilung des Infektionsstoffes, d. h. der Cholerabakterien im Wasser, ist allem Anscheine nach nicht so, wie man vielfach annimmt. Die neuesten bakteriologischen Untersuchungen ${ }^{1}$ ) lassen erkennen, daß die Cholerabakterien vielleicht nur ausnahmsweise in größerer Menge im Wasser vorkommen, und es ist deswegen durchaus nicht notwendig, daß in jedem Tropfen oder in jedem Schluck infizierten Wassers Cholerabalkterien enthalten seien. Es ist auch sehr die Frage, ob sie von Anfang an ganz gleichmäßig in dem Wasser verteilt sind oder, wenn sie dies sind, auch bleiben. Man kann sich wohl denken, daß sie ebenso wie andere Bakterien gelegentlich an festen Gegenständen, z. B. der Innenwand einer Rohrleitung, festhaften, was besonders dann der Fall sein wird, wenn die Bewegung des Wassers vorübergehend oder dauernd verlangsamt ist. Sie können dann an der Stelle, wo sie sich festgesetzt haben, zugrunde gehen, unter günstigeren Verhältnissen sich aber auch ver-

I) Zeitschrift für Hygiene und Infektionskrankheiten, Bd. XIV, p. 336. 
mehren, oder durch stärkere Strömungen wieder losgerissen werden. ¿̈berhaupt muß die ungleichmäßige Bewegung des Wassers in einem Leitungsnetz einen erheblichen Einfluß auf die Beförderung der Cholerabakterien ausüben, und es kann allein dadurch schon bewirkt werden, daß in einem Rohrstrang viele, in einem anderen Strang wenige Cholerabalkterien in die angeschlossenen Häuser gespült werden. Sind dann zufällig noch diese Häuser von. Wohlhabenden bewohnt, welche infolge ihrer Lebensgewohnheiten an und für sich der Cholera wenig Angriffspunkte bieten, dann kann es kommen, daß ganze Häuserreihen, selbst Straßen von der Krankheit verschont bleiben, ohne daß man berechtigt wäre, daraus einen Beweis gegen die Annahme der Wasserinfektion abzuleiten.

Dieselbe Frage, welche uns hier beschäftigt, ist auch schon in früheren Zeiten erörtert, und es dürfte wohl nicht überflüssig sein, an das zu erinnern, was $\mathrm{F}$ a $\mathrm{r}^{\mathrm{r}}{ }^{1}$ ) in sehr treffender Weise denjenigen erwiderte, welche bestritten, daß die im Jahre 1866 im Bereiche der East-London-Wasserwerke ausgebrochene Cholera durch Infektion des Wassers entstanden sei. Damals ließ sich die ungenügende Reinigung des Wassers in dem Filterwerke noch nicht durch die bakteriologische Untersuchung nachweisen, aber man hatte einen anderen Anhaltspunkt dafür, daß die Filtration vorübergehend defekt gewesen sein mußte. Es waren in der Wasserleitung einer Anzahl ron Häusern kleine Fische (Aale) zum Vorschein gekommen, welche den unzweideutigen Beweis dafür lieferten, daß in die Leitung auch unfiltriertes Wasser geraten war-2). F a r r schloß daraus, daß auf demselben Wege, den die Fische gefunden hatten, auch Choleragift aus dem mit Fäkalien stark verunreinigten Lea-Fluß in die Wasserleitung und damit in die Cholerahäuser gelangt sei. Nun sagten aber die Gegner F a r rs, daß in vielen Häusern, welche Wasser von dem East-London-Wasserwerk erhielten, keine Cholera gewesen sei und daß deswegen das Wasser an der Choleraverbreitung nicht beteiligt sein könne. Farrs Entgegnung auf diesen Einwand lautete folgendermaßen:

,Eels, as we have seen, were found in the water of a certain number of houses in East-London. To argue that in hundred of other houses no eels were found, and that therefore the company never distributed eels in the district, would be absurd. The fallacy of such reasoning is transparent. It assumes the form - if no eels are found in the waters of a certain number of houses none exist in the waters of any houses. As the eels are limited in number, they cannot be distributed universally, and the fact that they were discovered in one house and not another would depend on laws and circumstances so intricate as to make the ascertained distribution anomalous, but not necessarily more anomalous, than the distribution of the lower forms of organized matter, to which the phenomena of cholera in man are due."

Der zweite Typus der Cholera unterscheidet sich von dem ersten nicht allein durch die Gestalt der Kurve, sondern auch durch einige andere charakteristische Eigenschaften. Die Verteilung der einzelnen Fälle ist bei demselben keine gleichmäßige; es bilden sich in ganz ausgesprochener Weise Herde, an denen sich die Krankheit einnistet. An einem solchen Herde entstehen auch nicht plötzlich viele Fälle, sondern sie folgen einander, bilden gewissermaßen Ketten und es läßt sich sehr oft ein unmittelbarer Zusammenhang zwischen den einzelnen Fällen des Herdes ermitteln. Es erkrankt z. B. zuerst ein von auswärts gekommener Mensch, nach wenigen Tagen das eine oder andere Mitglied der Familie, in welcher der Erkrankte verpflegt wurde, dann rasch hintereinander, oft aber auch in längeren Pausen, weitere Angehörige der Familie, Bewohner desselben Hauses,

1) Report on the Cholera epidemic of 1866 in England, London 1868, p. XXV.

2) Eine Vernehmung der Arbeiter und Ingenieure des Wasserwerkas ergab, daß in der Tat wiederholt unfiltriertes Wasser in die Leitung gepumpt war. A. a. O. p. XVIIff. 
Nachbarn, Menschen, welche in dem verseuchten Hause verisehren usw. Von dem crsten Herde können durch Verschleppung neue Herde in anderen Stadtteilen, in benachbarten Orten ausgehen, in denen wiederum kettenförmig aneinandergereihte Fälle eine mehr oder weniger große Gruppenerkrankung ausmachen.

Auch hier darf man nicht verlangen, daß in der Kette der Erkrankungen jedes einzelne Glied deutlich erkennbar sein muß. Es ist unmöglich den Verkehr der Menschen untereinander bis in seine feinsten Fäden bloßzulegen und jede Person herauszufinden, die mit einem Cholerakranken direkt oder indirekt in Berührung gekommen ist. Würden die einzelnen Cholerafälle von vornherein so schwer verlaufen, daß sie sämtlich zur ärztlichen Kenntnis kommen müßten, würde die Ansteckungsfähigkeit des Cholerakranken mit der Überstehung des Choleraanfalls beendigt sein und geschähe die Ansteckung nur durch unmittelbaren Kontakt, dann würden allerdings trotz der verwickelten Beziehungen des Verkehrs mit Hilfe der bakteriologischen Diagnose mit nur wenigen Ausnahmen die einzelnen Kettenglieder herauszufinden sein.

Aber wir wissen jetzt, daß unter den Cholerainfizierten neben schweren auch Erkrankungen so leichten Grades vorkommen, daß sie in der Regel unerkannt bleiben; wir wissen ferner, daß der eigentliche Choleraanfall nur den am meisten in die Augen fallenden Teil der Erkrankung bildet, und daß sowohl vor als nach demselben der Infektionsstoff in den Ausleerungen der Kranken enthalten sein kann, also zu einer Zeit, wo diese Menschen für den Verkehr noch nicht verdächtig oder schon wieder als unverdächtig gelten. Schließlich kommt noch in Betracht, daß die Übertragung durchaus nicht immer unmittelbar von dem Cholerakranken ausgeht, sondern viel häufiger noch durch Wäsche, Kleider, Betten, Nahrungsmittel, Insekten usw. auf indirektem Wege zustande kommt. Wenn man dies alles berücksichtigt, dann wird man es gewiß erklärlich finden, daß zwar in einer dünn gesäten Bevölkerung auf dem Lande mit wenig komplizierten Verkehrsverhältnissen der Zusammenhang zwischen den einzelnen Fällen noch ziemlich vollständig gefunden wird, daß es aber in größeren Städten nur hin und wieder gelingt, die Zusammengehörigkeit der Glieder einer solchen vielfach verschlungenen, oft auch in Verästelungen auslaufenden Kette zu ermitteln. Ganz besonders wird der Überblick über diese Art der Choleraverbreitung dadurch erschwert, daß sie sich fast ausschließlich auf die untersten dicht züsammengedrängten und fortwährend fluktuierenden Schichten der Bevölkerung beschränkt, und nur hier und da einmal auf die besser Situierten übergreift. Und doch läßt sich dieser Typus der Cholera ziemlich leicht an der fleckweisen, herdförmigen Gruppierung der Cholerafälle erkennen. Bei sorgfältigem Nachforschen findet man in solchen Fällen regelmäßig Choleranester, in denen die Einschleppung und das weitere schrittweise Umsichgreifen deutlich hervortritt.

Es würde nun aber irrig sein, anzunehmen, daß die Cholera immer nur den einen oder den anderen der beiden Typen einhalten muß; denn es liegt doch auf der Hand, daß beide miteinander kombiniert sein können, oft genug sogar kombiniert sein müssen. So wird namentlich der erste Typus, welcher meistens anfangs rein auftritt, sich im weiteren Verlaufe mit dem zweiten Typus kombinieren und schließlich ganz in denselben übergehen. Auch kommt es vor, daß die Ortsepidemie mit dem zweiten Typus beginnt, bis der Infektionsstoff zufällig seinen Weg in das Wasser findet und dann je nach der Art der Wasserversorgung kleine umschriebene Explosionen bewirkt, oder einen ganzen Bezirk, unter Umständen auch den ganzen Ort plötzlich infiziert.

Auch das darf nicht unerwähnt bleiben, daß die Gestalt der Cholerakurve allein nicht ausschlaggebend für den einen oder anderen Typus ist. Es kann die Kurve sehr niedrig bleiben und doch eine Wasserepidemie vorliegen; wenn nämlich die Aussaat der Cholerabakterien durch das Wasser nur eine sehr dünne ist. Andererseits ist auch nicht 
ausgeschlossen, daß viele und fast gleichzeitig entstandene Herde der Kurve eine Gestalt geben können, welche sich derjenigen des ersten Typus mehr oder weniger nähert, so daß der zweite Typus die äußere Form des ersten Typus annehmen kann. Man darf eben bei der Beurteilung von Choleraepidemien, wenn man Irrtümer vermeiden will, nicht in das Schematisieren verfallen, sondern muß jede einzelne Ortsepidemie für sich untersuchen, um entscheiden zu können, wieviel davon dem einen oder dem anderen Typus angehört. Die jetzige Epidemie hat uns in dieser Beziehung außerordentlich lehrreiche Beispiele geliefert.

So gehörte die Hamburger Sommerepidemie in ihrem ersten Teile ausschließlich dem ersten Typus an. Von Anfang an waren die Erkrankungen ohne Zusammenhang und wiesen zuerst auf den Hafen als einzige Infektionsquelle hin. Wegen der Beziehungen der Wasserversorgung Hamburgs zur Elbe und indirekt zum Hafen mußte schon damals eine allgemeine Explosion befürchtet werden, welche leider auch nicht ausgeblieben ist. Gegen Ende ging dann die Epidemie in den zweiten Typus über.

Die Hamburger Winterepidemie dagegen hat sich während ihrer ganzen Dauer fast rein in der Form des zweiten Typus gehalten. Sie hatte von vornherein die Neigung zur Herdbildung.

Einer dieser Herde hatte seinen Sitz in der Neustadt, ein zweiter im Stadtteil St. Georg und der dritte in der Vorstadt St. Pauli. Ob alle drei Herde in Zusammenhang stehen, hat sich nicht ermitteln lassen. Es ist aber auch nicht wahrscheinlich, daß dies der Fall gewesen und daß die Krankheit etwa von dem ersten Herd in der Neustadt nach St. Georg und St. Pauli verschleppt ist. Es hat vielmehr den Anschein, daß die beiden ersten aus unentdeckt gebliebenen Nachzüglern der Sommerepidemie herrorgegangen sind. Die Sommerepidemie war, wie bereits früher angegeben ist, am 23. Oktober beendet. Aber am 9. und 11. November wurden noch Fälle von echter Cholera konstatiert und diese werden wohl nicht die einzigen gewesen sein. Wenn also am 6. Dezember die Nachepidemie ihren Anfang nahm, so war kein größerer Zwischenraum zwischen den beiden Hamburger Epidemien als höchstens vier Wochen, und da ist es wohl nicht notwendig, an eine neue Einschleppung zu denken. Ich wüßte auch nicht, woher die Cholera eingeschleppt sein sollte, da sie zu jener Zeit überall erloschen war.

$\mathrm{Ob}$ die Erkrankungen in St. Pauli als Herd zu bezeichnen sind, kann bezweifelt werden. Einige von ihnen sind höchst wahrscheinlich auf Altona zurückzuführen, andere stehen möglicherweise mit dem Herd in der Neustadt in Beziehung, so daß nur sehr wenig übrig bleibt.

Sehr charakteristisch ist für die Nachepidemie, daß die Erkrankten ausnahmslos den untersten Volksschichten angehörten. Es waren zum Teil arbeits- und obdachlose Menschen, Alkoholiker, welche in Bettlerherbergen und Branntweinschänken hausten; umherziehende Händler, welche Streichhölzer, Wurst oder dergleichen verkauften und durch ihr Gewerbe ebenfalls in jene Lokale geführt wurden; einzelne Matrosen, Hafenarbeiter, Polizeigefangene usw. Mit Ausnahme von acht Fällen ließen sich überall Beziehungen zu solchen Personen nachweisen, welche vorher an Cholera erkrankt waren und von denen sie direkt oder indirekt infiziert sein konnten. Dieser Nachweis ist allerdings nur der überaus gründlichen Untersuchung zu verdanken, welche die Sanitätspolizei auf jeden einzelnen Fall verwendet hat. Eine oberflächliche Untersuchung, wie sie früher unter ähnlichen. Verhältnissen üblich war, hätte den Zusammenhang gewiß nicht herausgefunden, und es wäre zu den vielen scheinbaren Cholerarätseln aus früheren Zeiten ein neues hinzugekommen.

Irgendeine gemeinsame Ursache, wie Einfluß des Bodens, Wassers oder dergleichen konnte während dieser Epidemie mit Sicherheit ausgeschlossen werden. Die Wasser- 
leitung konnte nicht in Frage kommen, da der Cholerabezirk sich nicht wie im Sommer mit dem Bereich der Wasserleitung deckte. Der Boden hätte insofern verdächtig erscheinen können, als die Krankheit mit einzelnen Lokalitäten verknüpft war. Doch konnte auch hierbei nicht der Ort das Maßgebende sein, sondern die auf demselben befindlichen Menschen, weil immer sofort nach Entfernung der Kranken und Verdächtigen die Krankheit aufhörte. Hätte das infizierende Agens an der Lokalität gehaftet, dann hätten trotz der Beseitigung der infizierten Menschen weitere Erkrankungen unter den ungehindert in den betreffenden Häusern Verkehrenden vorkommen müssen. Es bleibt also nur übrig, an Übertragung von Mensch zu Mensch zu denken. Fïr diese Auffassung spricht auch entschieden die kettenförmige Verbindung der meisten Fälle. Dabei ist aber immer wieder daran zu erinnern, daß die Cholerainfektion sich ganz anders verhält, wie diejenige von Pocken, Masern usw., bei denen schon der einfache Kontakt oder selbst der vorübergehende Aufenthalt in den Krankenräumen genügt, um die Infektion zustande kommen zu lassen. Eine solche unmittelbare Übertragung tritt nur gelegentlich auf und ist wohl nur da anzunehmen, wo in einer Familie hintereinander mehrere Cholerafälle entstehen, welche durch eine dem Inkubationsstadium entsprechende Zeit voneinander getrennt sind. Etwas dem Entsprechendes ist auch in der Hamburger Nachepidemie vorgekommen, indem in zwei Familien je vier Personen an Cholera erkrankten. Im übrigen scheint die Infektion immer eine indirekte gewesen zu sein, ohne daß sich erkennen ließ, auf welchem Umwege der Infektionsstoff von dem einen Menschen zum anderen gelangt war. Dies Verhalten der Cholera erinnert ganz an das auf Auswanderer-, Pilger- und Truppentransportschiffen Beobachtete, auf denen unter den dicht zusammengedrängten und in schlechten sanitären Verhältnissen befindlichen Menschen die Krankheit wochenlang in lose aneinander gereihten Fällen sich hinzog. Eins der am meisten charakteristischen Beispiele dieser Art ist die Choleraepidemie auf dem italienischen Auswandererschiffe Matteo Bruzzo'), ein Beispiel, welches so lehrreich ist, daß es nicht in Vergessenheit geraten sollte.

Wenn das Wasser in der Nachepidemie auch nicht als gemeinsam wirkender Faktor zur Geltung gekommen ist, so hat es doch seinen mächtigen Einfluß auf die Choleraverbreitung nicht ganz verleugnen können; denn bei dem Ausbruch der Cholera unter den Mannschaften von zwei Schiffen, welche im Hamburger Hafen lagen, ist es unzweifelhaft beteiligt gewesen.

Das erste dieser beiden Schiffe war der spanische Dampfer Murciano, welcher anfangs am Asiakai in der Nähe eines Klosetts lag, das von einem an Cholera erkrankten Hamburger Arbeiter benutzt sein soll. Am 8. Januar mußten zwei Leute vom Murciano als cholerakrank ins Hospital geschafft werden; die übrige Mannschaft wurde darauf evakuiert, und es fanden sich unter derselben bei genauerer Untersuchung noch vier weitere Cholerafälle. Darauf brachte man den Murciano nach dem Strandhafen, wo die Desinfektion vorgenommen und die eingefrorenen Klosetts des Schiffes aufgetaut wurden. An dieser zweiten Stelle lag er neben dem Dampfer Gretchen Bohlen, unter dessen aus Negern bestehender Besatzung am 15. Januar (drei Tage, nachdem der Murciano daneben gelegt war) die Cholera ausbrach. Auch von diesem Schiffe kamen ebenso wie vom Murciano anfangs zwei schwerkranke Leute ins Krankenhaus und erst bei weiterer Untersuchung wurden noch vier leichte Cholerafälle entdeckt.

Als die ersten Fälle auf dem Murciano auftraten, dachte man zunächst an eine Infektion durch das erwähnte Klosett, und zwar an eine unmittelbare Infektion durch die Benutzung des Klosetts. Gegen diese Annahme sprach jedoch der Umstand, daß von

1) Konferenz zur Frörterung der Cholerafrage (zweites Jahr). Deutsche Medizinische Wochenschrift, 1885, Nr. 37 A, p. 21. Diese Werke Bd. II, p. 106. D. Heransgeber. 
den 24 Personen, aus denen die Mannschaft des Schiffes bestand und ron denen gar nicht einmal sicher war, daß sie das am Ufer befindliche Klosett benutzt hatten, sofort sechs Leute erkrankten, während unter den zahlreichen am Ufer verkehrenden Hafenarbeitern, die ebenfalls auf das Klosett angewiesen waren, sich kein Cholerafall ereignete. Viel wahrscheinlicher mußte es sein, daß die Infektion nicht direkt durch Benutzung des Klosetts, sondern indirekt in der Weise zustande gekommen war, daß der Klosettinhalt in das Hafenwasser geflossen und durch dieses, das vielfach im Schiffe zum Trinken und Reinigen gebraucht wurde, die Mannschaft infiziert hatte. Die einzelnen Kais des Hamburger Hafens haben nämlich Siele, welche nicht mit dem städtischen Kanalisationssystem verbunden sind, sondern jedes für sich am Ende des Kais in den Hafen münden. Alle Schmutzwässer dieser Siele, also auch der Inhalt der zu ihnen gehörigen Spülklosetts geht in die Elbe und wird bei Ebbe und Flut neben den am Kai liegenden Schiffen hin und her geschwemmt. Auf diese Weise konnte auch der Inhalt des fraglichen Spülklosetts und etwa in dieses gelangte Choleradejektionen durch Vermittelung des Wassers auf ziemlich kurzem Wege in das Schiff gelangt sein.

Man hat es hier mit ganz denselben Verhältnissen zu tun, welche höchst wahrscheinlich die Choleraepidemie im vorhergehenden Sommer im Hamburger Hafen zum Ausbruch gebracht haben. Damals war es die Baracke der russischen Auswanderer auf dem Amerikakai, von welcher aus durch das Siel des Kai ganz ungenügend desinfizierte oder, richtiger gesagt, undesinfizierte Fäkalien und Schmutzwässer ron der Reinigung beschmutzter Wäsche in den Hafen gelangten. Diese Abgänge waren gar nicht unbedeutend, denn es kamen täglich einige Hundert Auswanderer an, welche sich mehrere Tage in der Baracke aufhalten mußten, bis sie weiter befördert werden konnten. Zur Zeit des Choleraausbruchs befanden sich infolgedessen durchschnittlich tausend Auswanderer in der Baracke, welche die Unterbrechung ihrer Reise vielfach dazu benutzten, eine Reinigung ihres Vorrats an schmutziger Wäsche und Bekleidungsstücken vorzunehmen. Gegen die Annahme, da $\beta$ die russischen Auswanderer die Cholera nach Hamburg gebracht haben, ist eingewendet, daß unter denselben vor dem Ausbruch im Hamburger Hafen keine Cholera vorgekommen sei. Schwere, klinisch unverkennbare Fälle von Cholera sind unter den Auswanderern allerdings nicht beobachtet, aber beweist denn das, daß die Auswanderer überhaupt keinen Cholerainfektionsstoff eingeschleppt haben können? Sie kamen zum großen Teil aus schwer verseuchten Gegenden, und wer kann da wohl behaupten, daß nicht Leichtkranke und Rekonvaleszenten, welche noch zwei bis drei Wochen lang Cholerabakterien in ihren Dejektionen haben können, darunter gewesen sind, oder daß nicht in den massenhaft mitgeführten Betten, Wäschestücken usw. Choleradejektionen hafteten. So wie die Verhältnisse lagen, wäre es wunderbar gewesen, wenn durch solche Auswanderer kein Cholerainfektionsstoff eingeschleppt und wenn, nachdem er einmal in die Auswandererbaracke und von da in das Siel und von diesem in den Hafen seinen Weg gefunden hatte, die Hafenbevölkerung nicht infiziert wäre. Der Hamburger Hafen mit seinen damaligen Einrichtungen bildete einen außerordentlich schwachen Puikt gegenüber der drohenden Cholerainvasion und an diesem mußte die Cholera Fuß fassen, wenn ihr durch einen unglücklichen Zufall Gelegenheit dazu geboten wurde. Eine andere Einschleppung der Cholera, etwa von französischen Häfen her, hat sich nicht nachweisen lassen, und da bleibt nichts anderes übrig, als den Auswandererverkehr zu beschuldigen, welcher, wie gezeigt wurde; überreiche Gelegenheit dazu geboten hat.

Während man in betreff des spanischen Dampfers Murciano, wenigstens anfangs, noch unentschieden war, ob die Infektion dem Wasser zuzuschreiben sei, blieb bei dem żweiten Schiffe von vornherein kein $Z$ weifel darüber. Das Schiff war bereits am 5. Januar 
im Hamburger Hafen angelangt; am 12. Januar wurde der Murciano in die Nähe desselben gebracht, desinfiziert und gereinigt und am 15. Januar brach die Cholera auf Gretchen Bohlen aus. Die aus 17 Negern bestehende Mannschaft war bis dahin cholerafrei gewesen, hatte sonst keine Gelegenheit zur Infektion gehabt, aber, wie in diesem Falle bestimmt festgestellt ist, reichlich Wasser direkt aus der Elbe getrunken. Da der Verlauf der Cholera auf diesem zweiten Schiffe sich genau so verhielt wie auf dem ersten, so wurde dadurch die Annahme, daß es sich auch auf diesem in der Tat um eine Wasserinfektion gehandelt habe, noch sicherer gemacht.

Eine der auffallendsten Eigentümlichkeiten, welche die Hamburger Nachepidemie bietet, ist die geringe Mortalität. Dieselbe betrug 28 Proz., während bekanntlich die Choleramortalität sonst sich um 50 Prozent bewegt. Meiner Meinung nach handelt es sich hierbei aber nicht um eine wirkliche, sondern wahrscheinlich nur um eine scheinbare Abweichung von der Regel. Die frühere Cholerastatistik rechnete nur mit denjenigen Fällen, welche klinisch ausgesprochene Symptome zeigten, d. h. mit den schweren Cholerafällen. Leichtere Brechdurchfälle und einfache Durchfälle wurden als Cholerinen bezeichnet und in der Regel beiseite gelassen. In der Hamburger Nachepidemie haben wir es nun aber zum ersten Male mit einer Epidemie zu tun, bei welcher die bakteriologische Diagnostik in möglichst vollständiger Weise durchgeführt und jeder Fall als Cholera registriert ist, bei welchem Cholerabakterien gefunden wurden. Unter diesen Fällen befinden sich nicht nur solche, welche man früher für choleraverdächtig gehalten und Cholerine genannt hätte, sondern auch solche, welche klinisch ganz unbedeutende, selbst gar keine Symptome darboten und nur deswegen untersucht wurden, weil sie mit unzweifelhaften Cholerakranken in Berührung gewesen waren. In dieser Epidemie sind eben zum ersten Male außer den klinisch Verdächtigen auch die ätiologisch Verdächtigen untersucht, was zu dem so außerordentlich wichtigen Ergebnis geführt hat, daß auch unter diesen eine gewisse Anzahl von Cholerainfizierten sich befinden, welche nur mit Hilfe der bakteriologischen Untersuchung als solche herausgefunden werden können. Während der großen Epidemie im Sommer hatte es teils an Zeit und an Hilfskräften zu solchen Untersuchungen gefehlt, teils lag auch keine eigentliche Veranlassung dazu vor, man beschränkte sich deswegen, auch selbst gegen Ende derselben, als die Fälle immer vereinzelter auftraten, auf die bakteriologische Untersuchung der klinisch Verdächtigen. In der Winterepidemie stellte sich aber sehr bald heraus, daß dies doch nicht genügte. Auch wenn die klinisch Verdächtigen sofort durch Isolierung unschädlich gemacht wurden, kamen immer wieder nachträglich vereinzelte Fälle zum Vorschein, welche mit aller Bestimmtheit darauf hinwiesen, daß doch noch nicht aller Infektionsstoff beseitigt war. Auf meinen Rat dehnte man dann die Evalkuierungen und die damit verbundenen bakteriologischen Untersuchungen immer weiter aus. Es leitete mich dabei die Vorstellung, daß, wie der Chirurg, wenn er eine bösartige Neubildung sicher entfermen will, im Gesunden schneidet, so auch die Exstirpation des Cholerakeimes gewissermaßen im Gesunden geschehen muß, wenn sie Aussicht auf Erfolg haben soll. Es wurden infolgedessen nicht nur einzelne Choleraverdächtige, sondern gruppenweise alle diejenigen, welche sich vermutlich in gleicher Weise wie diese oder von ihnen infiziert haben konnten, in die Evalkuationsanstalt gebracht und dort bakteriologisch untersucht, mochten ihre Darmausleerungen diarrhoisch sein oder nicht. Dabei stellte sich heraus, da $\beta$ in der Tat auch unter den scheinbar Gesunden sich einzelne Menschen befanden, deren Ausleerungen kaum diarrhoisch oder selbst normal waren, trotzdem aber Cholerabalkterien enthielten. Daß auch solche Menschen als Cholerainfizierte und demnach als Träger des Cholerainfektionsstoffes anzusehen sind, liegt auf der Hand; denn bei den sehr zahlreichen anderweitigen Untersuchungen von Dejelktionen Gesunder und an den verschiedensten Krankheiten 
Leidender, wie sie im Laufe der Zeit und speziell auch während der letzten Epidemien in bakteriologischen Laboratorien gemacht sind, ist niemals etwas derartiges gefunden worden; das Vorkommen solcher Fälle beschränkt sich ausschließlich auf solche Nenschen, unter denen einzelne auch klinisch unzweifelhafte Erkrankungen ron echter Cholera aufgetreten waren und von denen man daher annehmen muß, daß sie Gelegenheit zur Infektion gehabt haben. Wie es kommt, daß ein und dieselbe Infektionsgelegenheit so verschiedene Abstufungen der Krankheit bewirken kann und ob dies allein den Verschiedenheiten in der individuellen Disposition oder auch anderen uns bis jetzt noch unbekannten Einflüssen zuzuschreiben ist, muß vorläufig unentschieden bleiben. Hoffentlich werden weitere Beobachtungen und Untersuchungen uns auch die Beantwortung dieser Frage bringen. Auf jeden Fall steht jetzt die Tatsach fest, daß unter einer Anzahl von Menschen, welche der Cholerainfektion ausgesetzt gewesen sind, die daraus resultierenden Erkrankungen qualitativ die ganze Stufenleiter von den schwersten, schnell tödlichen, bis zu den allerleichtesten, nur noch bakteriologisch nachweisbaren Fällen aufweisen können. Ich halte diese Erfahrung für eine der wichtigsten Bereicherungen unserer Kenntnisse über die asiatische Cholera sowohl in praktischer als in theoretischer Beziehung.

Für die Praxis ist sie aus folgenden Gründen wichtig:

Würde man es, so wie früher, dabei bewenden lassen, nur die klinisch verdächtigen und nachträglich bakteriologisch als Cholera konstatierten Fälle durch Isolierung und Desinfektion unschädlich zu machen, dann wird es allerdings in manchen Fällen auch noch gelingen, einen sich entwickelnden Choleraherd zu ersticken; in anderen Fällen aber, namentlich in der dichtgedrängten Bevölkerung der Städte und unter so ungünstigen Verhältnissen, wie sie in Hamburg vorlagen, würden die Bemühungen, alle Cholerakeime zu vernichten, vergeblich sein. Dabei ist es noch besonders bedenklich, daß die der Untersuchung entgehenden leichtesten Fälle in bezug auf Choleraverschleppung die allergefährlichsten sind. Es wird sich das am einfachsten an einigen Beispielen auseinandersetzen lassen. Auf den beiden Choleraschiffen des Hamburger Hafens erkrankten je zwei Leute unter Symptomen, welche sie klinisch als choleraverdächtig erscheinen lassen mußten; selbstverständlich wurden sie sofort isoliert. Hätte man nun nach Desinfektion der Schiffe die übrige Mannschaft, welche ganz gesund zu sein schien, unbehelligt gelassen, dann würden acht Menschen, in deren Dejektionen sich Cholerabakterien befanden, Gelegenheit gehabt haben, den Infektionsstoff in der Umgebung des Hamburger Hafens aufs neue zu verschleppen. Gesetzt den Fall, daß die Schiffsmannschaften nicht Ausländer, sondern Inländer waren und nach der Abmusterung in ihre Heimatsorte reisten, hier vielleicht anfangs auch noch zur Entwicklung leichter und unerkannt bleibender Fälle Veranlassung gaben, während sie selbst niemals klinisch cholerakrank waren, dann hätte auf solche Weise die Cholera auf weitere Entfernung verschleppt werden können, ohne daß spätere T'ntersuchungen auch nur den geringsten Anhalt für die Herkunft der Cholera zu ergeben brauchten. In dieser Beziehung scheinen mir die Verhältnisse, wie sie sich in einer Hamburger Bettlerherberge zugetragen haben, besonders beachtenswert. Aus dieser Herberge, welche während der großen Epidemie acht Cholerafälle, darunter vier tödliche geliefert hatte, wurde ein am Durchfall leidender Mensch am 26. Dezember wegen Choleraverdachtes bakteriologisch untersucht und als wirklich cholerakrank befunden. Dies gab Veranlassung, von den Insassen der Herberge so viele, als man deren habhaft werden konnte, ebenfalls zu untersuehen, wobei noch ein Mann herausgefunden wurde, der zwar klinisch nicht choleraverdächtig erschien, aber in seinen Ausleerungen Cholerabakterien hatte. Als ich dieselbe Herberge einige Tage später besuchte, war sie angefüllt mit Leuten, 
welche zum allergrößten Teil keine Beschäftigung hatten, teilweise auch, wie sie sagten, die Aussicht eine Beschäftigung zu finden, aufgegeben hatten und im Begriff waren, Hamburg wieder zu verlassen. Sie stammten aus den verschiedensten Teilen Deutschlands, besonders waren darunter Angehörige der preußischen Provinz Sachsen und des Königreichs Sachsen vertreten. Man kann sich leicht vorstellen, wie duroh solche Menschen die Cholera unbemerkt von einem Ort zum andern verschleppt werden kann und wie sich ihre Spuren nicht selten der sorgfältigsten Nachforschung zu entziehen vermögen. Hätte man in Hamburg nicht in so nachdrücklicher Weise die Cholera bis in ihre äußersten Schlupfwinkel verfolgt und jede auffindbare Spur des Infektionsstoffes unschädlich gemacht, dann wäre es nach meiner Überzeugung gewiß nicht gelungen, des über die Stadt in so massenhafter Weise ausgebreiteten Zündstoffes Herr zu werden. Aber so wurden die einzelnen Funken, ehe sie von neuem zünden konnten, erstickt. Natürlich konnte nicht jeder sofort entdeckt werden und die einzelnen Ketten setzten sich im Verborgenen fort; aber sie wurden immer seltener und mußten schließlich ebenfalls fortzuglimmen aufhören. Auch den nach mehrmonatlicher Pause am 27. Mai konstatierten vereinzelten Fall möchte ich als Ausläufer einer solchen Kette ansehen. Derselbe beweist, daß die in Hamburg fortgesetzt beobachtete Vorsicht und die Gründlichkeit in der bakteriologischen Untersuchung der verdächtigen Erkrankungsfälle auch nach scheinbar beendigter Epidemie durchaus berechtigt ist.

Auf theoretischem Gebiet läßt sich der Nachweis der leichtesten Cholerafälle in zweifacher Richtung verwerten.

Zunächst wissen wir jetzt, daß unter den Cholerainfizierten eine nicht unbeträchtliche Anzahl und, wenn wir uns an das Beispiel der beiden Schiffe halten, sogar die überwiegende Zahl so unbedeutende Krankheitssymptome aufweist, daß man sie unter gewöhnlichen Verhältnissen, d. h. ohne balkteriologische Untersuchung für gesund halten mußte. Damit fallen aber alle die Schwierigkeiten fort, welche man bisher darin gefunden hat, daß der menschliche Verkehr auch dann die Cholera verbreiten kann, wenn nur gesunde Menschen dabei in Frage kommen. Es kommt in der Tat nicht selten vor, daß notorisch kranke Menschen oder mit Infektionsstoff beladene leblose Gegenstände, wie Wäsche usw:, nach dem infizierten Orte, wenigstens nachweislich, nicht gelangt sind. Solche Fälle hat man dann so gedeutet, daß, wenn hier die Verschleppung ohne cholerakranke Menschen oder deren Dejektionen geschehen konnte, der Cholerakranke überhaupt nicht zur Seuchenausbreitung geeigneter sei, als jeder andere Teil des menschlichen Verkehrs, und folgerecht ist man dann so weit gegangen, den Cholerakranken und seine Dejektionen für relativ ungefährlich zu erlzlären. Wie voreilig diese Deutung der Choleraverschleppung durch anscheinend gesunde Menschen ist, liegt jetzt auf der Hand. Wer heute noch behaupten wollte, daß nach einem cholerainfizierten Orte die Krankheit auch ohne Beteiligung von cholerainfizierten Menschen oder deren Dejektionen gekommen sei, würde in Zulkunft den Nachweis zu führen haben, daß unter den scheinbar gesunden Menschen, welche dahin verkehrten, keine leichtesten Cholerafälle sich befanden, ebenso daß keine mit Choleradejektionen beschmutzten Gegenstände eingeführt worden sind.

Den Erfahrungen, welche in der Hamburger Nachepidemie gemacht sind, verdanken wir schließlich auch das richtige Verständnis für die Ergebnisse der bisher an Menschen gemachten absichtlichen und unabsichtlichen Cholera-Infektionsversuche. Die erste dahin gehörige Beobachtung ist von $\mathrm{M}$ a $\mathrm{n} \mathrm{n}$ a $\mathrm{m}$ a $\mathrm{ra}^{1}$ ) gemacht. Derselbe berichtet, daß von 19 Personen, welche zufällig mit Choleradejektionen verunreinigtes Wasser tranken, fünf an Cholera erkrankten. Später sind unabsichtliche Infektionen im

1) Deutsche Medizinische Wochenschrift, 1885, Nr. 37 A. Diese Werke Bd. Ir, p. 83. D. Herausg. 
Laboratorium des Gesundheitsamtes ${ }^{1}$ ) und im Laboratorium des Stadtlazaretts zu Danzig²) vorgekommen. Daran schließen sich dann noch die bekannten absichtlichen Tersuche in München, Wien und Paris. Ob unter den von MI a n a mara beobachteten Fällen schwere und tödliche Erkrankungen sich befanden, ist aus seinen Mitteilungen nicht zu ersehen. Aber die übrigen erwähnten Infektionen, welche nur durch Reinkulturen von Cholerabakterien bewirkt sein konnten, haben insgesamt das Eigentümliche, daß mit dem Auftreten der Cholerabakterien in den Ausleerungen der Infizierten sich mehr oder weniger starker Durchfall einstellte, ohne daß es jedoch zu den eigentlichen schweren Cholerasymptomen kam (mit Ausnahme des einen Falles in Paris). Es fehlten also diejenigen Symptome, welche wir der Resorption des ron den Cholerabakterien produzierten Giftes zuschreiben müssen. Daraus könnte man schließen, daß die Cholerabakterien für sich allein wohl imstande seien, einen mehr oder weniger starken Durchfall herrorzurufen, daß sie aber keine wesentliche lebensgefährliche Cholera veranlassen können. Diese Schlußfolgerung ist indessen nicht richtig; denn wenn wir wiederum die mehrfach erwähnten Choleraausbrüche auf den beiden Schiffen im Hamburger Hafen zum Vergleich heranziehen und die $\mathrm{I}$ a c $\mathrm{n}$ a $\mathrm{m}$ a $\mathrm{r}$ a sche Beobachtung berücksichtigen, dann ergibt sich, daß von einer gewissen Anzahl von Menschen, welche zu gleicher Zeit der Infektion ausgesetzt sind, nur ein bestimmter Bruchteil schwer erkrankt und ein anderer leicht, während der Rest gesund bleibt. Auf den Hamburger Schiffen, welche in dieser Beziehung den sichersten Anhalt gewähren, erkrankten das eine Mal ron 24 Personen zwei schwer und vier leicht, das andere Mal von 17 Personen ebenfalls zwei schwer und vier leicht. Wenn also bei den rereinzelten Laboratoriumsinfektionen und den nur wenige Personen umfassenden absichtlichen Infektionen nur leichte Erkrankungen entstanden sind, so entspricht dies noch rollkommen dem, was nach den bisherigen Erfahrungen erwartet werden konnte. Selbst wenn jene Versuche ganz negativ ausgefallen wären, würden sie gegen die Spezifität der Cholerabakterien noch nicht das geringste beweisen, da ja unter den gruppenweise auf gewöhnlichem Wege Infizierten die Mehrzahl auch nicht krank wird. Wenn derartige Experimente den beabsichtigten Zweck erreichen sollen, dann müssen sie ganz den natürlichen Verhältnissen angepaßt sein. Es müßten also eine größere Anzahl von Personen sich der Infektion mit Cholerabakterien aussetzen. Einige davon müßten die Bakterien bei leerem Magen zugleich mit vielem kalten Wasser zu sich nehmen; andere müßten, wenn sich Durchfall und Cholerabakterien in den Ausleerungen eingestellt haben, Diätfehler begehen und Speisen zu sich nehmen, welche erfahrungsgemäß den Ausbruch der Cholera begünstigen usw. Erst wenn bei einer derartigen Versuchsanordnung und bei Verwendung frischer, vollvirulenter Kulturen nur leichte Erkrankungen resultieren, dann würde man weiter danach zu suchen haben, unter welchen besonderen Bedingungen die schweren Cholerasymptome zustande kommen und ob noch besondere Hilfsmomente dazu erforderlich sind, welche außerhalb der Eigenschaften der Cholerabakterien und außerhalb der Schwankungen im Zustande der Verdauungsorgane liegen. Bis dahin liegt kein Grund vor, die jetzige Auffassung $z u$ bezweifeln, daß die Cholerabakterien für sich allein imstande sind, je nach der individuellen Disposition der Infizierten, das eine Mal leichte und ein anderes Mal schwere Cholerasymptome zu bewirken. Damit verlieren selbstverständlich die bisher angestellten Versuche durchaus nicht ihre Bedeutung; sie liefern auf jeden Fall einen höchst wertvollen Beitrag zur Beurteilung der Leistungsfähigkeit der Cholerabakterien; aber sie beweisen nicht das, was diejenigen, welche sie an sich angestellt haben, damit zu beweisen gedachten.

1) Deutsche Medizinische Wochenschrift, 1885, Nr. 37 A. Diese Werke Bd. II, p. 84. D. Herausg.

2) Ebenda, 1893, Nr. 19. 
Von dem gewaltigen Choleraherd, welcher sich während der Monate August und September 1892 in Hamburg entwickelt hatte, ist die Seuche nach nahezu 300 Ortschaften in Deutschland und im Auslande verschleppt worden. Aber auch die extensiv und intensiv so außerordentlich geringere Winterepidemie ist nicht ohne Ausläufer geblieben.

Zu Anfang Januar reiste ein Mann von Hamburg nach Schwerin und starb daselbst an Cholera.

Vier Fälle wurden von Hamburg nach Elmshorn verschleppt, welcher Ort auch im vorhergehenden Sommer von Hamburg sechs Fälle erhalten hatte.

Ein allerdings nicht vollständig aufgeklärter Fall soll nahe bei Hamburg in Osdorf, Kreis Pinneberg, vorgekommen sein.

In Neuhof auf der Elbinsel Wilhelmsburg starb am 6. Januar ein Schiffszimmermann an Cholera, welcher im Hamburger Hafen und zwar in derselben Abteilung gearbeitet hatte, in welcher der früher erwähnte choleraverseuchte Dampfer Murciano lag. Wahrscheinlich ist dieser Fall deswegen auch auf dieselbe Infektionsquelle zu beziehen.

Drei Cholerafälle kamen in Schulau vor, und einer in der unmittelbar daneben gelegenen Stadt Wedel. Ein unmittelbarer Zusammenhang mit Hamburg ließ sich für diese Fälle nicht auffinden, aber indirekte Beziehungen waren durch das Elbwasser gegeben. Die am rechten Elbufer, ungefähr $20 \mathrm{~km}$ unterhalb von Hamburg und $8 \mathrm{~km}$ unterhalb des Altonaer Wasserwerkes gelegenen Orte Wedel und Schulau erhalten ihr Wasser aus Brunnen, nur eine Zuckerfabrik in Schulau bezieht ihren Wasserbedarf aus der Elbe vermittels einer eigenen Leitung. Die Wasserentnahmestelle für diese Leitung befindet sich dicht neben der Landungsbrücke, wo die Elbkähne, welche Rüben, Kohlen usw. zur Fabrik bringen, anlegen. An derselben Stelle macht der Fluß eine kleine Krümmung und hat eine ziemlich starke Strömung. Alte Korkstopfen und andere schwimmende Gegenstände, welche dort zahlreich angeschwemmt werden, lassen erkennen, daß die Verunreinigungen aus den Hamburg-Altonaer Sielen trotz der weiten Entfernung noch ziemlich konzentriert bis hierher gelangen. Das Elbwasser wird, ehe es in die Fabrik gelangt, filtriert, jedoch nur durch eine Kiesschicht, welche kaum die gröberen Schmutzstoffe zurückhält. Dieses Wasser wurde von den Fabrikarbeitern getrunken und es erkrankte von ihnen einer, welcher am 10. Januar starb, ein zweiter erkrankte am 26. Januar. Jener wohnte in Schulau, dieser in Wedel. Bald nach dem Tode des ersteren wurden zwei seiner Kinder von Cholera befallen. Wäsche und Kleidungsstücke dieses Arbeiters, dessen Krankheit anfänglich für eine Fleischvergiftung gehalten wurde, waren an Angehörige in Schlesien geschickt. Aber glücklicherweise waren gleichzeitig Leichenteile nach Kiel zur bakteriologischen Untersuchung gegeben, und als hier Cholera diagnostiziert wurde, konnte auf telegraphischem Wege noch zeitig genug die Vernichtung der gefährlichen Objekte angeordnet werden, ehe dieselben weiteres Unheil angerichtet hatten.

Alle diese von Hamburg ausgehenden. Verschleppungen gaben zu keinen intensiveren Ausbrüchen der Seuche Veranlassung. Nur in Altona und in Nietleben entwickelten sich eigentliche Epidemien, mit denen wir uns nummehr eingehender zu beschäftigen haben werden.

\section{Die Winterepidemie in Altona.}

Die mit der Hamburger großen Epidemie parallel gehende Choleraepidemie in Altona hatte ebenso wie jene gegen Ende Oktober ihren Abschluß gefunden. Vereinzelte Nachzügler am 4. und 29. November ${ }^{x}$ ) scheinen mit derselben noch in Verbindung zu

1) Wallichs, Die Cholera in Altona. Deutsche Medizinische Wochenschrift, 1893, Nr. 10. 
stehen. Dann aber folgte ein, wenigstens anscheinend, cholerafreier Zeitabschnitt, welcher bis Ende Dezember reicht. Um diese Zeit hatte die Nachepidemie in Hamburg mit fünf Fällen an einem Tage (26. Dezember) ihren Höhepunkt erreicht und nun begann auch in Altona die Seuche sich wieder zu zeigen. Diesmal trug sie aber einen ganz anderen Charakter, als während der vorhergehenden Epidemie. Damals waren die allermeisten Fälle solche, welche zu Hamburg in Beziehung standen und sich höchst wahrscheinlich auf Hamburger Gebiet infiziert hatten oder von solchen Fällen sekundär entstanden waren. Jetzt erkrankten dagegen Menschen, bei denen mit wenigen Ausnahmen eine derartige Infektion ausgeschlossen war. Dahin gehörten z. B. Arbeiter, welche sich in geordneten Verhältnissen befanden und durch ihre Beschäftigung nicht nach Hamburg geführt wurden, Frauen aus dem Mittelstande, kleine Kinder, welche wegen der kalten Witterung gar nicht aus dem Hause gekommen waren, ein Einjährig-Freiwilliger, Insassen des Krankenhauses, welche seit Wochen bettlägerig waren und mit niemanden außerhalb des Krankenhauses in Berührung kamen, ein Gefangener, bei dem die Cholera nach zwölftägiger Isolierhaft auftrat. Alle diese Fälle standen untereinander in keinerlei Zusammenhang. Während in Hamburg die Cholera sich gleichzeitig ausnahmslos in den untersten Volksschichten hielt und sich offenbar an bestimmten Stellen eingenistet hatte, kam unter den in Altona Erkrankten nur ein Fall bei einer obdachlosen Frau vor; die übrigen Fälle betrafen Personen, welche die Krankheit nicht durch unmittelbare Übertragung von seiten unreinlicher und in ungesunden Räumen zusammengedrängter Menschen erhalten haben konnten. Offenbar handelte es sich hier um einen ganz anderen Typus der Cholera, wie in Hamburg; und es ließ sich dieses Verhalten der Krankheit nur so auffassen, daß der Infektionsstoff über die ganze Stadt rerstreut und. zwar nur in spärlicher Menge wirkte. Zunächst mußte man an die Wasserversorgung denken; denn wenn in derselben Störungen eingetreten waren, dann hätten sie sich wohl in der Weise äußern können, wie es jetzt der Fall war. Es wären mit dem ungenügend filtrierten Elbwasser Cholerakeime, welche durch die Siele aus Hamburg in die Elbe gespült wurden, über ganz Altona ausgestreut worden und hätten zusammenhanglose Cholerafälle entstehen lassen müssen. Daß dieser Verdacht ein begründeter war und daß in der Tat Störungen im Filterbetrieb des Wasserwerks unmittelbar vor dem Ausbruch der Epidemie stattgefunden hatten, ferner welcher Art diese Störungen gewesen sind und daß die Cholerakeime, d. h. die Cholerabazillen im Elbwasser dicht unterhalb von Hamburg sowie in dem Rohwasser des Wasserwerkes von Altona nachgewiesen sind, ist in einer vorhergehenden Abhandlung ${ }^{1}$ ) eingehend besprochen, auf welche ich bezüglich dieser Verhältnisse verweise.

Kleine Epidemien sind in mancher Beziehung für die ätiologische Forschung vorteilhafter als große. Die einzelnen Fälle können jeder für sich viel gründlicher untersucht werden, und ihre Beziehungen untereinander lassen sich in einer Art und Weise ermitteln, wie es bei großen Epidemien gar nicht durchzuführen ist. Das Gefüge einer kleinen Epidemie bleibt deswegen in der Regel durchsichtig und in seinem Zusammenhange verständlich. Diese Vorzüge hat auch die uns hier beschäftigende Altonaer Epidemie. Es ließ sich wohl von vornherein erwarten, daß, wenn der Infektionsstoff über das ganze Gebiet einer Stadt ausgestreut wird und es infolgedessen zu einer Anzahl von Erkrankungen gekommen ist, es nicht bei diesen primären Fällen bleiben würde. Überall da, wo sich Verhältnisse finden, welche der weiteren direkten oder indirekten Übertragung der Cholera günstig sind, werden sich an die primären Erkrankungen sekundäre anschließen. Aber bei einer großen Epidemie können solche sekundär sich ent-

1) Wasserfiltration und Cholera. Zeitschrift für Hygiene und Infektionskrankheiten, Bd. XIV. Diese Werke Bd. II, p. $183 \mathrm{ff}$. D. Herausgeber. 
wickelnden Fortsetzungen der Infektion nur ausnahmsweise von dem Ganzen abgelöst und in ihrer Entstehungsweise richtig erkannt werden; gewöhnlich verlieren sie sich unerkannt in der Masse. In der kleinen Altonaer Epidemie ist es jedoch gelungen, auch die sekundären Infektionen, welche gewissermaßen aus der Basis der Wasserepidemie hervorgesproßt waren, genügend $\mathrm{zu}$ unterscheiden.

An drei Stellen entstanden Gruppenerkrankungen innerhalb von Familien.

So litt in einer Familie zuerst der Mann an Durchfall. wenige Tage darauf starben zwei Kinder an Cholera und wieder zwei Tage später die Mutter, welche mit der Pflege der Kinder beschäftigt gewesen war.

In einer anderen Familie erkrankte und starb zuerst ein sieben Monate altes Kind (1. Februar), zwei Tage später trat die Cholera bei einem anderthalbjährigen Pflegekind und einem 13 jährigen Mädchen auf, wiederum drei Tage später bei einem sechsjährigen Mädchen und bei dem Vater (die letzten drei sind am Leben geblieben).

Die dritte Familienepidemie ereignete sich bei einem Bäcker. Am 2. Februar erkrankten zwei Frauen. Da dieselben sich zu gleicher Zeit infiziert haben müssen, so ist es wahrscheinlich, daß ein leichter unerkannt gebliebener Cholerafall vorhergegangen ist und den Ausgangspunkt für diese Gruppenerkrankung gebildet hat. Am 3. und 5. Februar folgten den beiden ersten Fällen noch Choleraerkrankung bei einer Verwandten und bei einer Tochter des Bäckers. Sämtliche Fälle dieser Gruppe verliefen leicht.

Auch im Krankenhause scheint es zur Bildung einer kleinen Gruppenerkrankung infolge von direkter Übertragung gekommen zu sein. Der erste daselbst aufgetretene Cholerafall betraf eine Frau, welche seit vier Wochen im Hauptpavillon wegen Lungenphthisis behandelt wurde; der zweite Fall einen Typhusrekonvaleszenten in Baracke III, die dann folgenden drei Fälle in der Irrenabteilung. Diese drei letzten Choleraerkrankungen dürften wohl, namentlich auch nach den in Irrenanstalten anderweitig gemachten Erfahrungen als untereinander zusammenhängend angesehen werden.

Die interessanteste sekundäre Gruppenerkrankung kam in dem Stadtteil Ottensen vor. Hier (vgl. den umstehenden Plan Fig. 1) ${ }^{1}$ ) befindet sich von vier Straßenzügen (Rothestraße, Papenstraße, große und kleine Brunnenstraße) umgeben ein Häuserkomplex, welcher aus zwei Abteilungen besteht. Die westlich gelegenen Häuser sind (mit Ausnahme des Eckhauses an der Papenstraße) an die Altonaer Wasserleitung angeschlossen (auf dem Plan mit W bezeichnet). Der östlich gelegene Teil besteht aus mehreren von den angrenzenden Straßen her zugänglichen langgestreckten Höfen, welche zu beiden Seiten mit kleinen Häusern besetzt sind. Dieselben wurden nach dem großen Hamburger Brande (1842) errichtet, um für die Obdachlosen so bald als möglich eine Unterkunft zu schaffen ${ }^{2}$. Seit jener Zeit werden sie mietsweise von armen Leuten bewohnt. Diese von etwa 270 Menschen bewohnten Höfe tragen den Namen ,langer Jammer". Die angrenzenden Straßen sind kanalisiert und es gehen Tonrohrleitungen, welche mit Gullies versehen sind, von den Straßenkanälen bis auf die Höfe. Für die Ableitung der Schmutzwässer ist also leidlich gesorgt. Die Häuser des ,langen Jammers" sind nicht an die Wasserleitung angeschlossen. Es kommt dies daher, daß die Altonaer Wasserleitung im Besitz einer Privatgesellschaft ist, welche das Wasser gegen Bezahlung abgibt. Für die armen Bewohner des , ,langen Jammers" war der Preis des Leitungswassers zu hoch, als daß sie sich diese Wohltat verschaffen konnten, sie mußten also ihren Wasserbedarf in anderer Weise decken und konnten dies nur durch Benutzung eines aus früheren.

1) Die Skizze zu diesem Plan, die Angaben über die Bohrungen auf dem Grundstiuck, über die Grundwasserverhältnisse von Altona, sowie andere wertvolle Mitteilungen verdanke ich Hrn. Stadtbaurat Stah $\mathrm{I}$ in Altona.

2) Vgl. Wallichs a. a. O. 
Zeiten her bestehenden Pumpbrunnens, welcher neben dem Eingang zum Hofe Nr. 45 von der Papenstraße her sich befindet (vgl. den Plan). Auf Lage und Konstrultion dieses Brunnens, welcher für die Bewohner des , langen Jammers" eine so rerhängnisrolle Rolle gespielt hat, werde ich später zurückkommen. Da der ,.lange Jammer" keine Wasserleitung hat, so komnten auch keine Spülklosetts angelegt werden.

Zur Beseitigung der Fäkalien dienen Klosetts mit Tonneneinrichtung. Dieselben sind in anscheinend genügender Zahl und gruppenweise an fünf verschiedenen Stellen angebracht. Cm über die Bodenverhältnisse in dieser Stadtgegend etwas zu ermitteln, sind auf dem Hofe Nr. 45 zwei Bohrlöcher angelegt, von denen das eine in der Nähe des

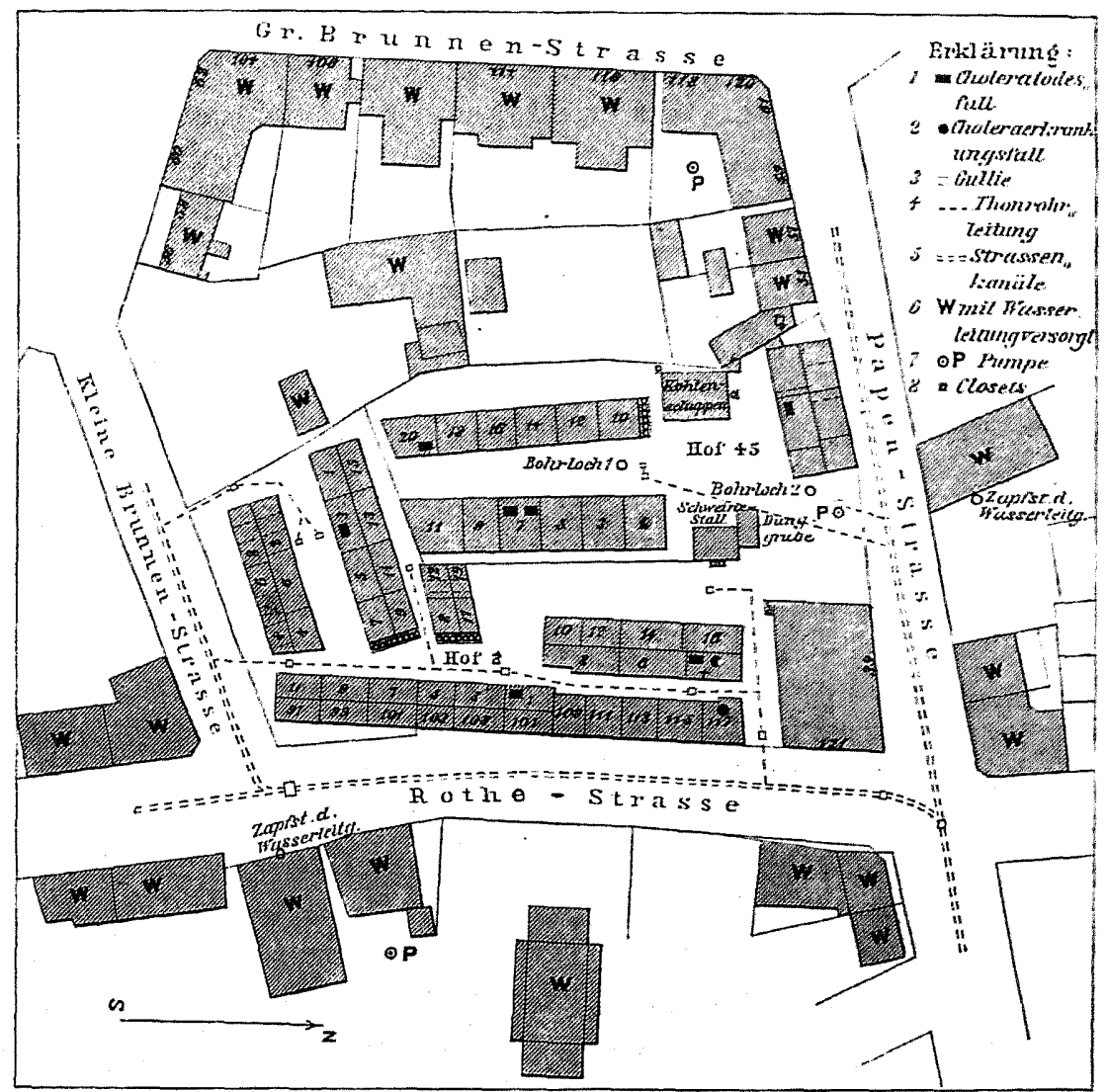

Figur 1.

Plan zur Brunnenepidemie in Altona.

Brunnens, das andere fast $30 \mathrm{~m}$ südlich von dem ersten liegt. An beiden Stellen folgte auf eine oberflächliche einen Meter starke Schicht von Humus und mit Humus vermischtem Sand $1 \frac{1}{2}$ bis $2 \mathrm{~m}$ Ton und toniger Sand, darauf feinkörniger Sand bis zum Grundwasser, welches in einer Tiefe von etwa $5 \mathrm{~m}$ angetroffen wurde. Es stimmt dies vollkommen mit den Beobachtungen überein, welche bei den Kanalisationsarbeiten in dieser Gegend gemacht sind. Der Grund und Boden unterschied sich also in nichts von demjenigen der benachbarten Stadtteile.

$\mathrm{Da}$ in Altona seit einigen Jahren regelmäßige Beobachtungen über die Grundwasserschwankungen gemacht werden, so will ich der Vollständigkeit halber auch das Ergebnis derselben, soweit es für den Choleraherd im ,langen Jammer" in Betracht kommen kann, hier wiedergeben. Der Grundwasserstand wird in Bohrlöchern gemessen, 
welche auf einer zur Elbe senkrechten, also von Nord nach süd verlaufenden Linie stehen. Von diesen Bohrlöchern ist Nr. V dem Choleraherd am nächsten gelegen und befindet sich auch fast in gleichem Niveau. Es ist deswegen wohl anzunehmen, daß die Grundwasserschwankungen an diesem Bohrloch sich nicht wesentlich anders verhalten, als an der uns hier interessierenden Stelle. Im ganzen genommen, sind die Grundwasserschwankungen auf dem Gebiet von Altona sehr gering, was offenbar teils dadurch bedingt ist, daß die Stadt ziemlich hoch oberhalb des Spiegels der Elbe liegt und ihr Untergrundwasser deswegen keinen Stauungen durch die Schwankungen im Stande des Elbniveaus ausgesetzt ist, teils dadurch, daß die Kanalisation der Stadt das Grundwasser auf ein bestimmtes Niveau gesenkt hat und ein Ansteigen über dasselbe hinaus verhindert. An dem Bohrloch Nr. V, dessen Oberkante auf Normal-Null $+27,45$ liegt, wurden folgende Grundwasserstände gemessen: (Die Zahlen geben den Abstand des Grundwassers von der Oberkante des Bohrlochs. Das Wachsen der Zahl zeigt also Sinken des Grundwassers an, und umgekehrt das Abnehmen der Zahl ein Steigen desselben.)

1891.

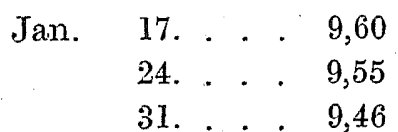

Febr. 14. . . 9,38

21. . . 9,41

28. . . 9,45
1892.

Jan.

Febr.

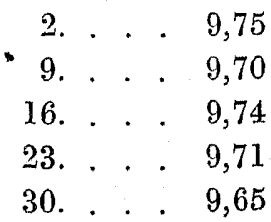

1893.

Jan. $\quad$ 7. . . 9,97

14. . . 10,07

21. . . 10,05

28. . . 10,11

Febr. $\quad$ 7. . . 10,02

14. . . 10,06

1891.

1892.

März

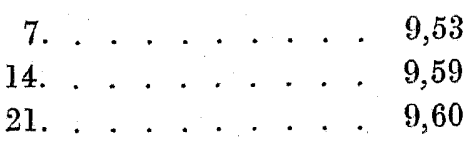

April 4. . . . . . . . 9,58

11. . . . . . . 9,56

Mai

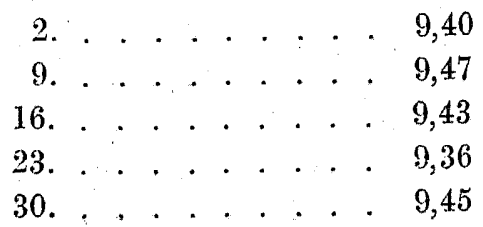

Juni

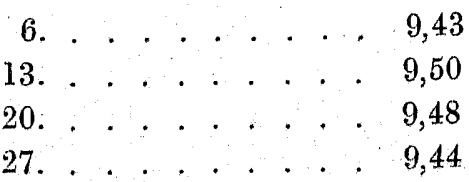

6. . . 9,73

13. . . 9,59

20. . . 9,56

27. . . 9,58

März

5. . . . . . . 9, 9,55

12. . . . . . . 9,49

19. . . . . . 9,50

26. . . . . . . 9,46

April

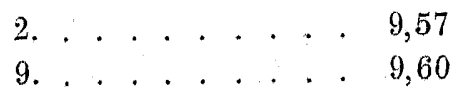

16. ...... 9,62

23. . . . . . . 9,53

30. ....... . 9,58

Mai

7. . . . . . 9,59

14. . . . . . . 9,58

21. . . . . . . 9,59

28. . . . . . . 9,57

Juni $\quad 4 . \ldots . \ldots, \ldots, 64$

11. . . . . . . 9,64

18. . . . . . 9,73

$25 . . . . . .99,56$ 
1891.

Juli

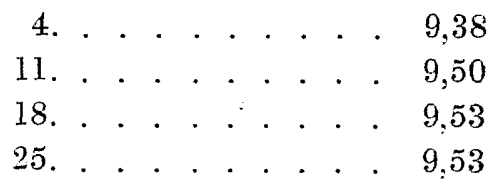

August

1....... 9,66

8........ 9,67

15. . . . . . . . 9,64

22. . . . . . 9,66

$29 . . . . .99,58$

September 5. . . . . . . 9,62

12. . . . . . . 9,60

19. . . .... . 9,60

26. . . . . . . 9,54

Oktober 3. . . . . . 9,56

11. . . . . . 9,62

17. . . . . 9,64

24. . . . . . 9,60

31....... . 9,67

November 7. . . . . . . 9,83

I4. . . . . . . . 9,64

21....... 9,70

28. . . . . . . 9,80

Dezember 5. . . . . . . 9,70

12. . . . . . . 9,82

17. . . . . . . 9,86

24. . . . . . 9,67

1892.

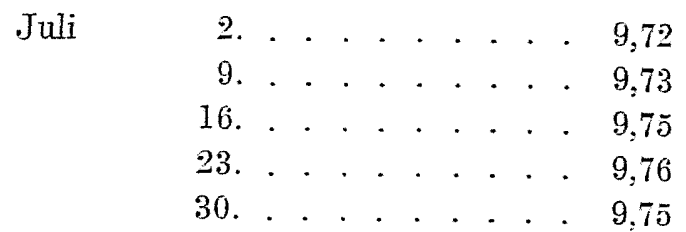

August

6. . . . . . . 9,77

13. . . . . . 9,78

20 . . . . . . 9,80

$27 . . . . . .9,80$

September 3. . . . . . . . 9,81

10. . . . . . 9,83

17. . . . . . . 9,85

24. . . . . . . 9,85

Oktober I. . . . . . 9,87

8. . . . . 9,90

15. . . . . . . 9,90

22. . . . . . . 9,91

29. . . . . . . . . 9,93

November 5. . . . . . . 9,94

12. . . . . . . 9,94

19. . . . . . 9,95

26. . . . . 9,95

Dezember 3. . . . . . . . $9 ; 98$

10....... 10,01

17. . . . . . 9,96

24. . . . . . . 10,02

31....... 9,98

Die Grundwasserschwankungen haben sich hiernach im Jahre 1891 zwischen 9,38 und 9,83, im Jahre 1892 zwischen 9,46 und 10,02 bewegt. Es gibt dies für 1891 eine Niveaudifferenz von $45 \mathrm{~cm}$ und für 1892 von $56 \mathrm{~cm}$. Der höchste Stand fällt in beiden Jahren auf den Frühling, der niedrigste auf den Herbst und Winter, wie dies fast überall in Norddeutschland der Fall ist. Im Jahre 1892 stand das Grundwasser im ganzen etwas niedriger als im vorhergehenden Jahre, was höchst wahrscheinlich durch die geringe Niederschlagsmenge dieses Jahres bedingt ist ${ }^{1}$ ). Gegen Ende des Jahres hatte das Grundwasser seinen tiefsten Stand ereicht. Nach der bekannten Theorie würde man hierin einen die Cholera begünstigenden Faktor erblicken können. Dies ist jedoch schon deswegen nicht angängig, weil die Cholera in Altona wieder verschwand, ehe dieser Faktor zu wirken aufhörte, denn wie aus der Tabelle zu sehen ist, hielt sich der niedrige Stand des Grundwassers bis in den Februar 1893. Außerdem wäre aber auch nicht einzusehen, daß gerade eine einzige Häusergruppe in Altona durch das Grund-

1) Nach van Bebber (Annalen der Hydrographie und maritimen Meteorologie, Januar 1893) hat Hamburg im Jahre 1892 eine um $190 \mathrm{~mm}$ geringere Niederschlagsmenge gehabt, als der Mittelwert beträgt. 
wasser so auffallend beeinflußt sein sollte, während viele andere ebenso belegene und beschaffene Häuser einen derartigen Einfluß nicht erkennen ließen.

Schon während der Sommerepidemie kamen im ,langen Jammer" Cholerafälle vor. Der erste ereignete sich am 29. August bei einem Tabaksarbeiter, welcher angeblich Ottensen nicht verlassen hatte und zu Hamburg in keinerlei Beziehung stand. Er gehörte also zu den verhältnismäßig wenig zahlreichen Erkrankungen, welche die der Stadt Altona selbst zukommende Choleraepidemie bildeten. Dieser Fall blieb damals isoliert. Ein zweiter, am 4. September auftretender, hatte keinen Zusammenhang mit dem ersten, er betraf einen Handelsmann, der in den vorhergehenden Tagen in Hamburg sein Handelsgewerbe betrieben und sich unzweifelhaft dort infiziert hatte. Auch dieser Fall blieb ohne weitere Folgen und man hätte, da die Cholera wiederholt in den ,langen Jammer" eingeschleppt war, ohne daß sie sich weiter ausgebreitet hatte, diesen Ort für einen der Cholera wenig günstigen halten sollen. Um so überraschender war es, daß kurz nach Beginn der Nachepidemie gerade hier im Laufe von einer Woche neun Cholerafälle entstanden, von denen sieben tödlich verliefen. Auf zwei Häuser kamen je zwei Fälle. Die übrigen blieben sämtlich isoliert und verteilten sich ziemlich gleichmäßig über die Häusergruppe des ,langen Jammers".

Als sich auf einem so engbegrenzten Gebiet der Stadt die Cholerafälle in so auffallender Weise häuften, wurden sofort Untersuchungen über die Ursachen angestellt, denen die Entstehung des Choleraherdes zugeschrieben werden konnte. Dabei stellte sich dann die überraschende, bereits oben berührte Tatsache heraus, daß in der im übrigen so vortrefflich mit Wasser versorgten Stadt sich hier eine Häusergruppe befand, welche kein Leitungswasser erhielt, und daß sich der Choleraherd ausschließlich auf diese Häuser beschränkte. Die Nachbarschaft des ,, langen Jammers" ist bis auf einen ziemlich weiten Umkreis vollkommen fret von Cholera geblieben. Es hatte sich somit hier in einem kleinen Maßstabe dasselbe wiederholt, was man im Sommer vorher viel hundertmal ausgedehnter in Hamburg erlebt hatte, nämlich daß sich die Ausbreitung der Cholera mit dem Gebiet einer Wasserversorgung haarscharf deckte. Die Wasserversorgung fand in diesem Falle durch einen Brunnen statt, dem sich selbstverständlich das weitere Interesse zuwandte.

Der Brunnen liegt auf dem Hofe Nr. 45 an der früher bezeichneten Stelle (vgl. den Plan Fig. 1). Er nimmt, wie es bei solchen Brunnen gewöhnlich der Fall ist, die tiefste Stelle des Hofes ein. Seine Höhenlage ist $28,00 \mathrm{~m}$ über Normal-Null, das ihm zunächst gelegene Bohrloch Nr. 2 hat 28,11 , die etwas weiter westlich davon befindliche Hausecke hat 28,26; das Bohrloch Nr. 1 hat 28,58; die in der Nähe des letzten befindlichen Klosetts 28,46 bis 28,54; die östlich vom Bohrloch Nr. 1 gelegene Hausecke (auf dem Plan mit 1 bezeichnet) 28,61; der Schweinestall nebst Dunggrube 28,52.

Bei dieser Lage mußte alles Flüssige aus der Umgebung des Brunnens seinen Weg naturgemäß in der Richtung nach diesem hin nehmen. 'Dafür, daß dies in der Regel nicht geschah, sorgte die zum Straßensiel führende Tonrohrleitung, welche in der Nähe des Klosetts mit einem Gully ihren Anfang nimmt und von da in gerader Linie, ziemlich dicht neben dem Brunnen vorbei nach der Straße geht. Auch am Brunnen selbst befindet sich ein Gully, welches das beim Pumpen vorbeifließende Wasser mit einer besonderen, kurzen Leitung ebenfalls zum Straßensiel ableitet.

Die Brunnenwandung besteht aus Ziegelsteinen. Oben ist der Brunnen durch Holzbohlen geschlossen, welche mit einer dünnen Schicht Erde und mit Steinen bedeckt sind. Der Wasserstand im Brunnen hat eine Höhe von etwas mehr als einen Meter; das Niveau entspricht demjenigen des benachbarten Bohrloches Nr. 2.

Aus dieser Beschreibung geht hervor, daß der Brunnen dieselben Eigenschaften besitzt, wie die meisten derartigen Brunnen und daß, wenn man ihn vor der Epidemie Ko ch, Gesammelte Werke. 
untersucht hätte, keine Veranlassung vorlag, ihn als schlecht zu bezeichnen. Dies ist auch in der Tat geschehen. Im Mai 1892 sind in Altona 366 Brunnen untersucht und davon 92 unbrauchbar befunden. In dem mir vorliegenden Verzeichnis der Brunnen ist aber gerade der später so gefährlich gewordene Brunnen an der Papenstraße nicht als unbrauchbar bezeichnet. An einem solchen Beispiel zeigt es sich so recht deutlich, wie wenig auf die heutzutage üblichen Brunnenuntersuchungen zu geben ist, und daß ein Kesselbrunnen, welcher vielleicht jahrelang ohne Nachteil benutzt ist, unter besonderen Umständen plötzlich der Ausgangspunkt für eine Infektion werden kann. Die Konstruktion der Kesselbrunnen bringt es eben, wie in einer vorhergehenden Abhandlung (Wasserfiltration und Cholera) auseinandergesetzt wurde, mit sich, daß das Eindringen infizierter Flüssigkeiten von oben her niemals mit Sicherheit ausgeschlossen ist. Etwas Derartiges muß auch bei dem Brunnen an der Papenstraße geschehen sein. Von unten her, d. $h$. rom Grundwasser aus, kann der Infektionsstoff nicht in das Brunnenwasser gelangt sein; denn der Brunnen steht mit seiner Sohle in gut filtrierendem feinkörnigen Sand, welcher überdies vor Verunreinigungen von der Bodenoberfläche her durch eine ziemlich dicke undurchlässige Tonschicht geschützt ist. Außerdem mußte, wenn das Grundwasser Träger des Infektionsstoffes gewesen wäre, nicht allein dieser, sondern mußten auch andere Brunnen, wenigstens die benachbarten, in ähnlicher Weise von Cholerafällen umgeben gewesen sein, was nicht der Fall war.

So hat das Eckgrundstück Papenstraße 59-61 und ebenso Große Brunnenstr. 118 bis 120 kein Leitungswasser, sondern benutzt einen Brunnen, trotzdem ist daselbst nicht ein einziger Fall von Cholera vorgekommen.

Es bleibt also nur die Möglichkeit übrig, daß der Infektionsstoff dem Brunnen von oben her zugeführt ist, und hierfür ließen sich denn auch bei näherer Untersuchung unverkennbare Anzeichen auffinden. Denn nach Entfernung der Holzbedeckung zeigten sich an derjenigen Seite des Brunnens, wo der Ausguß und daneben das Gully sich befindet, nasse Schmutzstreifen, welche von oben bis zum Wasserspiegel gingen und den Weg, welchen Schmutz und Flüssigkeit von oben her gefunden hatten, sichtbar kennzeichneten. An der Stelle, wo die Schmutzstreifen ihren Anfang hatten, mußten also Lücken und Spalten im Mauerwerk entstanden sein, und ebenso in der nach außen anliegenden dünnen Schicht von Erde und Steinen, so da $\beta$ hier ungehindert Flüssigkeit von der Bodenoberfläche in den Brunnen hineinfließen konnte. Für gewöhnlich wird dies nur Wasser gewesen sein, welches aus dem Brunnen selbst stammte und beim Pumpen, oder wenn am Brunnen gespült und gewaschen wurde, danebenfloß. Aber auch schon auf diese Weise hätte Infektionsstoff in das Brunnenwasser geraten können, wenn beispielsweise mit Dejektionen von Typhus- oder Cholerakranken beschmutzte Wäsche oder Gefäße gleich am Brunnen gereinigt wären. Daß dies nicht schon früher einmal und namentlich nicht während der Sommerepidemie geschah, ist nur einem glücklichen Zufall zuzuschreiben. So wie hier die Dinge lagen, hätte bereits im Sommer ein Seuchenherd plötzlich entstehen können. Auch der im Winter erfolgte Ausbruch kann möglicherweise in dieser Weise verursacht sein, aber es ist mir wahrscheinlicher, daß Choleradejektionen oder Spülwasser von Cholerawäsche auf dem Hofe Nr 45 in der Nähe des Brunnens ausgegossen und auf die sogleich zu erläuternde Weise in den Brunnen gekommen sind. Im Sommer hätte vermutlich eine derartige Flüssigkeit ihren Weg durch die Gullies in die Tonrohrleitung und von da in die Straßenkanäle genommen, oder der trockene Boden würde sie aufgenommen und festgehalten haben, so daß sie nicht sehr weit geflossen wären. Jetzt im Winter, wo der Boden fast einen Meter tief gefroren und auch die Gullies eingefroren waren, so daß sie überhaupt keine Flüssigkeit mehr aufnehmen konnten, blieb für Schmutzwässer, die auf den Hof gegossen wurden, gar 
kein anderer Weg, als derjenige, welcher ihm durch das natürliche Gefälle auf der Bodenoberfläche angewiesen wurde, und dies war der Weg nach dem an tiefster Stelle gelegenen Brunnen. Daß es sich in der Tat so verhält, geht auch daraus hervor, daß das Wasser des Brumnens, als gleich nach dem Auftreten der ersten Fälle der Hof gesäubert und mit Karbollösung besprengt wurde, das Wasser des Brunnens, in welchen direkt keine Desinfektionsmittel gelangt sein konnten, vorübergehend nach Karbolsäure gerochen haben soll. Zu bemerken ist noch, daß an der östlichen Seite des Brunnens, wo die Tonrohrleitung an ihm vorbeigeht, keine Schmutzstreifen an der Innenwand zu bemerken waren. Von dieser Seite konnten demnach wohl keine Verunreinigungen dem * Brunnen żugeflossen sein. Übrigens mußte die Tonrohrleitung, welche zwar selbst an dieser Stelle $2 \mathrm{~m}$ tief, also frostfrei, liegt, seinerzeit leer sein, da ihr von den eingefrorenen Gullies her nichts zugeführt wurde.

Da in diesem Falle die Witterungsverhältnisse von so großer Bedeutung gewesen sind, so wird es nicht unwichtig sein, dieselben für den hier in Betracht kommenden Zeitraum genauer kennen zu lernen. Ich gebe die betreffenden Daten für Hamburg nach den Beobachtungen der Seewarte, welche mir Hr. Professor van $\mathrm{B}$ e b b e $\mathrm{r}$ in dankenswerter Weise zur Verfügung stellte (siehe umstehende Tabelle).

Aus dieser Tabelle ist zu ersehen, daß auf eine kurze Periode von Tauwetter, welche auf die Zeit vom 15. bis 21. Dezember 1892 fiel, eine Periode von andauernder Kälte folgte. Dieselbe begann am 21. Dezember und reichte bis zum 24. Januar. Während dieser Zeit müssen die Gullies eingefroren und funktionsunfähig gewesen sein. Der Choleraausbruch im ,langen Jammer" " begann am 21. Januar und endigte am 1. Februar. Also wird die Infektion des Brunnens vermutlich einige Tage früher, $d . h$. noch innerhalb der Frostzeit stattgefunden haben, zu einer Zeit, wo die Schmutzwässer nicht in den Boden versickern oder durch die Gullies aufgenommen werden konnten, sondern oberirdisch ihren Weg zum Brunnen nehmen mußten. An den meisten Tagen war die Kälte allerdings so stark, daß auch derartige Flüssigkeiten sich sehr bald in Eis verwandelt haben werden und nicht weit geflossen sein können, an einzelnen Tagen, wie z. B. am 14. Januar, blieb jedoch die Temperatur nur sehr wenig unter dem Gefrierpunkt und an einem solchen Tage kann die Verunreinigung des Brunnens geschehen sein.

Auf jeden Fall müssen Cholerabakterien, mag es nun so, wie ich es hier zu erklären versucht habe, oder auf einem anderen ähnlichen Wege sich zugetragen haben, in den Brunnen gelangt sein; denn sie sind tatsächlich in dem Brunnenwasser nachgewiesen. Wir haben es hier mit einem der seltenen Fälle zu tun, in welchem die Verhältnisse so lagen, daß die Untersuchung frühzeitig genug gemacht werden konnte. Hätte man das Brunnenwasser, wie es gewöhnlich nach Wasserinfektionen geschieht, einige Wochen nach dem Ausbruch der Krankheit untersucht, dann würde man nichts Verdächtiges mehr gefunden haben. Da sich hier aber von vornherein der Verdacht gegen den Brumnen richten mußte, so konnte die Untersuchung schon am 31. Januar gemacht werden. Sic wurde in der Weise ausgeführt, wie es in einer vorhergehenden Abhandlung ${ }^{1}$ ) beschrieben ist, und da schon in den ersten mit Pepton versetzten und bei Brüttemperatur gehaltenen Proben die Cholerabakterien in sehr großer Menge gefunden wurden, so muß3 wohl auch das ursprüngliche Wasser ziemlich reich daran gewesen sein.

Von dem am 31. Januar aus dem Brunnen entnommenen Wasser wurde ein Liter in einem Raum, der eine ziemlich gleichmäßige Temperatur von 3 bis $5^{0}$ hatte, aufbewahrt und von Zeit zu Zeit auf das Vorhandensein der Cholerabakterien geprüft. Sie konnten noch am 2., 3. und 17. Februar nachgewiesen werden. Sie hatten sich also unter den

1) Die bakteriologische Choleradiagnose. Zeitschrift für Hygiene und Infelktionskrankheiten, Bd. XIV. Diese Werke Bd. II, p. $167 \mathrm{ff.}$ D. Herausgeber. 
angegebenen Bedingungen im Brunnenwasser noch 18 Tage lebend erhalten. Dem Brunnen selbst später entnommene und untersuchte Wasserproben enthielten keine cholerabakterien.

Nachdem der Brunnen am 26. Januar geschlossen war, sind noch am 27., 28., 29. Januar und am 1. Februar je ein Cholerafall vorgekommen, sämtlich Fälle, die noch

\begin{tabular}{|c|c|c|c|c|c|c|c|c|c|}
\hline & \multicolumn{3}{|c|}{ Dezember 1892} & \multicolumn{3}{|c|}{ Januar 1893} & \multicolumn{3}{|c|}{ Februar 1893} \\
\hline & \multicolumn{2}{|c|}{ Temperatur ${ }^{\circ} \mathrm{O}$} & \multirow{2}{*}{$\begin{array}{c}\text { Nieder- } \\
\text { schlag } \\
\mathrm{mm}\end{array}$} & \multicolumn{2}{|c|}{ Temperatur $^{\circ} \mathrm{C}$} & \multirow{2}{*}{$\begin{array}{c}\text { Nieder- } \\
\text { schlag } \\
\mathrm{mm}\end{array}$} & \multicolumn{2}{|c|}{ Temperatur ${ }^{\circ} \mathrm{C}$. } & \multirow{2}{*}{$\begin{array}{c}\text { Nieder- } \\
\text { schlag } \\
\mathrm{mm}\end{array}$} \\
\hline & Min. & Max. & & Min. & Max. & & Min. & Max. & \\
\hline 1 & 0,4 & 4,6 & 5,9 & $-8,1$ & $-5,1$ & 3,7 & 8.9 & $4, \overline{3}$ & 1,0 \\
\hline 2 & $-2,5$ & 1,9 & 0,9 & $-7,9$ & $-5,3$ & 0.0 & 1,1 & 4,8 & 4,5 \\
\hline 3 & $-6,4$ & 0,8 & 12,1 & $-13,1$ & $-7,3$ & 0,0 & -3.1 & 2,9 & 0,0 \\
\hline 4 & $-2,1$ & 3,1 & 3,4 & $-14,8$ & $-9,5$ & 6,4 & $-4,6$ & -1.3 & 0,0 \\
\hline 5 & $-1,9$ & 3,6 & 4,5 & $-4,9$ & -1.8 & 0,0 & -89 & -2.4 & 0,0 \\
\hline 6 & $-4,9$ & 0,5 & 0,3 & $-4,1$ & $-3,4$ & 0,0 & -4.2 & -1.4 & 0.0 \\
\hline 7 & $-3,1$ & $-0,9$ & 0,4 & $-11,8$ & $-3,4$ & 0.0 & $-5,4$ & 0.9 & 2,6 \\
\hline 8 & $-3,1$ & 0,3 & 0,2 & $-13,9$ & -9.4 & 0,0 & 0,6 & 2.5 & 5,0 \\
\hline 9 & $-0,3$ & 1,6 & 0,0 & -9.2 & $-7,4$ & 0,0 & 0.1 & 3,6 & 4,6 \\
\hline 10 & $-4,8$ & 0,6 & 0,0 & $-7,9$ & $-3,4$ & 0,0 & 19 & 3,6 & 2,6 \\
\hline 11 & $-10,5$ & $-4,4$ & 0,9 & $-9,1$ & -1.9 & 0,1 & 2,6 & 4.6 & 2,8 \\
\hline 12 & $-5,4$ & 0,6 & 4,9 & $-14,9$ & $-6,4$ & 0,2 & $-1,3$ & 6,3 & 10,2 \\
\hline 13 & 0,6 & 1,9 & 0.1 & -9.8 & $-5, i$ & 6,2 & $-4,9$ & 1.1 & 19.5 \\
\hline 14 & $-1,9$ & 1,9 & 4,7 & $-5,9$ & $-0,4$ & 0,2 & 0,0 & 2,6 & 17,3 \\
\hline 15 & 0,5 & 3,6 & 2,9 & $-11,9$ & $-4,3$ & 3,3 & 3.1 & 7,0 & 0,1 \\
\hline 16 & 3,0 & 5,1 & 0,4 & $-15,1$ & $-7,9$ & 5,0 & & & \\
\hline 17 & 2,8 & 5,8 & 1,9 & $-13,7$ & $-5,6$ & 0,5 & & & \\
\hline 18 & 5,2 & 6,6 & 0,0 & $-18,4$ & $-9,4$ & 0,2 & & & \\
\hline 19 & 4,8 & 7,8 & 0,4 & $-18,2$ & $-14,6$ & 0,0 & & & \\
\hline 20 & 3,9 & 8,1 & 0,3 & $-18,2$ & -8.6 & 3,3 & & & \\
\hline 21 & $-1,0$ & 5,1 & 0,3 & $-3,7$ & 0,8 & 0,0 & & & \\
\hline 22 & 1,1 & 3,1 & 0,0 & $-8,8$ & $-0,8$ & 0,1 & & & \\
\hline 23 & $-4,2$ & 2,4 & 0,0 & $-6,6$ & $-4,8$ & 0,1 & & & \\
\hline 24 & $-7,7$ & $-1,3$ & 0,0 & $-10,7$ & $-1,9$ & 4,8 & & & \\
\hline 25 & $-8,7$ & $-5,1$ & 0,0 & 1,7 & 2,6 & 0,0 & & & \\
\hline 26 & $-7,7$ & $-2,6$ & 0,0 & 0,8 & 3,6 & 0,0 & & & \\
\hline 27 & $-3,4$ & $-0,2$ & 1,0 & $-0,6$ & 1,1 & 0,1 & & & \\
\hline 28 & $-2,0$ & $-0,1$ & 1,2 & 0,7 & 1,5 & 0,0 & & & \\
\hline 29 & $-0,3$ & 0,6 & 0,2 & $-3,8$ & 1,8 & 0,8 & & & \\
\hline 30 & $-1,1$ & 0,8 & 0,1 & 1,1 & 2,9 & 0,7 & & & \\
\hline 31 & $-6,8$ & 0.0 & 1,1 & 1,9 & 3,9 & 3,2 & & & \\
\hline
\end{tabular}

innerhalb der Inkubationsperiode liegen (der zuletzt Erkrankte litt schon seit den letzten Tagen des Januar an Durchfall) und deswegen der Infektion durch das Brunnenwasser zugeschrieben werden müssen.

Auf welche Weise die Cholera ihren Weg in den ,langen Jammer" gefunden hat, ließ sich trotz aller Bemühungen nicht ermitteln. Ich vermute deswegen, daß unter den seit Ende Dezember über die ganze Stadt verstreuten einzelnen Fällen auch der eine oder andere im , langen Jammer" vorgekommen, aber wegen wenig auffallender 
Symptome unerkannt geblieben ist. Die Bewohner des „langen Jammers" gehören eben nicht zu der Bevölkerungsklasse, welche schon wegen eines Durchfalles ärztliche Hilfe aufsucht und es ist deswegen die Annahme, daß ein leichter Cholerafall unter diesen Leuten unbemerkt verlaufen ist, wohl gerechtfertigt. Wenn Dejektionen von einem derartigen Fall in den Brunnen geraten sind, dann würde die kleine Epidemie damit in einfacher Weise ihre Erklärung gefunden haben. Will man eine derartige Annahme nicht zulassen, dann könnte man sich auch die Sache so zurechtlegen, daß man die beiden ersten Fälle vom 21. Januar der allgemeinen Epidemie der Stadt Altona zuschreibt, und von einem dieser Fälle die Brunneninfektion ausgehen läßt. Die Brunnenepidemie würde dann erst am 24. Januar begonnen haben und nur sieben Choleraerkrankungen mit sechs Todesfällen umfassen.

In der Altonaer Epidemie ist noch eine Erscheinung aufgetreten, welche unsere Aufmerksamkeit beansprucht.

Sie hat in der Zeit vom 23. Dezember 1892 bis 12. Februar 1893 geherrscht und umfaßt 47 Erkrankungen mit 27 Todesfällen. Die Mortalität beträgt somit 57,4 Proz. Diese Zahl ist zwar etwas hoch, aber doch noch nicht außergewöhnlich. Im höchsten Grade muß es indessen auffallen, daß fast gleichzeitig in dem benachbarten Hamburg eine Epidemie herrschte, welche mit 64 Erkrankungen und 18 Todesfällen eine noch nicht einmal halb so große Mortalität (28 Prozent) aufweist. Der Unterschied muß sogar noch größer erscheinen als es in den Prozentzahlen zum Ausdruck kommt, wenn man berücksichtigt, daß in Hamburg ausschließlich schlecht genährte, heruntergekommene und zum großen Teile dem Trunke ergebene Menschen, in Altona dagegen Personen aus allen Klassen der Bevölkerung an Cholera erkrankten. Woher mag es gekommen sein, daß die Cholera in Altona sich so sehr viel bösartiger verhielt?

Man könnte zunächst daran denken, daß in Hamburg viel eingehender untersucht wurde als in Altona und daß aus diesem. Grunde in Altona die ebenso wie in Hamburg vorhandenen nur noch bakteriologisch erkennbaren Fälle nicht herausgefunden seien. Nun ist zuzugeben, daß dieser Umstand einen gewissen Einfluß, namentlich im Anfang der Altonaer Epidemie, gehabt haben mag; denn es wurden anfangs nur die klinisch verdächtigen Fälle bakteriologisch untersucht und dabei mögen einige leichte Fälle entgangen sein. Aber später sind wiederholt, so im Gefängnis und in der Garnison, Massenuntersuchungen gemacht, ohne daß man dabei so wie in Hamburg auf klinisch unverdächtige, nur noch bakteriologisch charakterisierte Cholerafälle gestoßen ist. Die Epidemie in Altona ist also in der Tat qualitativ von der Hamburger Epidemie verschieden gewesen. Fast noch auffallender tritt dieses eigentümliche Verhalten der Cholera hervor, wenn man die einzelnen Gruppenerlkrankungen in Betracht zieht. So starben in der einen Familie von vier Erkkrankten drei, in einer zweiten von vier nur einer, in der dritten kam auf fünf Erkrankungen kein Todesfall, dann die Gruppenerkrankung im „langen Jammer" mit sieben Toten auf neun Erkrankungen. Gründe für diese Verschiedenheit können nur entweder in äußeren Faktoren wie Boden, Wohnungsverhältnissen usw. liegen, oder in individuellen Bedingungen, oder in der Art der Infektion, oder schließlich in dem Verhalten des Infektionsstoffes, d. h. der Cholerabakterien. Die beiden ersten Möglichkeiten sind hier auszuschließen; denn Unterschiede in bezug auf den Boden haben sich nicht ergeben und ebensowenig können andere von außen wirkende Faktoren maßgebend gewesen sein, da Wohnung, Reinlichkeit, Irnährung für die Opfer der Cholera in Hamburg noch weit ungünstiger waren, als für die Bewohner des ,langen Jammers". Ebensowenig ist einzusehen, wie gerade die Individuen der einen Familie oder die im "langen Jammer" von der Cholera ergriffenen Menschen individuell schlechter gestellt gewesen sein sollten, als die Obdachlosen unf Alkoholisten 
in Hamburg. Am meisten scheint deswegen noch der Einfluß in Frage zu kommen, welchen die Art der Infektion und die Beschaffenheit des Infektionsstoffes ausüben könnten. Es wäre doch möglich, daß die Übertragung der Cholera durch Wasser, wie sie in Altona und speziell im , langen Jammer" geschehen ist, eine ganz besonders gefährliche Form annimmt. Es spräche dafür auch der bösartige Charakter, welchen die große Sommerepidemie in Hamburg, die doch unzweifelhaft eine Wasserepidemie gewesen ist, zeigte. Aber es läßt sich auch wieder dagegen geltend machen, daß die Choleraepidemie auf den beiden Schiffen im Hamburger Hafen, obwohl sie ebenfalls durch das Wasser vermittelt waren, eine milde Form repräsentierten.

In bezug auf den Infektionsstoff selbst ließen sich Unterschiede in der Virulenz vermuten. Aber alle auf diesen Punkt gerichteten Untersuchungen sind erfolglos geblieben. Die Cholerabakterien, welche von den leichtesten Fällen der Nachepidemie stammen, haben in betreff ihrer Virulenz und der Fähigkeit der Produktion des der Cholera eigentümlichen Giftstoffes bisher keine konstanten Unterschiede erkennen lassen gegenüber denjenigen, welche von den schwersten Cholerafällen vom Beginn einer Epidemie gezüchtet sind

Ich muß gestehen, daß ich für dieses auffallend verschiedene Verhalten der Cholera, welches sich sowohl in kleinen Gruppenerkrankungen wie in ganzen Epidemien zu erkennen gibt, noch keine befriedigende Erklärung geben kann und ich halte es für eine der wichtigsten Aufgaben der ferneren Choleraforschung, diese rätselhafte Erscheinung aufzuklären.

In Altona traf es sich glücklicherweise so, daß die Ursachen der Epidemie frühzeitig erkannt wurden und daß diese Ursachen sich ohne Verzug beseitigen ließen. Von seiten der betreffenden Behörde, welche volles Verständnis für die Sachlage hatte, geschah sofort alles, um der Seuche Herr zu werden. Die Störung in dem Filterbetrieb wurde schleunigst ausgeglichen, der infizierte Brunnen wurde geschlossen; alle Cholerafälle, welche eine Verschleppung des Infektionsstoffes befürchten ließen, wurden isoliert und wo die Wohnungsverhältnisse zu ungünstig lagen, die der Ansteckung ausgesetzten Insassen evakuiert; daneben kamen überall in sachgemäßer Weise Desinfektionsmaßregeln zur Anwendung.

Diesem zielbewußten Vorgehen ist es gewiß zuzuschreiben, daß die Epidemie schnell und ohne große Verluste an Menschenleben ihr Ende fand.

Am 12. Februar 1893 wurde der letzte Cholerafall in Altona beobachtet. Seitdem ist nichts mehr vorgekommen und man kann deswegen die Epidemie für diese Stadt als vollkommen erloschen ansehen.

\section{Die Choleraepidemie in der Irrenanstalt zu Nietleben bei Halle.}

Obwohl der unmittelbare Zusammenhang zwischen der Choleraepidemie in Nietleben und derjenigen von Hamburg nicht festgestellt werden konnte, so muß doch auch diese Epidemie als ein Ausläufer der Hamburger Nachepidemie angesehen werden. In der Mitte des Monats Januar 1893, als in Nietleben die Cholera ausbrach, herrschte die Cholera nur noch in Rußland, Frankreich und Hamburg-Altona. Eine Einschleppung vom Auslande nach Nietleben ist wegen der Abgeschlossenheit der Irrenanstalt geradezu unmöglich. Will man daher nicht eine bereits im Sommcr stattgehabte, bis zum Winter latent gebliebene Einschleppung von einem der damals ergriffenen Orte hier annehmen, was aus später zu erörternden Gründen nicht angängig ist, dann bleibt nichts anderes übrig, als die Epidemie von einer frischen, aber unerkannt gebliebenen Einschleppung aus Hamburg abzuleiten. 
In der Gegend von Halle (vgl. die Karte, Fig. 2) und einige Meilen flußabwärts hat die Saale einen stark gewundenen Verlauf und teilt sich wiederholt, so namentlich bei Halle, in mehrere Arme. Zu beiden Seiten des Ufers tritt in diesem Teil des Flußlaufes Porphyr zutage, an manchen Stellen die Ebene des Flußtales kaum

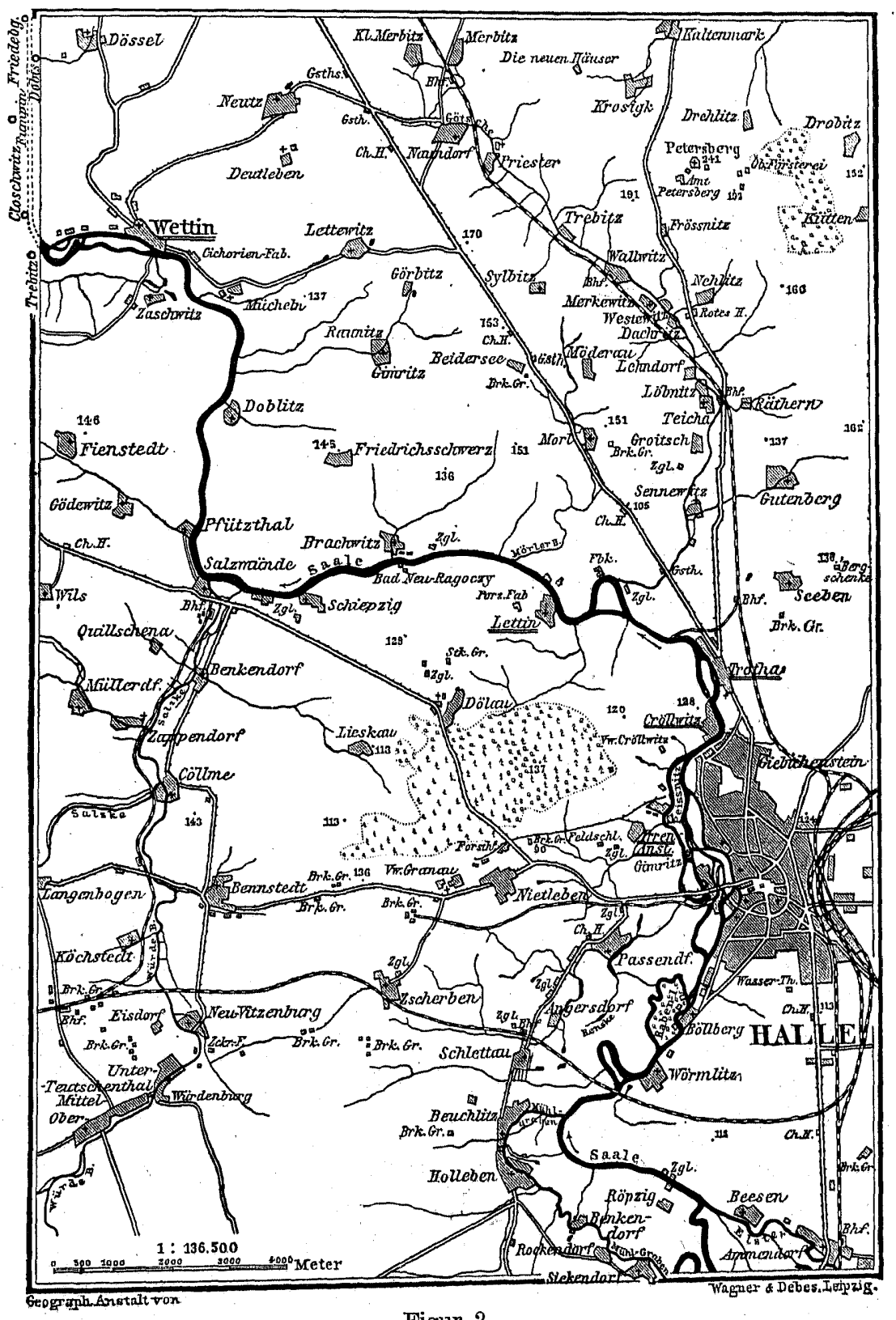

Figur 2.

Karte von Halle und Umgegend. (Die Choleraorte sind unterstrichen.)

überragend, an anderen Stellen kuppenförmige Erhöhungen bildend, welche nach dem Fluß zu steil abfallen. Die Stadt Halle liegt zum großen Teil auf Porphyr und auch die an der gegenüberliegenden westlichen Seite des Flußtales, in einer Entfernung von $4 \mathrm{~km}$ von Halle, befindliche Provinzialirrenanstalt Nietleben steht auf einer solchen Porphyrkuppe. Am Fuße der letzteren strömt ein Arm der Saale, welcher ,wilde Saale“ 
genannt wird. Die Nietlebener Porphyrkuppe erhebt sich $30 \mathrm{~m}$ über den mittleren Stand der Saale. Sie steht mit dem dahinter gelegenen fast ebenso hohen Terrain durch einen

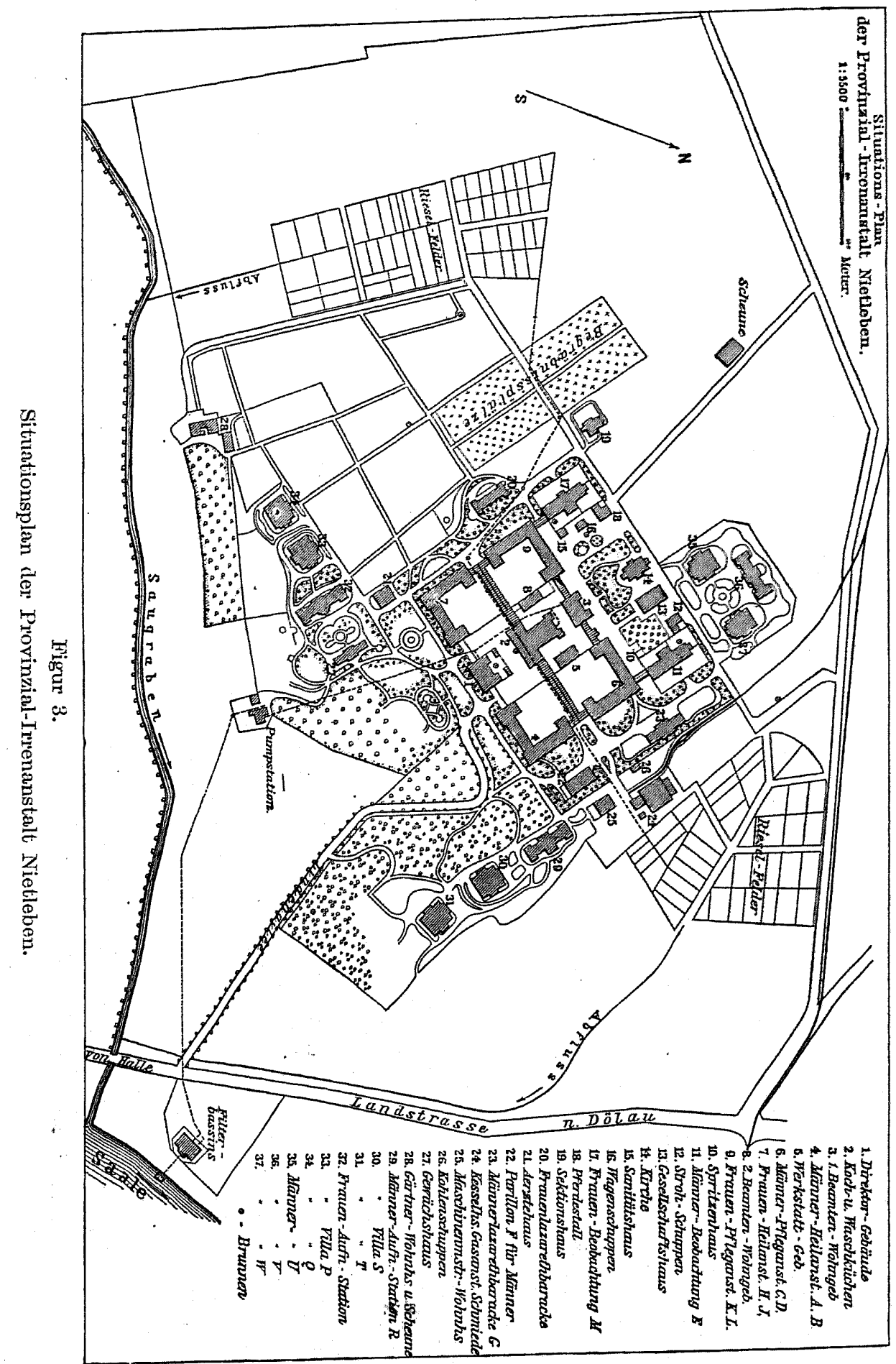

schmalen Rücken in Verbindung, welcher auf dem beifolgenden Situationsplan (Fig. 3) dem vom Gebäude 18 in der Richtung nach Westen an einer Scheune vorbeigehenden Weg entspricht. Nach den beiden Seiten, wo auf dem Plan die Rieselfelder angegeben 
sind, dacht sich die hügelartige Erhöhung ab; nach dem Flußtal zu endigt sie mit einem ziemlich steilen Abhang, an dessen Fuß die Pumpstation liegt. Nach dieser letzteren Seite ist sie nicht durch eine regelmäßige Kurve begrenzt, sondern sie hat zwei kurze Ausläufer, von denen der eine (in nahezu östlicher Richtung). die Pavillons 29, 30 und 31 trägt; der andere (in südlicher Richtung) mit den Pavillons 32, 33 und 34 besetzt ist. Zwischen diese beiden Ausläufer hinein erstreckt sich eine steile, schluchtartige Einbuchtung (bis an das Gebäude 1). An einzelnen Punkten tritt der nackte Fels zutage, aber im übrigen ist der Porphyr an seiner Oberfläche verwittert und mit den Verwitterungsprodukten, die aus losen Gesteinsbrocken und einem lehmigen Bindemittel bestehen, bedeckt. Eine erheblichere Dicke erreichte diese Verwitterungsschicht nur auf der Höhe der Kuppe. Hier hat sich in dem felsigen Untergrund eine rimmenartige Vertiefung gebildet, welche in der Gegend des Gebäudes 3 beginnt und sich in der Richtung nach der

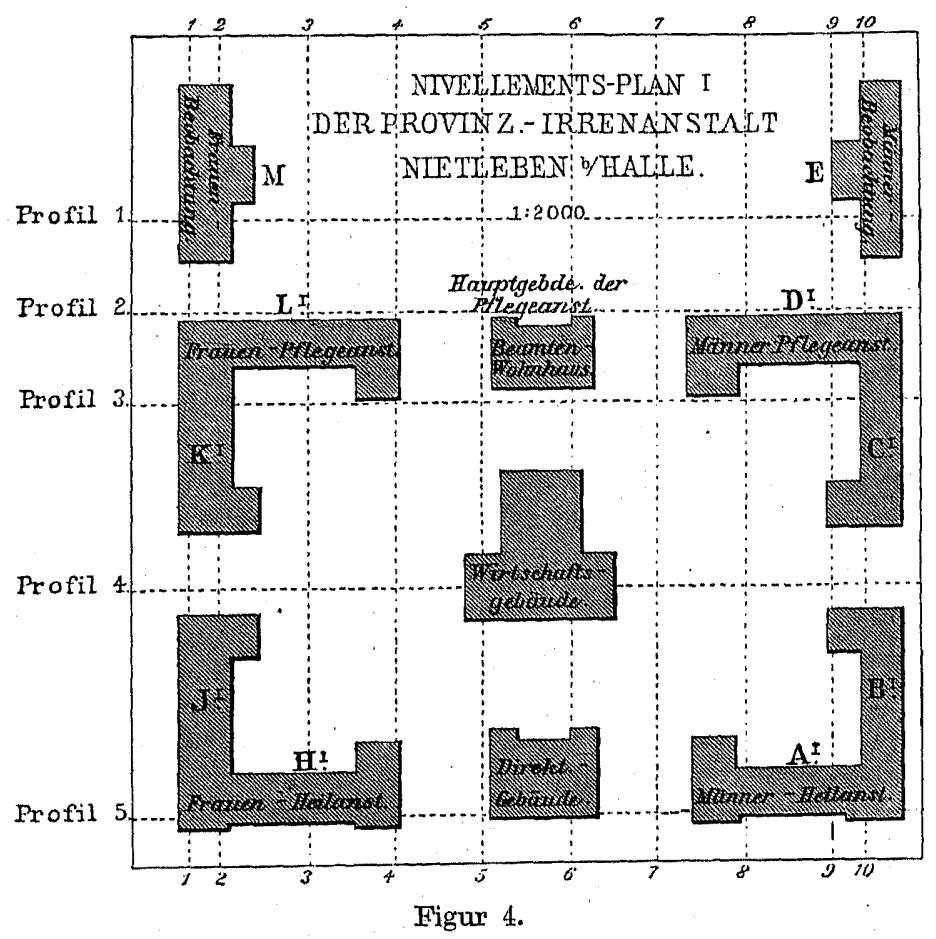

Nivellementsplan I der Provinzial-Irrenanstalt Nietleben.

oben erwähnten Einbuchtung unter den Gebäuden 2 und 1 hinzieht, in ihrem Verlauf immer tiefer werdend und schließlich in die Einbuchtung übergehend. Lage und Ausdehnung der Rinne ist am besten aus den Skizzen (Fig. 4 und 5) zu ersehen, welche einige Querprofile von der Höhe der Porphyrkuppe wiedergeben. Diese Rinne, mag sie nun von.Anfang bestanden haben, oder mag sie sich durch stärkere Verwitterung im Laufe der Zeit gebildet haben, vermittelt offenbar die natürliche Drainage für die breit gewölbte und in ihrer Mitte etwas eingesunkene Oberfläche der Porphyrkuppe. Über die sonstige Gestaltung des Hügels geben einige weitere Profile (Fig. 7a und 7b) Auskunft, welche die Höhenverhältnisse in Linien durch die Vorderfront der Anstaltsgebäude und durch die Längs- und Querrichtung der beiden Ausläufer des Hügels zeigen. Die Lage dieser Profillinien ist mit Hilfe der gleichnamigen Buchstaben auf dem Nivellements-Plan (Fig. 6) leicht zu ermitteln. Den Aufbau des Untergrundes der Trrenanstalt hat man sich nach dem Vorhergehenden folgendermaßen zu denken. Der Kern 
des Hügels besteht aus kompaktem, derben Porphyr. Derselbe ist in seiner äußersten, etwa 1 bis $2 \mathrm{~m}$ dicken Schicht verwittert und gelockert. Der Fels zeigt in dieser Rinde Spalten und Risse, welche von lehmartigen Massen ausgefüllt $\operatorname{sind}^{1}{ }^{1}$. Noch weiter nach außen folgt eine Schicht von losem Gestein und Lehm von wechselnder Stärke und darüber Ackererde. Der Fels ist nach allen Richtungen hin abschüssig. Gelegenheit zur Ansammlung von Grundwasser ist daher nirgends geboten. Auch auf der Höhe, wo sich eine flache Einsenkung findet, kann sich kein Grundwasser bilden, da einsickernde Tagewässer durch die früher beschriebene Rinne ungehinderten Abfluß haben²). Ebensowenig können von dem westwärts gelegenen höheren Terrain Wasserströmungen bis in das Gebiet der Anstalt kommen, da der Verbindungsrücken dafür zu schmal und von beiden
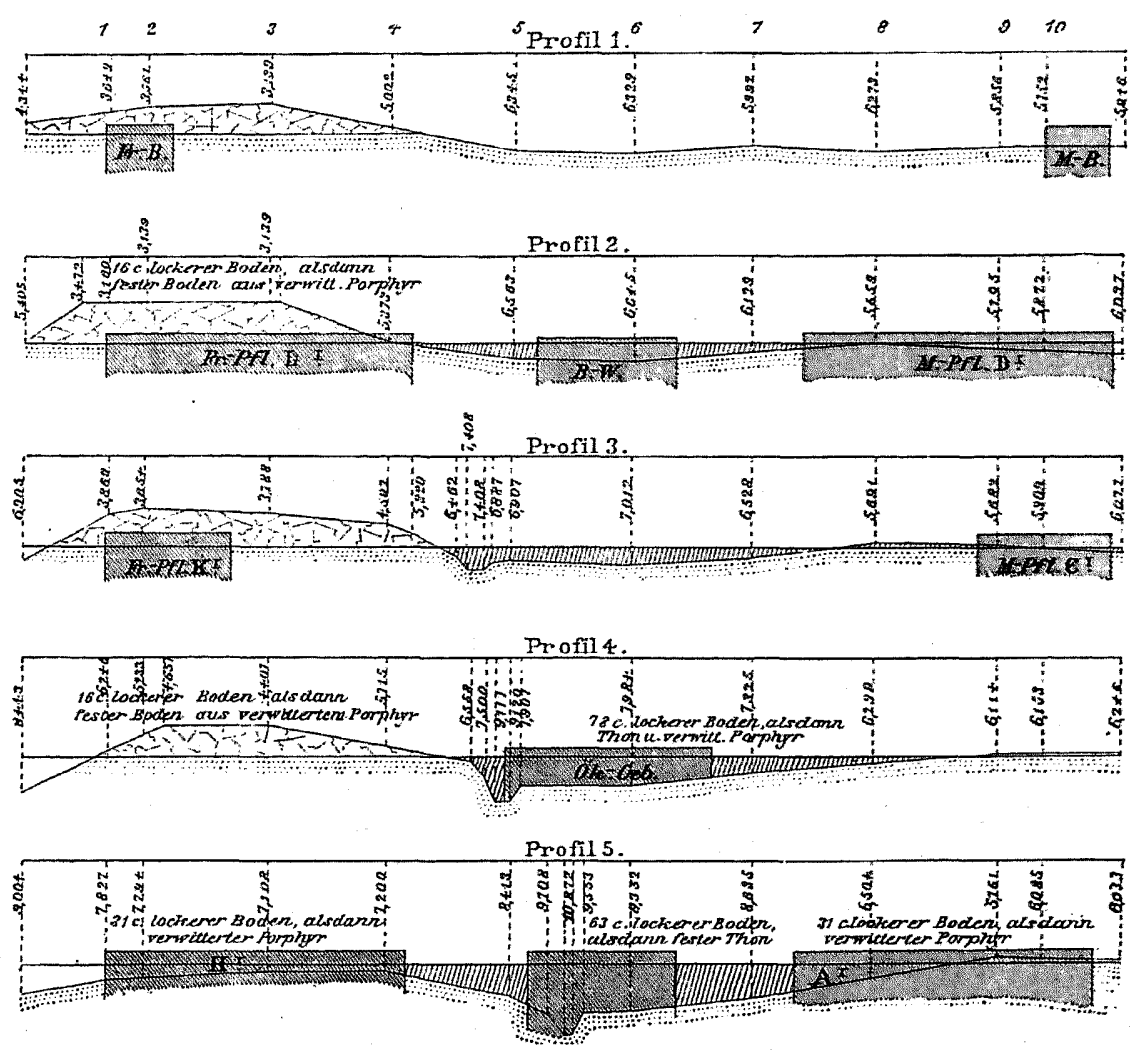

Figur 5.

Profile zum Nivellementsplan I.

Seiten her bis fast auf die Höhe mit künstlicher Drainage versehen ist, welche das etwa zuströmende Untergrundwasser in der Richtung nach den Rieselfeldern hin ableitet. Auf das Vorhandensein von Grundwasser könnte man allerdings daraus schließen, daß auf der Höhe des Hügels, zwischen den Anstaltsgebäuden, mehrere Brunnen sich befinden. Dieselben sind aber in den kompakten Fels selbst tief hineingetrieben; sie bilden

1) Das Porenvolumen des unverwitterten Porphyr schwankt zwischen 5 und 6,5\%. Dasselbe steigt je nach dem Grade der Verwitterung auf 8,5 bis $11,5 \%$. Die höchsten erhaltenen Zahlen betragen 11,6 und $11,7 \%$.

2) Durch den Bau des Direktorialgebäudes ist die Rinne nahe an ihrem AusfluB quer abgesperrt; doch ist durch einen tiefen Abzugskanal, welcher zwischen dem Direktorialgebäude und der daneben gelegenen Männer-Heilanstalt angelegt ist, dafür gesorgt, daß das in der Rinne fließende Sickerwasser neben dem Direktorialgebäude vorbei einen Ausweg findet. 
also gewissermaßen Zisternen und sammeln eine gewisse Menge von Sickerwasser, schaffen aber kein eigentliches Grundwasser.

Sämtliche Gebäude der Anstalt liegen auf der Höhe der Porphyrkuppe und stehen mit ihren Fundamenten auf dem festen unverwitterten Felsen, welcher an manchen Stellen, so namentlich unter den neuen Pavillons 29, 30, 31 und 32, 33, 34 durch Sprengarbeiten für den Bau hergerichtet werden mußte. Die Kellerräume der Gebäude zeigen.

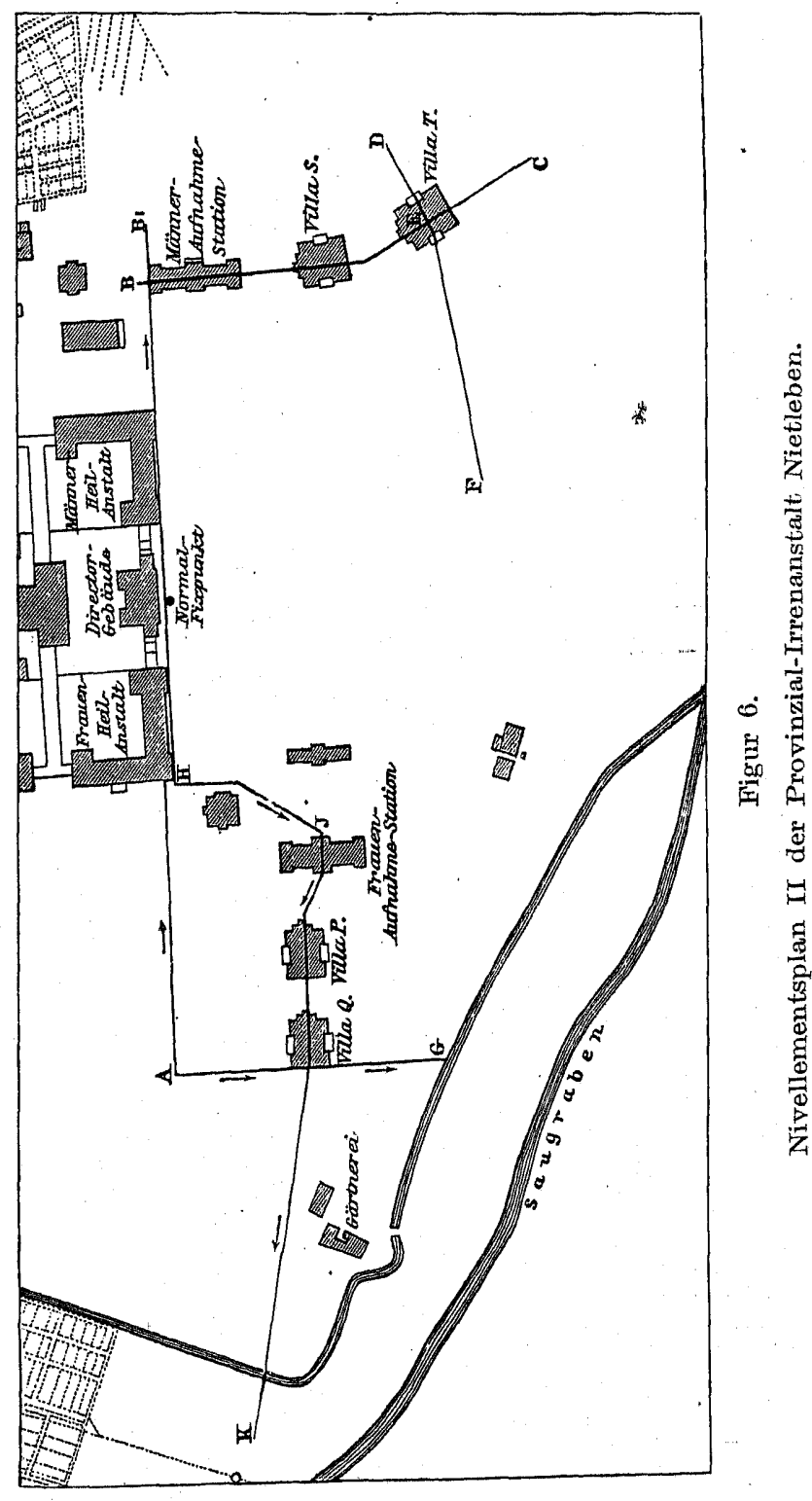

deshalb auch, wovon ich mich durch eigene Besichtigung überzeugt habe, nirgendwo Spuren von Bodenfeuchtigkeit. Wo solche scheinbar vorhanden war, z. B. unter dem Gebäude 6 (Männerpflegeanstalt), da ließ sich feststellen, daß es sich üm. Wasser handelte, welches aus den undicht gewordenen Ableitungsröhren der Dampfheizung stammte. Das einzige bewohnte, nicht auf Felsen fundamentierte, zur Anstalt gehörige Gebäude ist die Gärtnerwohnung (28). Dieselbe liegt am Fuße des Hügels auf angeschwemmtem 
Boden, in welchem das Grundwasser steigt und fällt. Bei hohem Stand soll es die Keller des Hauses teilweise überschwemmen.

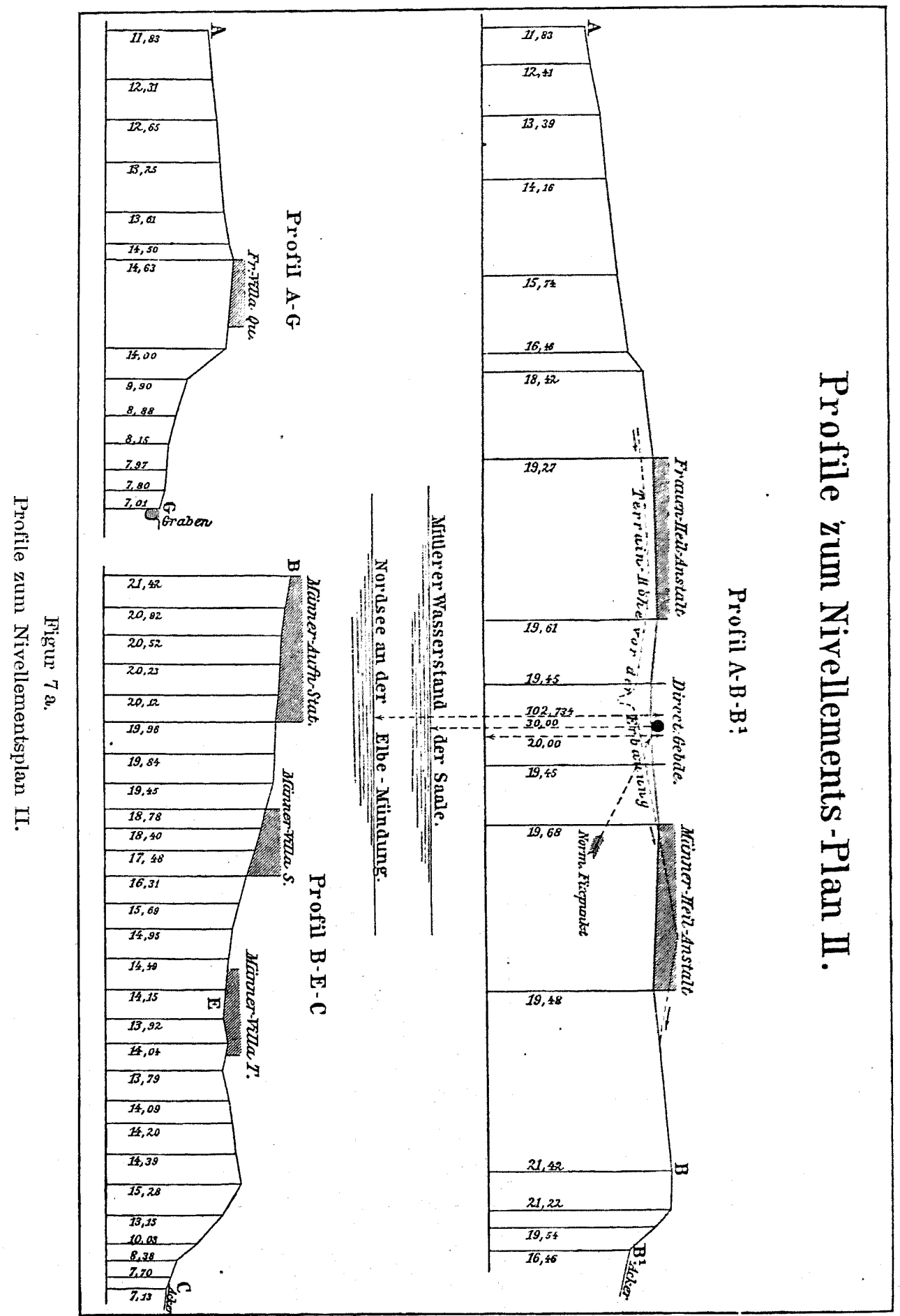

Die Anstalt wurde im Jahre 1840 erbaut und bestand ursprünglich aus einem Gebäudekomplex in rechteckiger Anordnung; der die Verwaltungsgebäude 1, 2, 3 und die zweistöckigen Korridorbauten 4, 6, 7 umfaßte. Später kam ein ebensolcher Korridor- 
bau (9) für die Frauenpflegeanstalt hinzu, und noch später wurden mehrere Gruppen von Pavillons außerhalb des Rechtecks gebaut; es sind dies die Pavillons 29, 30, 31

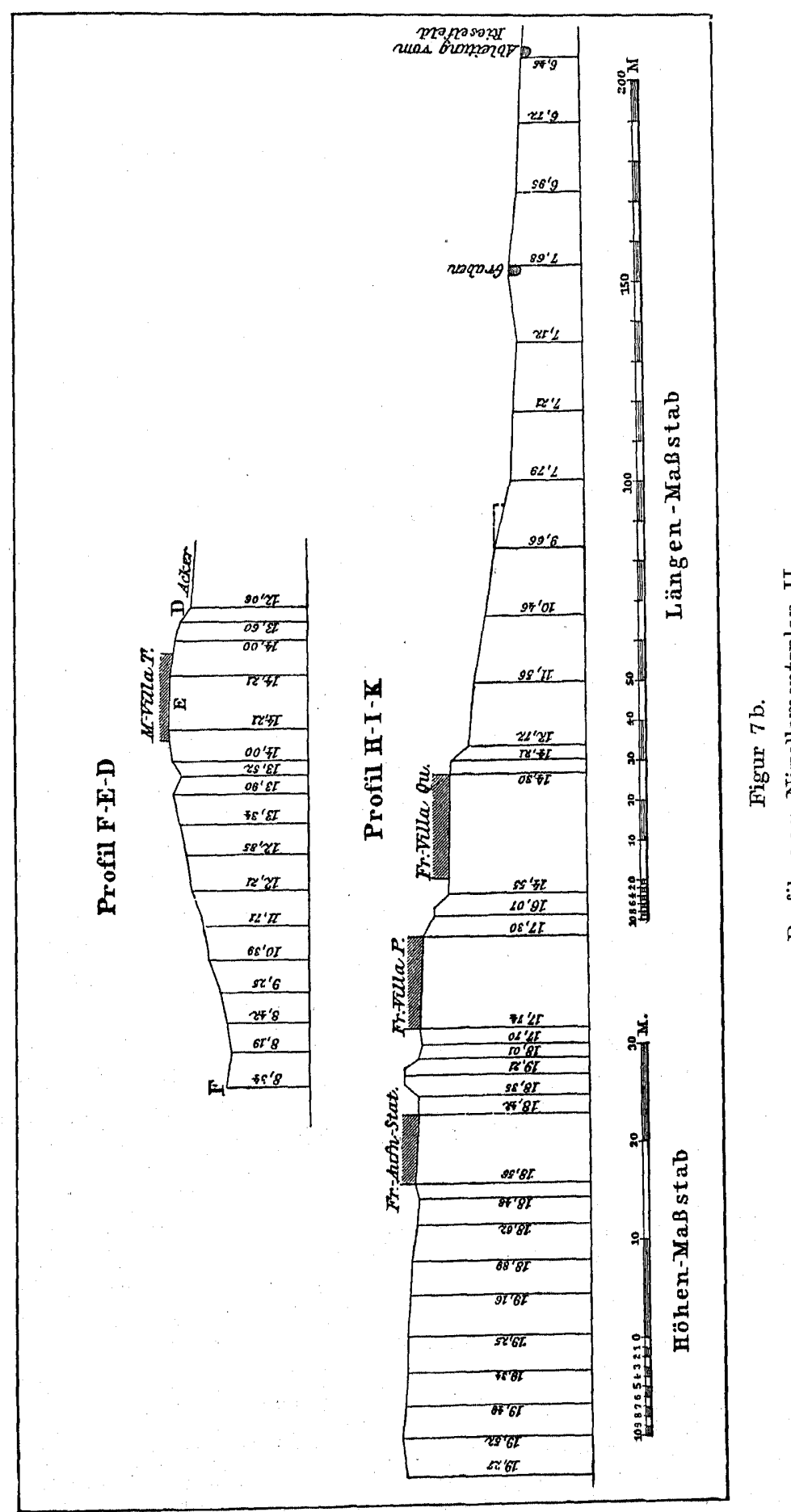

auf der Männerseite, 32, 33, 34 auf der Frauenseite, und die westlich von der Hauptanstalt gelegenen Pavillons 35, 36, 37. 
Seit fast zehn Jahren ist die Anstalt mit Wasserleitung und Kanalisation versehen. Die Einrichtung und der Betrieb der Wasserleitung, welche das Wasser aus der wilden Saale entnimmt, ist in einer früheren Abhandlung (Wasserversorgung und Cholera) eingehend beschrieben. Auf dem Plan läßt sich dieselbe in ihrem hauptsächlichen Verlauf verfolgen. Dicht neben der wilden Saale liegen die Filter; von da führt ein unterirdisches eisernes Rohr das Wasser zur Pumpstation, welche am Fuße des Hügels gelegen ist. Die Pumpe hebt es dann in die Höhe und drückt das Wasser in die Hochreservoirs (auf den Gebäuden 2 und 3 angebracht), von wo es vermittels eines Rohrnetzes in den Anstaltsgebäuden verteilt wird. Ein anderes Rohrsystem sammelt das Schmutzwasser aus den Ausgüssen, Wasserklosetts, Badezimmern, Küchen usw. und leitet es in die beiden Hauptkanäle, welche am Gebäude 2 beginnen und in entgegengesetzter Richtung nach den zu beiden Seiten der Anstalt an den Abhängen des Hügels gelegenen Rieselfeldern gehen. Es sind in Mauerwerk ausgeführte, mit Einsteigeschächten versehene, den heutigen Anforderungen durchaus entsprechende Kanäle: Auch die Rieselfelder sind vorschriftsmäßig angelegt. Sie bestehen aus horizontalen Beeten, welche terrassenförmig ansteigen. Der Boden derselben ist hinreichend tief drainiert. Das abfließende Wasser wird in einem Hauptrohr gesammelt und sowohl von dem nördlich (Männerseite) als von dem südlich (Frauenseite) gelegenen Rieselfelde schließlich in offenen Gräben, deren Verlauf auf dem Plane angedeutet ist, in den Saugraben, einen kleinen schmutzigen Bach, geführt. Daß dieser Bach in sehr geringer Entfernung oberhalb der Entnahmestelle für das Leitungswasser in die wilde Saale mündet, und welche schweren Bedenken gegen eine solche Anordnung der Schmutzwasserableitung und Wasserentnahme zu erheben sind, habe ich in der zitierten Abhandlung bereits auseinandergesetzt.

Ursprünglich war die Anstalt für 600 Kranke bestimmt, allmählich ist der Bestand aber auf 800 Kranke angewachsen und unter Hinzurechnung des Wartepersonals, der Ärzte, Beamten und der sonstigen in der Anstalt Beschäftigten hat sie ungefähr 1000 Bewohner ${ }^{1}$.

Die Irrenanstalt in Nietleben ist schon in früheren Jahren wiederholt der Schauplatz von Choleraepidemien gewesen und zwar unter Verhältnissen, welche einer Anwendung der Bodentheorie auf dieselben ganz besonders günstig zu sein schienen. Diese Epidemien spielen deswegen in der Choleraliteratur eine gewisse Rolle, sie sind oft zitiert und wir können sie hier nicht wohl unberücksichtigt lassen. Die Angaben darüber stammen von $\mathrm{Del} \mathrm{br} \mathrm{ü} \mathrm{ck}^{2}$ ) her und ich entnehme denselben folgendes.

Im Jahre 1866 beschränkte sich die Cholera auf die Männerabteilung, wo innerhalb 36tägiger Dauer der Epidemie 17 Personen starben. An Gelegenheit zur Einschleppung in die Frauenabteilung fehlte es nicht, es herrschten auf letzterer auch während der Epidemie Diarrhöen, aber es kam nicht zu ausgebildeten Cholerafällen. Umgekehrt verhielt es sich 1850; damals blieb die Männerabteilung frei, dagegen wurde die Frauenabteilung heftiger befallen. Den Grund für dieses. Verhalten der Cholera sucht D e l$\mathrm{b} \mathrm{r} \mathrm{ü} \mathrm{ck}$ in der Gestaltung des Bodens. 1850 existierte auf der Frauenabteilung noch

1) Am 14. Januar 1893 befanden sich in der Anstalt an Kranken:

an verpflegten Beamten... 124

an nicht verpflegten Beamten 56

im ganzen 991 Personen

2) Delbrück, Bericht über die Choleraepidemie des Jahres 1866 in Halle. Halle 1867 p. 19. - Verhandlungen der Cholerakonferenz in Weimar. Redigiert von $\mathbf{T}$ h o mas. Müncher 1867, p. 24. 
nicht das jetzt als Pflegeanstalt dienende Gebäude (auf dem Plan mit 9 bezeichnet), an seiner Stelle war ,,ein großer Berg, der, einen Steilrand bildend, den Zufluß des Wassers usw. vermehrte und den Abfluß der Feuchtigkeit von dieser. Stelle aus verhinderte; durch den Bau ist der Berg aber weggeschafft, und das Wasser hat dadurch einen sehr leichten Abfluß erhalten." Wenn man diese Bodenbeschreibung liest, ohne die Verhältnisse an Ort und Stelle gesehen zu haben, dann muß man den Eindruck gewinnen, daß in diesem Falle der Untergrund wirklich von Einfluß gewesen sein könne. Das ist nun aber keineswegs der Fall. Bei näherer Untersuchung schrumpft der „große Berg" mit seinem „Steilrand" in Nichts zusammen und die Delbrü ck sche Schilderung der früheren Choleraverhältnisse von Nietleben zeigt einmal wieder so recht deutlich, in wie naiver Weise man früher mit Untersuchungen über Choleraätiologie umgegangen ist und wie vorsichtig man in der Benutzung älterer Choleraberichte sein sollte. Ein Blick auf die Fig. 5, auf welcher der hier in Frage stehende Boden in seiner früheren Gestalt und nach Errichtung des Gebäudes 9 (Profile 1 bis 4) wiedergegeben ist, lehrt sofort, daß der angebliche, große Berg" nichts weiter ist, als ein etwa $2 \mathrm{~m}$ betragendes Ansteigen des Bodens am südlichen Rande des Anstaltsterrains. Von einem „Steilrand“ ist überhaupt nichts zu bemerken, wenn nicht etwa die nach innen von dieser Stelle gelegene, früher beschriebene Rinne gemeint ist. Aber gerade das Vorhandensein dieser Rinne hätte $\mathrm{D}$ el b $\mathrm{r} \ddot{\mathrm{c}} \mathrm{k}$ darüber belehren müssen, daß der Abfluß von Flüssigkeit in einer ganz anderen Richtung vor sich geht, als er annahm. Übrigens trat an Stelle des „Berges“ ein ausgedehntes Gebäude, das mit seinen den Felsen fest aufsitzenden Fundamentmauern den Bewegungen des Grundwassers, wenn hier solche stattgefunden hätten, mindestens ebenso große Hindernisse bereitet haben würde, als der „,Berg““ Glücklicherweise sind aber auch noch genauere Aufzeichnungen über den Gang jener Epidemie vorhanden, welche mir von der Direktion der Anstalt aus den Akten derselben bereitwilligst zur Verfügung gestellt wurden. Herr Dr. B u c h h o l z, Oberarzt der Anstalt, hat sich der Mühe unterzogen, die einzelnen Fälle in die Grundrisse der betreffenden Gebäude einzuzeichnen und die erforderlichen Notizen aus den Berichten auszuziehen; ich kann mich darauf beschränken, seine Skizzen und Notizen hier so wiederzugeben, wie er sie mir übergeben hat, da sie alles enthalten, was hier für uns von Interesse ist.

1. Epidemie im Jahre 1850 (Fig. 8).

Zur Zeit dieser Epidemie waren sämtliche weibliche Patienten in der zweistöckigen Frauenheilanstalt (auf dem Plan 7) untergebracht. Das Gebäude war für 75 Kranke
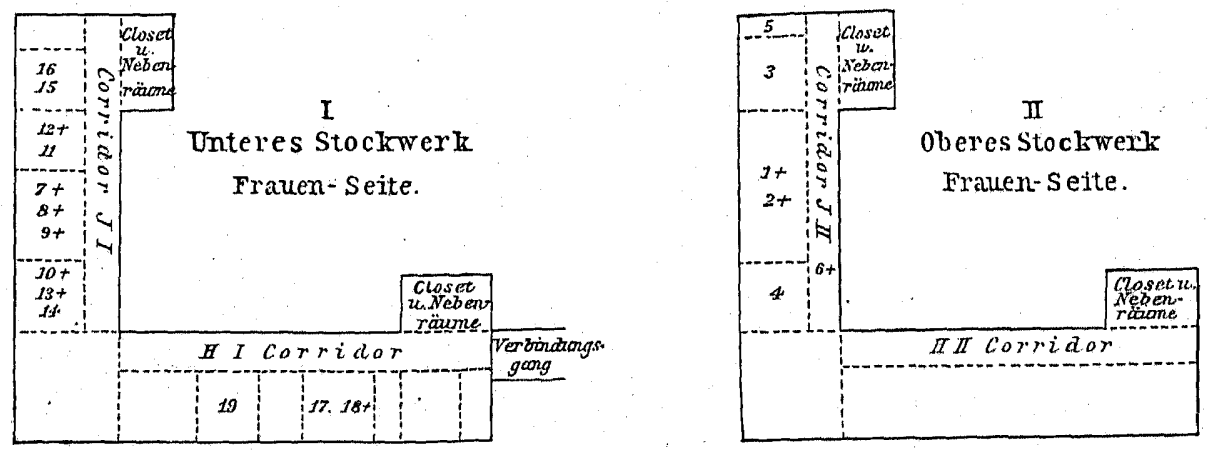

Figur 8. Choleraepidemie im Jahre 1850.

bestimmt, aber belegt mit $110 \mathrm{Kranken.} \mathrm{Auf} \mathrm{der} \mathrm{Abteilung} \mathrm{JI} \mathrm{lagen} \mathrm{die} \mathrm{erblödeten}$ Kranken, auf J II die Rekonvaleszenten. Die Wasserversorgung geschah durch die alte 
Leitung aus der Saale (ohne Filtration), daneben wurde Wasser aus dem Brunnen zum Trinken benutzt. Für die Fäkalien bestanden Abortgruben.

In betreff der einzelnen Kranken ist folgendes notiert:

Nr. 1. Patientin T. aufgenommen aus cholerainfiziertem Nerseburg (in dem Hause keine (holera, aber Durchfälle). Am 14. August aufgenommen, in der Nacht rom 17. zum 18. August an Durchfall erkrankt, als Cholera erkannt am 18. August, $\uparrow$ am 19. August.

Nr. 2. Wärterin des Korridors JII, hat Nr. 1 gepflegt, am 20. NIII. Durchfälle, bald ausgesprochene Cholerasymptome, $\uparrow$ 19./VIII.

$\left.\begin{array}{r}\text { Nr. 3. } \\ , 4 .\end{array}\right\}$ Pat. des Korridors JII, erkrankten am 23./TIII.

" 5. Pat. des Korridors JII, erkrankt am 24. VIII.

„6. Oberwärterin, welche die Kranken gepflegt und bei ihnen gewacht hatte, erkrankt am 24./VIII., † 25./VIII.

Bis hierher nur Erkrankungen im oberen Korridor JII; ron da ab geht die (holera auf den unteren Korridor JI über.

Nr. 7. Pat. erkrankt am 24./VIII., $\dagger$ in der Nacht rom 25. zum 26./VIII.

Am 25./VIII. Durchfälle bei mehreren Pat. auf JI.

Nr. 8. Pat. erkrankt 26./VIII., † 26. NIII.

, 9. " , $\quad, \quad 26 . /$ VIII., † 27.NIII.

"10. ", " 27./VIII. (mehrere Wochen später an Entkräftung ge-

storben).

"11. $\quad, \quad$, $\quad$ 27./VIII.

, 12. " " $\quad$ 27./VIII., † 28./VIII.

, 13. " " $\quad$ 28./VIII., † 29./VIII.

" 14. ", " $\quad$, 28./VIII.

" $15 . \quad, \quad, \quad$, 28./VIII.

" $16 . \quad, \quad$, 28./VIII.

Von hier ab Erkrankungen auf HI.

Nr. 17. Blödsinniges Kind erkrankt 29./VIII., am 29./NIII. Durchfälle bei einigen Pat., bei einer sogar starker Durchfall.

Nr. 18. Blödsinniges Kind von 9 Jahren, in demselben Zimmer wie Nr. 17; erkrankt 31./VIIT., † 31./VIII.

Nr. 19. Pat. in einem anderen Zimmer, erkrankt 31./VIII.

2. Epidemie im Jahre 1866 (Fig. 9).

Beim Ausbruch der Cholera hatte die Anstalt:

$$
\begin{array}{r}
\text { Kranke } 470 \\
\text { Beamte, Wärter usw. } 90 \\
\cline { 2 - 2 }
\end{array}
$$

In Halle herrschte die Cholera seit Mitte Juli. Ob die Einschleppung von da her oder von einem anderen Orte geschehen ist, konnte nicht festgestellt werden.

In bezug auf den Untergrund ist erwähnt, daß an der Vorderseite der Anstaltsgebäude (auf dem Plan 4 und 6) ein Abzugskanal verlief, welcher die Abwässer der MännerPflege- und Heilanstalt, sowie der Beobachtungsstation aufnahm und in einen offenen Graben führte. Dieser Kanal (6 Zoll im Geviert stark) wurde verstopft und von Wurzeln durchwachsen gefunden und es hatte sich infolgedessen Wasser in den Kellern unter 
der Pflegeanstalt angesammelt. Nach Erlöschen der Epidemie ist er durch einen Kanal von größerem Durchmesser ersetzt worden.

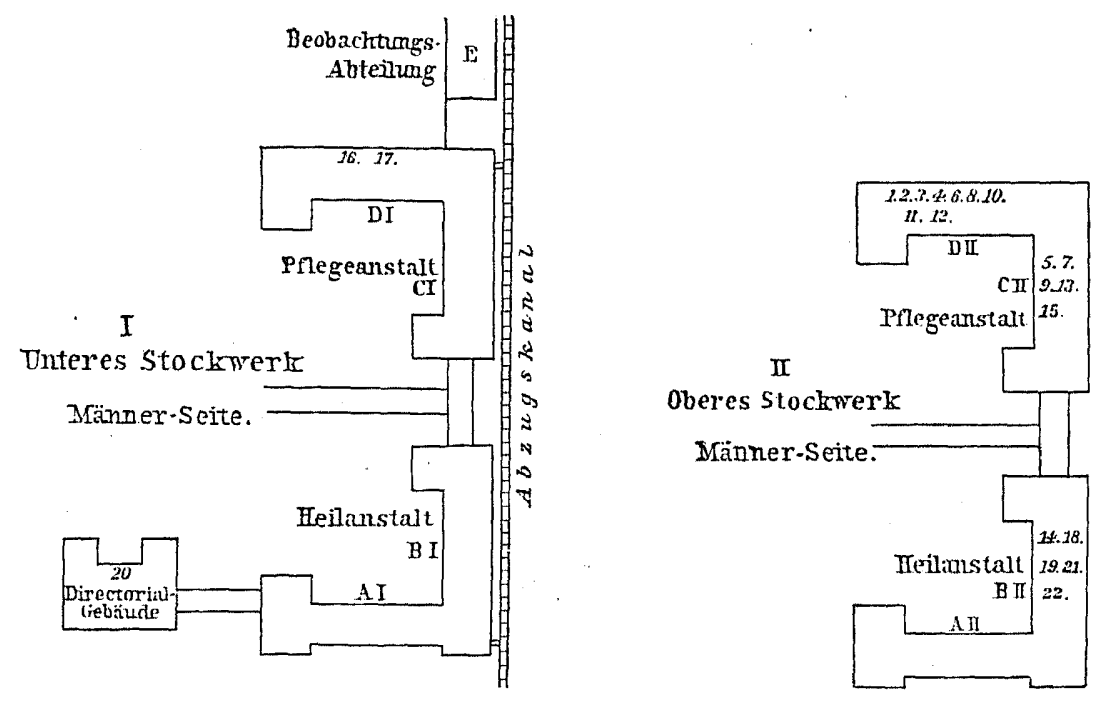

Figur 9.

Choleraepidemie im Jahre 1866.

Wasserversorgung und Aborte mit Gruben für die Fäkalien waren noch ebenso wie im Jahre 1850. Die Cholerafälle reihten sich in folgender Weise aneinander:

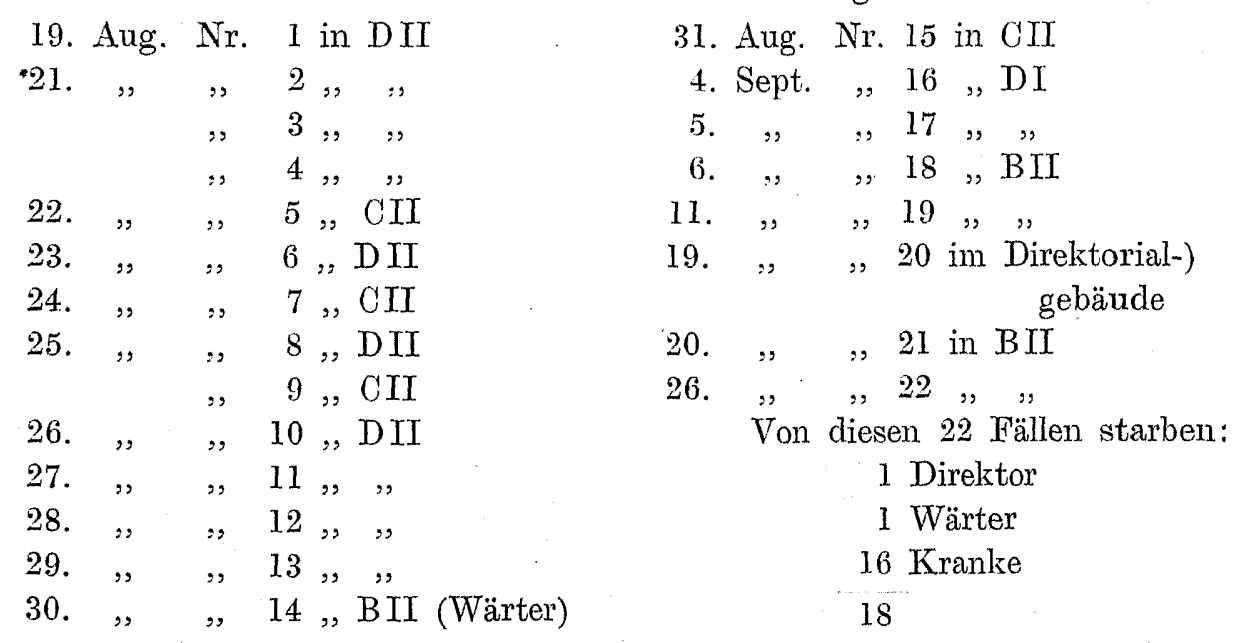

Außer den hier aufgezählten Fällen sollen noch 45 Personen auf den verschiedensten Abteilungen an heftigen Diarrhöen oder Erbrechen gelitten haben. Auf der Frauenabteilung kamen einige 50 derartige Erkrankungen vor, ohne daß die Symptome in einem einzigen Falle gefahrdrohend geworden wären.

So weit geht das, was sich über die früheren Epidemien ermitteln ließ; dasselbe genügt aber vollständig, um auch jetzt noch ein klares Bild von dem Verhalten der Cholera in den Jahren 1850 und 1866 zu gewinnen. Hätte die Cholera damals unter dem Einfluß allgemein wirkender Ursachen gestanden, dann mußte sie gleichzeitig und in gleichmäßiger Verbreitung über die ganze Anstalt hin, oder wenigstens in dem unter solchem Einfluß stehenden Gebäude ausgebrochen sein. Hätte z. B. im Jahre 1866 der verstopfte Abzugskanal zu den Ursachen der Seuche in Beziehung gestanden, dann hätte sich die

Koch, Gesammelte Werke. 
Krankheit zuerst und vorwiegend im unteren Stockwerk und hauptsächlich in der Abteilung $\mathrm{B}$ und $\mathrm{C}$ zeigen müssen. Das hat sie keineswegs getan. Sie trat zuerst im oberen Stockwerk in der Abteilung $D$ auf, griff später nach der angrenzenden Abteilung CII über, dann kam sie in die daran stoßende Abteilung BII. Nur nebenher und fast zwei Wochen nach Ausbruch der Epidemie finden sich zwei Fälle im unteren Geschoß der Abteilung $\mathrm{D}$.

Verfolgt man in beiden Epidemien auf den Grundrissen und unter Führung der Zahlen die örtliche Ausbreitung der Cholera, dann ergibt sich sofort und in ganz unverkennbarer Weise, daß beide Male die Krankheit von einem Punkte, nach dem sie eingeschleppt sein mußte (1855 konnte die Einschleppung auch nachgewiesen werclen), sich auf die Nachbarschaft ausbreitete; sie kroch wie ein Brand nach der Richtung weiter, wo sie Verzehrbares fand. Es handelte sich also keineswegs um die Wirkung außerhalb der Menschen liegender Ursachen des angeblichen „Berges" oder des „, verstopften Kanals", sondern die Menschen boten schon an und für sich der Cholera so günstige Angriffspunkte, daß sie keiner besonderen Vermittelung bedurfte und direkt vom Henschen zum Menschen überspringen konnte. Es ist das dieselbe Form der (holera, die ich im Eingange dieser Abhandlung als zweiten Typus beschrieben habe, wie wir sie in der Nachepidemie in Hamburg kennen gelernt haben und wie sie häufig genug auf Auswandererschiffen, in Gefängnissen, ganz besonders auch in Irrenanstalten früher beobachtet ist, also überall, wo Menschen unter ungünstigen Ferhältnissen dicht zusammengedrängt leben. Damit findet sich auch am einfachsten die Erklärung dafür, daß in beiden früheren Epidemien der Anstalt Nietleben die Pfleglinge, d. h. die unreinen Kranken, in überwiegender Mehrzahl betroffen wurden.

Außerordentlich lehrreich ist es nun $\mathrm{zu}$ sehen, wie in derselben Anstalt, welche schon zweimal Choleraepidemien vom zweiten Typus gehabt hat, auch der erste, der explosionsartige, Typus auftreten kann, wenn die Verhältnisse dies bedingen. Denn die Epidemie von 1893, zu deren Beschreibung ich jetzt übergehe, hatte einen ausgesprochen explosionsartigen Charakter.

\section{Epidemie im Jahre 1893.}

Während des Sommers 1892, als die Cholera von Hamburg aus nach allen Richtungen verschleppt wurde, sind in Halle und Umgegend keine Fälle von echter Cholera beobachtet. Nur einen Fall hat man für choleraverdächtig angesehen; derselbe betraf einen Hilfsheizer, der in der Anstalt Nietleben am 25. August mit Durchfall, Erbrechen und Wadenkrämpfen erkrankte und sofort der Universitätsklinik in Halle übergeben wurde. Später ist nichts Derartiges mehr vorgekommen. Einfache Diarrhöen, welche in Irrenanstalten immer mehr oder weniger anzutreffen sind, fehlten in Nietleben selbstverständlich während jener Zeit auch nicht. Dieselben nahmen aber zu Anfang Oktober so $z u$, daß allein für die Zeit vom 3. bis 26. Oktober 73 Diarrhöen in der Krankenliste aufgeführt sind. Das war indessen schnell vorübergehend, wie das nebenstehende Krankenverzeichnis, in welchem nur die Fälle von Diarrhöe, Dysenterie und Abdominaltyphus berücksichtigt sind, erkennen läßt.

Der November brachte nur wenige Fälle von Diarrhöe, ebenso der Dezember; nur in den letzten Tagen dieses Monats und bis zum 2. Januar sind 9 Durchfallerkrankungen notiert. Vom 2. bis zum 14. Januar kam nur ein einziger Fall vor. Es deutete also nichts darauf hin, daß die Anstalt sich unmittelbar vor der verhängnisvollen Katastrophe befand. Auf diesen Punkt möchte ich die Aufmerksamkeit besonders lenken, da mehrfach behauptet ist, daß in Nietleben prämonitorische Diarrhöen der Epidemie vorausgegangen seien. Die Diarrhöen, welche ein Vierteijahr vorher im Oktober vorkamen, 
kann man doch unmöglich als prämonitorische bezeichnen; abgesehen hiervon ist aber die Zeit vor der Epidemie und namentlich die unmittelbar vorhergehenden Wochen durch nichts gekennzeichnet, was auf einen Zusammenhang mit Cholera schließen lassen könnte.

Krankenliste.

\begin{tabular}{|c|c|c|c|c|c|c|c|}
\hline Datum & Diarrhöe & Dysent. & Typh. abdom. & Datum & Diarrhöe & Dysent. & Typh. abdom. \\
\hline Oktober & 1 & 1 & - & Dezember 8 & 1 & - & - \\
\hline 10 & 66 & - & - & 11 & 2 & - & - \\
\hline 26 & 6 & - & - & 16 & 4 & - & - \\
\hline November 12 & - & - & 2 & 20 & - & 1 & - \\
\hline 17 & 1 & - & - & 23 & 3 & - & - \\
\hline 24 & 2 & - & - & 26 & 3 & - & 2 \\
\hline 25 & 2 & - & - & Januar & 3 & - & - \\
\hline 26 & 1 & - & - & 7 & 1 & - & 1 \\
\hline Dezember 4 & 1 & - & - & 8 & - & - & 1 \\
\hline
\end{tabular}

Ich habe mich überhaupt noch nicht davon überzeugen können, daß sich der sogenannte Genius epidemicus in solcher Weise schon vor einer Choleraepidemie zu erkennen gibt. In Orten, wo die Cholera unerwartet zum Ausbruch gekommen ist, findet

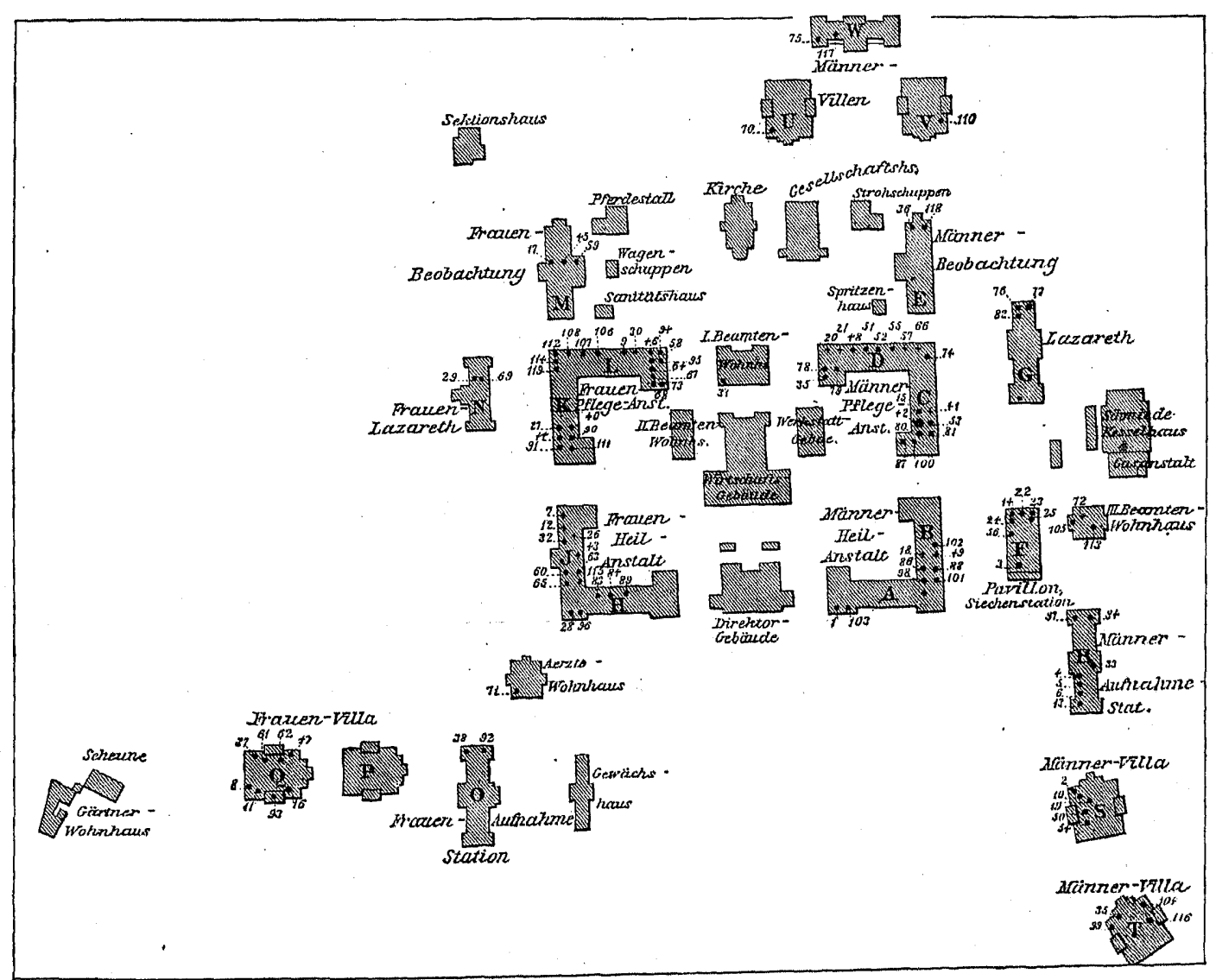

Figur 10. Verteilung der Cholerafälle in der Irrenanstalt Nietleben. + bedeutet die im oberen Stockwerk vorgekommenen Fälle.

man, wenn unbefangen nachgeforscht wird, keine auffallende Zunahme von Verdauungsstörungen; oder doch nur eine solche, wie sie der Jahreszeit entsprechend auch in anderen Jahren stattfindet. So ist es in Hamburg vor der großen Epidemie und in Nietleben 
gewesen. Die vermeintlichen prämonitorischen Diarrhöen finden sich dagegen regelmäßig da, wo mit gespannter Aufmerksamkeit der Ausbruch der Cholera erwartet wird; da wird jeder, auch der unbedeutendste Fall von Durchfall, Erbrechen usw. beachtet und womöglich schon auf Rechnung der Cholera gesetzt. So wurden z. B. nach dem Ausbruch der Cholera in Hamburg auffallend viele choleraverdächtige Fälle in die Krankenhäuser Berlins geliefert; ein mit einiger Phantasie ausgestatteter Beobachter hätte darin unzweifelhaft schon das Walten des Genius epidemicus spüren können. In Wirklichkeit waren es aber die gewöhnlichen Sommerdiarrhöen, Indigestionen, Alkoholrausch usw., Erkrankungen, die ohne Cholerafurcht gar nicht in solcher Anzahl ins Hospital gekommen wären.

In Berlin gab es also prämonitorische Diarrhöen in hinreichender Zahl, aber es folgte keine Cholera, in Hamburg und Nietleben dagegen, wo die Cholera unerwartet hereinbrach, fehlten sie und der vielbesprochene Genius epidemicus hat nichts von sich merken lassen, wo doch sein warnender Einfluß ganz besonders am Platze gewesen wäre.

Am 14. Januar $1893 \mathrm{kam}$ der erste Cholerafall in Nietleben zur Beobachtung. Ein Pflegling der Anstalt erkrankte ganz plötzlich an heftigem Brechdurchfall und starb noch am selben Tage. Die klinischen Symptome waren diejenigen der asiatischen Cholera, auch der Obduktionsbefund war damit übereinstimmend und in dem Darminhalt der Leiche wurden die Cholerabakterien nachgewiesen.

Diesem ersten Fall, welcher sich in dem Gebäude A auf dem umstehenden Plan Fig. 10 (auf dem Situationsplan der Anstalt Gebäude 4) ereignete, folgten am nächsten Tage 15. Januar) 6 weitere, welche sämtlich tödlich verliefen, am darauffolgenden Tage (16. Januar) 11 Erkrankungen mit 8 Todesfällen.

Ganz im Gegensatz zu den Epidemien von 1850 und 1866, in denen die Cholera an einem bestimmten Punkt eingesetzt hatte und erst allmählich auf benachbarte Räume und Abteilungen fortgekrochen war, erschien diesmal die Seuche sofort an den verschiedensten Stellen, sowohl auf der Männer- wie Frauenseite. Die 18 Fälle der drei ersten Tage verteilten sich auf 11 verschiedene Abteilungen und 10 verschiedene Gebäude der Anstalt. Über die räumliche Verteilung der Cholerafälle gibt der Plan Fig. 10, in welchem sie sämtlich eingetragen sind, Auskunft und der zeitliche Verlauf ist aus der nachstehenden Tabelle zu ersehen:

\begin{tabular}{|c|c|c|c|c|c|}
\hline Datum & Erkrankungen & Davon gestorben & Datum & Erkrankungen & Daron gestorben \\
\hline & & & Übertrag: & 93 & 41 \\
\hline 14. Januar & 1 & 1 & 24. Januar & 13 & 1 \\
\hline 15. & 6 & 6 & 25. & 5 & 4 \\
\hline 16. & 11 & 8 & 26. & 3 & 1 \\
\hline 17. & 15 & 7 & 28. $\quad "$ & 2 & 1 \\
\hline 18. & 8 & 2 & 31. " & 1 & 1 \\
\hline 19. , & 7 & 2 & 1. Februar & 1 & - \\
\hline 20. & 16 & 6 & & 1 & 1 \\
\hline 21. " & 9 & 3 & 5. & 1 & 1 \\
\hline 22. & 12 & 5 & 10. & 1 & 1 \\
\hline 23. $\quad, \ldots$ & 8 & 1 & 13. $"$ & 1 & - \\
\hline Summa: & 93 & 41 & Summa: & 122 & 52 \\
\hline
\end{tabular}

Die 122 Erkrankungen verteilen sich auf:

63 Männer (darunter 3 Ärzte),

59 Frauen (darunterer 7 Wärterinnen und 3 Frauen von Beamten). 
Um eine noch genauere Einsicht in die örtliche und zeitliche Verteilung der Cholera zu ermöglichen, lasse ich hier noch eine Tabelle folgen, welche die einzelnen Abteilungen der Anstalt enthält mit Angabe der Bettenzahl, der Belegung am Tage des Choleraausbruchs und der in diesen Abteilungen vorgekommenen und mit dem Datum der Grkrankung versehenen Cholerafälle:

\section{Männerseite.}

\begin{tabular}{|c|c|c|c|c|}
\hline Abteilung & $\begin{array}{c}\text { Zahl } \\
\text { der } \\
\text { Betten }\end{array}$ & $\begin{array}{c}\text { Belegung am } \\
\text { 14. Jan. } 1893 \\
\text { inkl. Warte- } \\
\text { personal }\end{array}$ & Cholera-Erkrankungen & Bemerkungen \\
\hline $\begin{array}{l}\text { Männer-Heilanstalt } \\
\text { unteres Stockwerk (A. I) }\end{array}$ & 30 & 28 & 2 (Jan. 14., 24.) & \\
\hline $\begin{array}{c}\text { Männer-Heilanstalt } \\
\text { oberes Stockwerk (A. II) }\end{array}$ & 9 & 8 & 0 & $\begin{array}{l}7 \text { Kranke I. und II. Ver- } \\
\text { pflegungsklasse mit }\end{array}$ \\
\hline $\begin{array}{l}\text { Männer-Heilanstalt } \\
\text { unteres Stockwerk (B. I) }\end{array}$ & 34 & 34 & 4 (Jan. 23., 24., 24., 24.) & \\
\hline $\begin{array}{c}\text { Männer-Heilanstalt } \\
\text { oberes Stockwerk (B. II) }\end{array}$ & 34 & 33 & 4 (Jan. 16., 20., 23., 25.) & \\
\hline $\begin{array}{l}\text { Männer-Pflegeanstalt } \\
\text { unteres Stockwerk (C. I) }\end{array}$ & 20 & 18 & $\begin{array}{l}4 \text { (Jan. 16., 20., 23., } \\
\text { Febr. 10.) }\end{array}$ & $\begin{array}{l}16 \text { Kranke I. und II. Klasse } \\
\text { mit } 2 \text { Wärtern. }\end{array}$ \\
\hline $\begin{array}{l}\text { Männer-Pflegeanstalt } \\
\text { oberes Stockwerk (C. II) }\end{array}$ & 51 & 48 & $\begin{array}{l}5 \text { (Jan. 19., 19., 22., 22., } \\
\text { 23.) }\end{array}$ & \\
\hline $\begin{array}{l}\text { Männer-Pflegeanstalt } \\
\text { unteres Stockwerk (D. I) }\end{array}$ & 54 & 52 & $\begin{array}{l}5 \text { (Jan. 20., 20., 22., 22., } \\
\text { 23.) }\end{array}$ & \\
\hline $\begin{array}{l}\text { Männer-Pflegeanstalt } \\
\text { oberes Stockwerk (D. II) }\end{array}$ & 46 & 45 & $\begin{array}{l}7 \text { (Jan. 17., 17., 20., 20., } \\
\text { 20., 21., 22.) }\end{array}$ & \\
\hline $\begin{array}{c}\text { Männer-Beobachtungsstation } \\
\text { (E.) }\end{array}$ & 30 & 29 & 2 (Jan. 18., Febr. 4.) & \\
\hline Männer-Pavillon (F.) & 33 & 32 & $\begin{array}{l}7 \text { (Jan. 15., 16., 17., 17., } \\
\text { 17., 17., 20.) }\end{array}$ & \\
\hline Männer-Lazarett (G.) & 36 & 23 & 2 (Jan. 22., 22., 22.) & \\
\hline Männer-Aufnahmestation (R.) & 33 & 32 & $\begin{array}{l}7 \text { (Jan. 15., 15., 15., 16., } \\
\text { 18., 18., 24.) }\end{array}$ & \\
\hline Männer-Pavillon (S.) & 44 & 37 & $\begin{array}{l}5 \text { (Jan. 15., 16., 16., 20., } \\
\text { 20.) }\end{array}$ & . \\
\hline Männer-Pavillon (T.) & 44 & 36 & 4 (Jan. 18., 24., 24., 26.) & \\
\hline Männer-Pavillon (U.) & 44 & 0 & 1 (Jan. 21.) Wärterin & Gleich nach Ausbruch der \\
\hline Mänuer-Pavillon (V.) & 44 & 36 & $\begin{array}{l}1 \text { (Jan. 26.) ein bei der } \\
\text { Desinfektionsanstalt } \\
\text { beschäftigter Pflegling }\end{array}$ & $\begin{array}{l}\text { Cholera als Cholera- } \\
\text { lazarett benutzt. Die } \\
\text { Kranken von } \nabla . \text { wurden }\end{array}$ \\
\hline Männer-Pavillon (W.) & 44 & 0 & $\begin{array}{l}3 \text { (Jan. 22., Febr. 1., 13.) } \\
3 \text { Wärterinnell }\end{array}$ & $\begin{array}{c}\text { auf andere Abteilungen } \\
\text { verlegt. }\end{array}$ \\
\hline \multicolumn{5}{|c|}{ II. Frauenseite. } \\
\hline $\begin{array}{c}\text { Frauen-Heilanstalt } \\
\text { unteres Stockwerk }(\mathrm{H} . \mathrm{I})\end{array}$ & 34 & 31 & $\begin{array}{l}6 \text { (Jan. 17., 22., 22., 23., } \\
\quad 23 ., 24 .)\end{array}$ & $\begin{array}{l}\text { Die am 24. Jan. Erkrankte } \\
\text { ist eine Wärterin. }\end{array}$ \\
\hline $\begin{array}{c}\text { Frauen-Heilanstalt } \\
\text { oberes Stockwerk (H. II) }\end{array}$ & 12 & 9 & 0 & $\begin{array}{l}8 \text { Kranke I. und II. Klasse } \\
\text { mit } 1 \text { Wärterin. }\end{array}$ \\
\hline $\begin{array}{c}\text { Frauen-Heilanstalt } \\
\text { unteres Stockwerk (J, I) }\end{array}$ & 32 & 31 & 3 (Jan. 20., 20., 21.) & \\
\hline \multicolumn{5}{|c|}{ (Fortsetzung der Tabelle umstehend.) } \\
\hline
\end{tabular}




\begin{tabular}{|c|c|c|c|c|}
\hline Abteilung & $\begin{array}{c}\text { Zabl } \\
\text { der } \\
\text { Betten }\end{array}$ & $\begin{array}{c}\text { Belegung am } \\
\text { 14. Jan. } 1893 \\
\text { inkl. Warte- } \\
\text { personal }\end{array}$ & Cholera-Erkrankungen & Bemerkungen \\
\hline $\begin{array}{c}\text { Frauen-Heilanstalt } \\
\text { oberes Stockwerk (J. II) }\end{array}$ & 39 & 38 & $\begin{array}{l}6 \text { (Jan. 15., 16., 17.; 17., } \\
\text { 19., 25.) }\end{array}$ & \\
\hline $\begin{array}{c}\text { Frauen-Pflegeanstalt } \\
\text { unteres Stockwerk (K. I) }\end{array}$ & 43 & 40 & 4 (Jan. 17., 18., 19.. 23.) & \\
\hline $\begin{array}{l}\text { Frauen-Pflegeanstalt } \\
\text { oberes Stockwerk (K. II) }\end{array}$ & 28 & 28 & 1 (Jan. 26.) & $\begin{array}{l}24 \text { Kranke I. u. II. Klasse } \\
\text { mit } 4 \text { Wärterinnen. }\end{array}$ \\
\hline $\begin{array}{c}\text { Frauen-Pflegeanstalt } \\
\text { unteres Stockwerk (L. I) }\end{array}$ & $\begin{array}{r}47 \\
\because\end{array}$ & 44 & $\begin{array}{l}12 \text { (Jan. 19., 20., 21., } 21 \\
\text { 21., 22., 24., 25., 25., } \\
\text { 28., 31., Febr. 5.) }\end{array}$ & \\
\hline $\begin{array}{c}\text { Frauen-Pflegeanstalt } \\
\text { oberes Stockwerk (L. II) }\end{array}$ & 42 & 41 & $\begin{array}{l}5 \text { (Jan. 16., 17., 18., 24., } \\
\text { 25.) }\end{array}$ & $\begin{array}{c}\text { Die am 17. Jan. Erkrankte } \\
\text { ist die Oberwärterin. }\end{array}$ \\
\hline $\begin{array}{l}\text { Framen-Beobachtumgsstation } \\
\text { (MI.) }\end{array}$ & 33 & 33 & $3(\operatorname{Jan} .16 ., 19 ., 20)$. & \\
\hline Frauen-Lazarett (N.) & 24 & 25 & 2 (Jan. 17., 21.) & \\
\hline Frauen-Aufnahmestation (0.) & 33 & 34 & 2 (Jan. 18., 23.) & \\
\hline Frauen-Pavillon (P.) & 44 & 23 & 0 & \\
\hline Frauen-Pavillon (Q.) & 44 & 42 & $\begin{array}{l}8 \text { (Jan. 16., 16., 16., 18., } \\
\text { 19.. 20., 24.) } \\
\quad\end{array}$ & $\begin{array}{l}\text { Die am 24. Jan. Erkrankte } \\
\text { ist eine Wärterin. }\end{array}$ \\
\hline \multicolumn{5}{|c|}{ III. Beamten-Wohnhäuser. } \\
\hline I. Beamtenhaus & & & 2 (Jan. 17., 17.) & 2 Beamtenfrauen. \\
\hline II. Beamtenhaus & & & 3 (Jan. 21., 24., 28.) & $\begin{array}{l}2 \text { Ärzte und } 1 \text { Beamten- } \\
\text { frau. }\end{array}$ \\
\hline Ärzte-Wohnhaus & & & 1 (Jan. 21.) & 1 Arzt. \\
\hline
\end{tabular}

Die Tabellen und der Plan Fig. 10 lassen ohne weiteres erkennen, daß die Cholera nicht nur in ihrem Beginn, sondern auch im weiteren Verlaufe über die ganze Anstalt, abgesehen von einigen Stellen, auf die ich noch zurückkommen werde, ziemlich gleichmäßig verteilt war. Die ursächlichen Momente konnten also auch nur solche gewesen sein, welche nicht einzelne Gebäude oder einzelne Gruppen unter den Bewohnern der Anstalt, sondern die Anstalt im ganzen getroffen hatten. Solchen gemeinschaftlichen Einfluß konnte im vorliegenden Falle nur entweder der Boden, oder die Nahrungsmittel, oder das Wasser ausgeübt haben.

Der Boden war von vornherein mit aller Sicherheit auszuschließen. Alle Gebäude stehen auf festem Felsen. Die einzigen, welche möglicherweise vom Boden ungünstig hätten beeinflußt werden können, waren die älteren Anstaltsgebäude, welche ein Rechteck bildend, rings um die Depression auf der Höhe der Porphyrkuppe gruppiert sind (auf dem Plan Fig. 10 A, B, C, D, H, I, K, L). Wegen der natürlichen und künstlichen Drainage der Depression war an eine Stauung des Untergrundwassers wohl nicht zu denken; aber der lockere Boden, welcher die Depression ausfüllt, ist vermutlich von früheren Zeiten her, wo die Schmutzwässer der Anstalt noch nicht durch Kanalisation beseitigt wurden, mit Schmutzstoffen imprägniert, und man hätte erwarten können, daß dieser verunreinigte Boden in irgendeiner Weise das Verhalten der Cholera beeinflussen würde. Davon ist aber nicht das geringste zu bemerken; denn die Cholera verhielt sich in den älteren Anstaltsgebäuden gar nicht anders als in den neuen Gebäuden, 
deren felsiger Untergrund auch in früheren Zeiten niemals außergewöhnlichen Verunreinigungen ausgesetzt war.

Auch die Versorgung der Anstalt mit Nahrungsmitteln bot trotz sorgfältiger Nachforschungen keinen Anhalt dafür, daß auf diesem Wege die Allgemeininfektion vermittelt gewesen wäre. Die meisten Nahrungsmittel wurden von den Lieferanten auch gleichzeitig an die klinischen Institute in Halle geliefert, ohne daß diese von Cholera heimgesucht wurden, und in der Anstalt traten Choleraerkrankungen auch bei solchen Personen auf, welche nicht von der Anstalt verpflegt wurden.

Es blieb somit nur noch die Annahme übrig, daß das Wasser der Träger des Infektionsstoffes gewesen sei. Von vornherein sprachen allerdings gewichtige Gründe gegen diese Annahme. Denn die Anstalt war gerade in dieser Beziehung mit Einrichtungen versehen, welche einen hinreichenden Schutz hätten gewähren müssen ${ }^{1}$ ). Gesetzt den Fall, daß der Infektionsstoff der Cholera durch irgendeinen Zufall in die Anstalt eingeschleppt und in die Abwässer derselben geraten wäre, dann hätte er schon durch die filtrierende Wirkung des Bodens auf den Rieselfeldern zurückgehalten werden müssen und selbst wenn die Rieselfelder ihn hätten entschlüpfen lassen, dann mußte er auf der Oberfläche der Sandfilter liegen bleiben, durch welche das Leitungswasser vor dem Eintritt in die Anstalt geht. Daß der Infektionsstoff diese beiden Schranken, von welchen erfahrungsgemäß jede einzelne imstande war ihn abzuhalten, überwunden hätte, war nicht sehr wahrscheinlich. Gleichwohl mußten die Filteranlage und die Rieselfelder daraufhin untersucht werden, ob sie auch so funktionierten, daß sie den Infektionsstoff wirklich abzuwehren vermochten.

Was die. Untersuchung der Filteranlage ergeben hat, ist von mir bereits in der Abhandlung ,Wasserfiltration und Cholera" ausführlich beschrieben. Sie zeigte, um es hier kurz zu wiederholen, daß die Anlàge in der Konstruktion zwar einige Mängel hatte, aber bei sorgfältiger Bedienung ein Wasser hätte liefern können, welches frei von Infektionsstoffen gewesen wäre. Die Benutzung der Filter geschah jedoch in einer Art und Weise, daß das Wasser fast unfiltriert durch die Sandfilter ging. Hier bestand also schon eine gewaltige Lücke in den sanitären Einrichtungen, welche die Anstalt gegen Infektion schützen sollten.

Nicht viel besser stand es mit der Funktion der Rieselfelder. Dieselben sind im großen und ganzen vorschriftsmäßig konstruiert; entbehren aber der Staubassins, welche im Winter, wenn der Boden gefroren und undurchlässig geworden ist, die Schmutzwässer bis zum Ablauf der Frostperiode aufzunehmen haben. Man wird bei der Anlage der Rieselfelder die Staubassins vermutlich aus dem Grunde weggelassen haben, weil im Notfall auch die einzelnen von einem niedrigen Wall umgebenen Beete als Staubassins dienen konnten. Es hätte in diesem Falle ein Beet nach dem andern mit dem Schmutzwasser gefüllt werden müssen, so weit es davon zu fassen vermochte. Die Fläche der vorhandenen Beete ist auch groß genug, um während einer langen Frostperiode das Schmutzwasser auf dem Rieselterrain zu stauen und die Rieselanlage hätte selbst in dem harten Winter von $1892 \mathrm{zu} 1893$ richtig funktionieren können. Aber zu meinem Bedauern muß ich auch hier wieder, ebenso wie in betreff der Filteranlage, die Bemerkung machen, daß wohl niemand von den Beteiligten die richtige Behandlung der Rieselanlage gekannt hat; denn es ist nicht einmal der Versuch gemacht, das Schmutzwasser während der Frostperiode auf den einzelnen Feldern zu stauen. Die Folgen dieser Unterlassung machten sich denn auch in der Weise geltend, daß, nachdem der Boden gefroren war, das Schmutzwasser oberflächlich oder in gröberen Bodenspalten und Mäuselöchern über

1) Die Brunnen der Anstalt kamen für die Wasserversorgung nicht in Betracht, weil sie seit einem halben Jahre geschlossen waren. 
die Rieselfläche floß, ohne durch den Boden eine nennenswerte Reinigung zu erfahren. Als ich die Rieselfelder untersuchte, waren sie mit einer ziemlich hohen Schneelage bedeckt, darunter war der Boden fast einen Meter tief gefroren und unter dem Schnee, aber auf dem gefrorenen Boden floß das Schmutzwasser ungehindert ab, wo es sich gerade einen Weg gebahnt hatte. Zu- und Abfluß der Rieselfelder wurden wiederholt bakteriologisch untersucht und in bezug auf den Bakteriengehalt, wie unter solchen Verhältnissen wohl auch nicht anders zu erwarten war, ohne wesentlichen L'nterschied gefunden. So enthielt z. B. das Schmutzwasser in einem Falle, ehe es auf das Rieselterrain der Frauenseite trat, 400000 Keime im Kubikzentimeter, gleichzeitig geschöpftes Wasser von einem Beet 350000 , aus einem Seitengraben 450000 , aus dem Hauptdrainrohr am unteren Ende des Rieselterrains 470000.

Also auch diese Schutzeinrichtung erwies sich als vollkommen insuffizient und der Infektionsstoff konnte mit dem Flüssigkeitsstrom ungehindert durch die Anstalt zirkulieren. Dafür, daß dies in der Tat geschehen ist, lieferte die weitere bakteriologische Untersuchung den unumstößlichen Beweis; denn die Cholerabakterien wurden an verschiedenen Stellen dieses Kreislaufs nachgewiesen. Sie wurden gefunden auf der Frauenseite in dem Schmutzwasser bei seinem Eintritt in das Rieselterrain, auf den Rieselfeldern selbst und in dem Wasser, welches durch das Hauptdrainrohr das Rieselterrain verließ; auf der Männerseite ebenfalls in der Flüssigkeit beim Eintritt und beim Verlassen des Rieselterrains. Ferner wurden sie nachgewiesen im Wasser der wilden Saale unterhalb der Einmündungsstelle des Saugrabens, in dem filtrierten Wasser des Filter Nr. II und in einer Wasserprobe, welche aus einem Leitungshahn innerhalb der Anstalt entnommen war.

Daß der Nachweis der Cholerabakterien in solcher Vollständigkeit gelungen ist, ist unzweifelhaft hier ebenso, wie bei dem Cholerabrunnen in Altona, dem Cmstande zu verdanken, daß die Untersuchung so bald nach dem Ausbruch der Cholera ausgeführt werden konnte.

Damit ist die unmittelbare Veranlassung für den explosionsartigen Ausbruch der Cholera in Nietleben vollkommen klar gelegt. Der Infektionsstoff muß auf irgendeine Weise in die Anstalt verschleppt sein, ist dann mit den Abwässern der Anstalt über die gefrorenen Rieselfelder hinweg in den Saugraben, von da in die wilde Saale gelangt und aus dieser durch die Wasserleitung der Anstalt wieder zugeführt. Das Wasser war allen Bewohnern der Anstalt zugänglich und es mußte je nach dem Gehalt desselben an Cholerabakterien und je nach den Beziehungen der Bewohner zum Wasser, sowie nach ihrer individuellen Disposition eine mehr oder weniger gleichmäßig über die ganze Anstalt verbreitete explosionsartige Epidemie entstehen, wie es tatsächlich geschehen ist.

Auch in diesem Falle kann es nicht allein bei der ursprünglichen Wasserinfektion geblieben sein. Von den Erstinfizierten sind unzweifelhaft in dem so außerordentlich empfänglichen Menschenmaterial, wie es eine Irrenanstalt beherbergt, auch sekundäre Infektionen ausgegangen. Als solche möchte ich einen Teil derjenigen Choleraerkrankungen auffassen, welche in den Pflegeabteilungen mit ihren unreinlichen Kranken vorgekommen sind, so namentlich in der Abteilung LI, wo mehr als der vierte Teil der Insassen befallen wurde. Auch die Wärterinnen, welche in den als Choleralazarett benutzten Pavillons U und W während der Pflege von Cholerakranken die Cholera bekamen, werden sich vermutlich nicht durch das Wasser, sondern direkt von den Kranken infiziert haben, und das gleiche dürfte in bezug auf die drei erkrankten Ärzte gelten.

Wenn sich an solchen Stellen, wo sich Gelegenheit zu Sekundärinfektionen bot, die Cholerafälle häuften, so blieben sie andererseits in denjenigen Abteilungen dünner gesät, wo die Verhältnisse für das Zustandekommen einer Infektion weniger günstig 
lagen. Dies war der Fall in den Abteilungen AII, HII, und K II, in denen Kranke erster und zweiter Klasse verpflegt wurden. A II mit 8 und HII mit 9 Personen sind ganz verschont geblieben, in KII kam unter 28 Personen nur ein Fall vor. Die Erklärung für diese Erscheinung ist wohl darin zu finden, daß den Pfleglingen erster und zweiter Klasse Kaffe, Tee und anderweitige Getränke mehr zur Verfügung stehen als den Pfleglingen dritter Klasse, und daß sie schon deswegen mit dem infizierten Wasser weniger in Berührung gekommen sind. Gegen diese Auffassung würde allerdings sprechen, daß in der Abteilung CI, welche ebenfalls der ersten und zweiten Klasse angehört, unter 18 Personen 4 Cholerafälle vorgekommen sind. Obwohl einer dieser Fälle, der zuletzt Erkrankte, kurz vorher von DI nach CI verlegt war und sich vermutlich noch in DI infiziert hat, so bleiben immerhin noch drei Cholerafälle, eine auffallend große Zahl, und es ist mir nicht gelungen, hierfür eine befriedigende Aufklärung zu gewinnen.

Eigentümlich ist es ferner, daß der Frauen-Pavillon $\mathrm{P}$ ganz verschont geblieben ist. Derselbe unterscheidet sich weder durch seine Bauart, noch durch seinen Untergrund von dem benachbarten Frauen-Pavillon $Q$ und von dem korrespondierenden Männer-Pavillon $\mathrm{S}$, welche beide reichlich Cholerafälle hatten. Der Pavillon $\mathrm{P}$ nahm nur insofern eine außergewöhnliche Stellung ein, als er zur Zeit des Choleraausbruchs nur zur Hälfte belegt war. Einen gewissen Einfluß hat dieser Umstand wohl auf das Freibleiben des Gebäudes gehabt, ob derselbe aber allein oder in Verbindung damit, daß diese Abteilung eine besonders sorgsame Wärterin hatte, welche ihren Pfleglingen stets abgekochtes Wasser verabreicht haben soll, genügt, um das Ausbleiben der Cholera zu erklären, muß ich dahingestellt sein lassen.

$\mathrm{Zu}$ erwähnen ist ferner, daß auch in der Gärtnerei mit fünf Bewohnern kein Cholerafall vorgekommen ist. Dieses Gebäude ist das einzige bewohnte Haus der Anstalt, welches nicht auf felsigem Untergrund, sondern auf dem Alluvium des Talbodens steht, welcher an dieser Stelle stark verunreinigt und dem Wechsel der Bodenfeuchtigkeit unterworfen ist. Hier hätte den Lehren der Bodentheorie entsprechend die Cholera einen besonders günstigen Angriffspunkt finden müssen. Die Angehörigen der Gärtnerfamilie beziehen ihr Wasser aus einem Rohr der Wasserleitung, welches bis in die Nähe des Hauses geführ.t ist. Sie gaben auch zu, das Wasser getrunken zu haben, aber nur in geringen Mengen und nach der Mittagsmahlzeit. Doch möchte ich hierauf weniger Gewicht legen, als auf die geringe Zahl der Bewohner des Grundstücks. Dieselben konnten wegen der kleinen Anzahl ebensogut verschont bleiben, wie die schwach besetzten Abteilungen erster und zweiter Klasse AII und HII.

Nachdem die Untersuchung darüber Gewißheit geschafft hatte, daß die Nietlebener Cholera mit ihrem explosionsartigen Verlauf durch eine Infektion des Leitungswassers entstanden war, mußte nun weiter danach geforscht werden, auf welche Weise der Infektionsstoff in die Wasserleitung eingedrungen sein konnte. Ich habe schon früher angedeutet, wie ich mir die nächste Herkunft des Infektionsstoffes denke, und daß ich die .Infektion der Leitung als von den Rieselfeldern der Anstalt ausgehend annehme. Denn dagegen, daß die Saale die Cholerabazillen von weiter flußaufwärts gelegenen Ortschaften herabgeschwemmt haben sollte, spricht der Umstand, daß oberhalb von Nietleben keine Cholera vorgekommen ist. Am plausibelsten erschien deswegen die Voraussetzung, daß in die Anstalt selbst zuerst die Cholera in einem vereinzelten Falle eingeschleppt wurde und daß dieser danh der Ausgangspunkt für den im Circulus vitiosus durch die Anstalt kreisenden Infektionsstoff geworden ist. Dieser subsumierte erste Fall war aber nicht zu finden und infolge dieses Mangels sind eine ganze Reihe von Hypothesen über die Entstehung der Cholera in Nietleben aufgetaucht, welche so ziemlich alle Möglichkeiten und Unmöglichkeiten von der autochthonen Enstehung der Cholera 
an bis zum zugereisten Handwerksburschen, der heimlich seine Choleradejektionen am Ufer der Saale deponiert haben sollte, umfassen. Es kann hier nicht meine Aufgabe sein, diese Hypothesen zu erörtern und ich werde mich darauf beschränken, dasjenige zu berichten, was zur Aufklärung dieses dunklen Punktes noch am meisten beitragen kann.

Zu der Zeit, als die Cholera in Nietleben ausbrach, bestand der einzige Choleraherd, von dem aus die Seuche eingeschleppt sein konnte, in Hamburg-Altona; aber wie sollte sie von dort aus gekommen sein, mitten im Winter und unter C̈berspringen so zahlreicher dazwischenliegender Ortschaften? Etwa auf dem Wasserwege durch Flußfahrzeuge konnte sie nicht eingeschleppt sein, denn die Flußschiffahrt, welche allerdings von Hamburg aus auf der Elbe und der Saale bis über Nietleben hinauf geht, hatte wegen der Eisverhältnisse schon etwa seit anderthalb Monaten aufgehört. Man konnte also nur noch an Waren oder von Hamburg zugereiste Personen denken.

In bezug auf Waren konnte, da sämtlicher Verkehr und insbesondere auch der Postpaketverkehr durch das Bureau der Anstalt geht, sehr bald festgestellt werden, daß außer einigen Briefen nichts von Hamburg nach der Anstalt in direktem Verkehr gelangt war. Übrigens würden, auch wenn wirklich Waren in die Anstalt aus Hamburg Eingang gefunden hätten, diese doch nicht als Choleraträger zu beschuldigen sein, da bekanntlich durch eigentliche Handelswaren noch niemals Cholera verschleppt ist und auch während der großen Hamburger Epidemie keine einzige Verschleppung durch Waren nachgewiesen werden konnte, obwohl noch zu Anfang der Epidemie große Mengen von Waren aus Hamburg ausgeführt sind.

Danach könnte die Einschleppung nur durch den Personenverkehr stattgefunden haben und diese Annahme scheint mir auch die größte Wahrscheinlichkeit für sich zu haben. Da die Anstalt ihren Krankenzugang nur aus der Provinz Sachsen hat, so kommen die Kranken hierbei zunächst nicht in Frage. Es müßte denn sein, daß die Cholera von Hamburg nach der Provinz Sachsen durch einen leichten Cholerafall gebracht wäre, wie sie damals wiederholt in den Hamburger Bettlerherbergen aufgefunden wurden, und daß durch diesen unentdeckt gebliebenen Fall zufällig ein Mensch infiziert wäre, der bald darauf wegen Geisteskrankheit in die Anstalt geliefert wurde. Statt dieses etwas komplizierten Weges, der zwar nicht als unmöglich, aber doch auch nicht gerade als wahrscheinlich bezeichnet werden kann, steht für die direkte Einschleppung von Hamburg noch ein anderer einfacherer Weg zur Verfügung, nämlich durch das Wärterpersonal der Anstalt, das immer mehr oder weniger fluktuierend ist. Die Anstalt hat in den letzten drei Monaten dreizehn Wärter und Wärterinnen neu eingestellt. Unter diesen befindet sich keine Person, welche als ihren letzten Aufenthaltsort Hamburg angegeben hätte, aber es hat sich doch zufällig herausgestellt, daß ein aus Halle engagierter Wärter unmittelbar vorher aus Hamburg gekommen war. Er hatte sich in Halle selbst nur wenige Tage aufgehalten, um hier zu erfahren, ob er in Nietleben Anstellung finden werde. Dieser selbe Wärter litt in den ersten Tagen seiner Beschäftigung in Nietleben an starkem Durchfall, was auch nicht zur Kenntnis gekommen wäre, wenn er nicht unterlassen hätte, sich in Halle nach der damals noch bestehenden Vorschrift als aus Hamburg zugereist zu melden. Erst als er deswegen in Polizeistrafe genommen werden sollte, entschuldigte er sich damit, daß er sich zu unwohl gefühlt habe, um sich melden zu können. Daß gerade dieser Wärter, welcher übrigens in einer Hamburger Anstalt gewesen sein soll, die von Cholera frei geblieben $\stackrel{d}{w}$ ar, die Cholera nach Nietleben gebracht hat, kann nicht ohne weiteres behauptet werden. Er litt in der Zeit vom 5. bis 8. Dezember an Durchfall und da würde doch eine auffallend lange Zeit zwischen der Einschleppung des ersten Krankheitskeimes und dem Ausbruch der Epidemie verflossen sein. Aber auf jeden Fall beweist dieses Vorkommnis, daß ein direkter Personenverkehr zwischen 
Hamburg und Nietleben in der Zeit vor der Epidemie bestanden hat. In Hamburg ging damals die Epidemie zu Ende, viele Personen, welche dorthin gegangen waren, um als Krankenwärter Beschäftigung zu finden, mußten sich nach anderen Stellen umsehen, und so mag unter den für Nietleben aus der Stadt Halle angeworbenen Personen - es waren acht in der angegebenen Zeit -- auch noch der eine oder andere kurz vorher in Hamburg gewesen sein.

Die von anderer Seite ausgesprochene Vermutung, daß die Cholera bereits im vorhergehenden Sommer nach Nietleben gebracht sei und sich dort längere Zeit latent gehalten habe, um dann plötzlich explosionsartig auszubrechen, kann ich nicht teilen; denn ich kann mir nicht denken, daß der Infektionsstoff während der für ihn so günstigen warmen Jahreszeit irgendwo, z. B. im Boden, untätig gelagert hätte und gerade in der kältesten Zeit, wo der Boden tief gefroren war, plötzlich erwacht wäre, und ebensowenig, daß er unter den für die Cholera so überaus günstigen Verhältnissen der Anstalt etwa innerhalb der Menschen durch eine Kette von leichten Fällen sich monatelang unbemerkt gehalten habe.

Nach allem, was über die Art und Weise der Einschleppung der Cholera ermittelt werden konnte, erscheint es mir immer noch als das Wahrscheinlichste, daß sie durch das Wartepersonal and zwar auf direktem Wege von Hamburg aus geschehen ist.

Es ist zu bedauern, daß über diesen Punkt keine volle Sicherheit zu gewinnen war. Wenn aber, wie es tatsächlich geschehen ist, aus diesem Mangel gefolgert wurde, daß damit der eigentliche Kern der Frage, welche uns durch die Nietlebener Epidemie gestellt ist, ungelöst geblieben sei, und daß somit die ganze Untersuchung ihre Bedeutung verliere, dann irrt man sehr. Es wäre ja gewiß recht schön gewesen, namentlich für den Laien, wenn man die Person, welche die Cholera nach Nietleben vermutlich gebracht hat, bestimmt hätte bezeichnen können, aber eine das ganze Gebäude zum Einsturz bringende Lücke entsteht dadurch nicht, daß diese Person unentdeckt geblieben ist. In welcher Weise die Cholera durch den menschlichen Verkehr verbreitet wird, das haben wir im Laufe der jetzigen Epidemie vielhundertfach erfahren und wir müssen, wenn es ausnahmsweise einmal nicht gelingt, den Zusammenhang zwischen verschiedenen Seuchenherden aufzufinden, annehmen, daß es sich auch in solchem Falle ebenso verhalten haben wird, wie in der weitaus überwiegenden Mehrzahl der übrigen Fälle, in denen der Nachweis der Verschleppung gelungen ist. Es wäre doch ein kindisches Verlangen, wenn gefordert würde, daß die Choleraforschung entweder jede Choleraverschleppung unter allen Umständen und trotz des so verwickelten menschlichen Verkehrs klarlegen oder überhaupt auf ihre Untersuchungen verzichten soll. In bezug auf die Nietlebener Epidemie können wir es als vollkommen gesichert ansehen, daß die Cholera von dem Hamburger Seuchenherd und zwar durch den Personenverkehr eingeschleppt ist. Die bei dieser Epidemie gewonnenen wichtigen Erfahrungen und die ebenso wichtigen aus diesen wieder zu entnehmenden Lehren verlieren nicht im geringsten dadurch an ihrem Wert, daß die infizierende Person selbst nicht mehr bezeichnet werden konnte, ebenso wie auch die Hamburger Epidemie nicht weniger lehrreich für uns ist, weil der einzelne russische Auswanderer nicht mehr namhaft gemacht werden kann, der den ersten Krankheitskeim dorthin gebracht hat.

In bezug auf die Maßregeln, welche in Nietleben zur Bekämpfung der Seuche zur Anwendung gekommen sind, ist folgendes mitzuteilen.

Schon im Sommer 1892, als die Cholera in Hamburg ausbrach, war von der. Direktion angeordnet, daß in allen Abteilungen nur gekochtes Trinkwasser benutzt werden solle, und es war, um genügende Mengen von abgekochtem Wasser immer in Vorrat zu haben, die Einrichtung getroffen, daß in der gemeinschaftlichen Küche zwei große 
kupferne Kessel, von denen jeder 400 Liter Inhalt hatte, zum Abkochen von Wasser beständig in Betrieb waren. Anfangs soll aus der Küche das gekochte Wasser in reichlicher Menge durch die Wärter abgeholt sein, aber im Laufe der Zeit nahm der Gebrauch an gekochtem Wasser so weit ab, daß kurz vor dem Ausbruch der Epidemie nur noch zwei bis drei Kessel voll, also 800 bis 1200 Liter, im Laufe einer Woche geholt wurden.

Sofort nach dem Beginn der Epidemie wurde diese Maßregel ron neuem eingeschärft und es sollen seitdem wieder ein bis zwei Kessel voll Wasser täglich gebraucht sein.

Einen wesentlichen Nutzen kann ich in dieser Einrichtung nicht finden. Wenn Mensçhen ihr sämtliches Brauchwasser in gekochtem Zustande beziehen können, dann wird damit allerdings eine Wasserinfektion ausgeschlossen werden. Aber wenn in einer Irrenanstalt die Verabreichung von abgekochtem Trinkwasser angeordnet wird, während die Geisteskranken daneben an Badewasser, Waschwasser, Klosettspülung usw. kommen können und es außerdem fraglich ist, ob auch alle Wärter so gewissenhaft sind, daß sie das Wasser von der Kochstelle holen, dann wird die Auswahl des Wassers wohl meistens durch den besseren Geschmack des ungekochten Wassers oder durch die Bequemlichkeit des Wärters bestimmt werden und man darf sich nicht dem Glauben hingeben, daß mit einer derartigen Maßregel ein zuverlässiger Schutz gegen Cholerainfektion gegeben ist.

Es wurde denn auch, als die eigentliche Ursache der Epidemie erkannt war, in Aussicht genommen, die Anstalt gegen das infizierte Leitungswasser möglichst bald und vollständig abzusperren. Einer sofortigen Absperrung stellten sich aber unüberwindliche Hindernisse entgegen und es zeigte sich in diesem Falle, wie außerordentlich schwierig es ist, eine zentralisierte Wasserversorgung, welche mit allen Teilen des versorgten Gebietes in Verbindung steht und mit dem Leben und Treiben in demselben gewissermaßen verwachsen ist, plötzlich abzuändern. An einen Ersatz für das auszuschließende Wasser fehlte es zwar nicht, da die Stadt Halle sich sofort bereit erklärt hatte, von ihrem Leitungswasser in Wagen, die sonst zum Sprengen benutzt wurden und zum Wassertransport sehr geeignet waren, täglich 20 bis $30 \mathrm{cbm}$ nach der Anstalt schicken zu wollen und vom 20. Januar ab mit der Zufuhr von Wasser begonnen hatte. Aber mit der so zur Verfügung gestellten Wassermenge konnte doch nur der Bedarf in der Küche und in den Krankenabteilungen gedeckt werden, zur Speisung der Dampfkessel, zur Versorgung der Waschküche und zur Klosettspülung mußte das infizierte Wasser auch ferner dienen und so blieb denn nichts anderes übrig, als die Auslaßhähne in den Krankenabteilungen, in der Küche und sonstigen Wirtschaftsräumen zu sperren, die Wasserleitung im übrigen aber in Tätigkeit zu lassen. Sehr bald stellte sich dann aber heraus, daß einzelne Wärter die noch in ihrem Besitz gebliebenen Schlüssel zur Wasserleitung trotz der strengsten Anordnungen der Direktion benutzt hatten, um Leitungswasser für ihre Abteilung zu erhalten, offenbar aus Bequemlichkeit. Es war auch beobachtet, daß Geisteskranke an die Klosettspülung gegangen waren und das Wasser getrunken hatten. So mußte schließlich auch die Klosettspülung geschlossen und dem Wartepersonal die Schlüssel zur. Wasserleitung abgenommen werden. Erst vom 25. Januar ab konnte man darauf rechnen, daß die Anstaltsbewohner in Wirklich-. keit gar kein Leitungswasser mehr erhielten. Von diesem Zeitpunkte an nahm denn auch die Epidemie schnell ab. Selbstverständlich können sich Abschluß der Wasserleitung und Ende der Epidemie nicht vollständig decken. Der Abschluß ging, wie geschildert, nur allmählich vor sich und überdies konnte er keinen Einfluß auf die nicht durch Wasserinfektion sondern durch unmittelbare Übertragung, also durch sekundäre Infektion entstehende Cholerafälle haben. Aber die günstige Wirkung, welche die Schließung der Leitung gehabt hat, ist aus den Erkrankungszahlen doch leicht zu 
ersehen und wird noch deutlicher, wenn man sich die einzelnen nach dem 25. Januar entstandenen Fälle etwas näher ansieht.

Am 26. Januar erkrankten noch drei Personen, davon eine auf der Station der Unreinlichen (LI). Dieselbe hatte, wie konstatiert wurde, noch drei Tage vorher Leitungswasser getrunken. Der zweite Fall betraf einen Geisteskranken, welcher die beschmutzte Wäsche von der Cholerastation zur Desinfektionsanstalt zu befördern hatte und vermutlich infolge dieser Beschäftigung infiziert war.

Der 28. Januar ist mit zwei Cholerafällen notiert. Der eine davon ist wieder ein unreinlicher Pflegling von Abteilung LI, der andere Fall betrifft die Frau des Maschinenmeisters (im Beamtenhaus III). Letztere litt schon seit dem 24. Januar an Durchfall und hatte bis zu diesem Tage in ihrer Küche den Leitungshahn offen gehabt und auch gebraucht.

Am 31. Januar ein Cholerafall wieder von der Abteilung LI.

Der nächste Fall am 1. Februar war eine mit der Pflege der Choleralkranken beschäftigte Wärterin.

Dann folgte ein Fall am 4. Februar, über welchen nichts besonderes notiert ist, und ein Fail am 5. Februar von der mehrfach erwähnten Abteilung LI.

Nun kommt eine längere Pause, nach welcher am 10. Februar ein ganz vereinzelter Fall sich ereignete, bei dem anfangs gar kein Zusammenhang mit der übrigen Epidemie zu finden war, bis sich zur allseitigen Überraschung herausstellte, daß der Erkrankte trotz aller bisher aufgebotenen Vorsichtsmaßregeln doch noch an das Leitungswasser gelangt war. Ein Wärter hatte nämlich mit dem Schlüssel der Gasleitung, welcher zufällig auch zur Wasserleitung paßte, die Spülung des Pissoirs in Gang gesetzt und ein zufällig auf diese Station lzommender Heizer hatte gesehen, wie die Kranken mit den Händen das Wasser auffingen und tranken.

Infolge dieses Vorkommnisses ließ dann die Direktion sämtliche Wasserauslässe verlöten.

Die letzte Choleraerkrankung ereignete sich am 13. Februar bei einer Wärterin der Cholerastation. Dieser Fall dürfte, ebenso wie die Erkrankungen der anderen Wärterinnen dieser Station, als durch direkte Infektion entstanden aufzufassen sein.

Obwohl beim Beginn der Epidemie Zweifel bestanden, ob es sich wirklich um asiatische Cholera handle, so hatte die Direktion der Anstalt doch in richtiger Erkenntnis der drohenden Gefahr schon vom zweiten Tage ab alle Vorkehrungen getroffen, um eine weitere Verbreitung der Seuche auf die Umgebung zu verhüten. Es wurden keine Kranken entlassen und keine aufgenommen. Auch ordnete das Landratsamt an, daß Wärter und Wärterinnen, welche die Anstalt verlassen wollten, ihren zukünftigen Aufenthaltsort angeben mußten. In solchem Falle sollte dann die betreffende Ortsbehörde von der Ankunft der choleraverdächtigen Personen in Kenntnis gesetzt werden, um sie fünf Tage lang bezüglich ihres Gesundheitszustandes zu beobachten. Unnötige Besuche wurden während der Epidemie nicht zugelassen und den von auswärts kommenden Personen, welche in der Anstalt verkehren mußten, untersagt, in der Anstalt etwas zu genießen. Anderer als dieser unbedeutenden und durchaus gerechtfertigten Verkehrsbeschränkungen hätte es für die Anstalt gewiß nicht bedurft. Aber es wurden darüber hinaus und trotz meines Abratens von seiten der Stadt Halle der Anstalt gegenüber noch einige weitere, übrigens ganz harmlose Beschränkungen zur Anwendung gebracht, offenbar in der Absicht, die Einwohnerschaft von Halle, welche durch das so plötzlich über Nietleben hereingebrochene Unglück in Schrecken gesetzt war, zu beruhigen.

Die zweckmäßige Unterbringung und Isolierung der zahlreichen Cholerakranken ließ sich glücklicherweise ohne allzu große Schwierigkeiten bewerkstelligen. Zwei neu 
eingerichtete Pavillons (U, W), welche abseits liegen, waren zufällig noch nicht belegt, ein dritter zur selben Gebäudegruppe gehöriger Pavillon $(V)$ konnte evakuiert werden und es standen somit drei Gebäude zur Verfügung. Das in der Mitte gelegene (W) wurde zum Choleralazarett eingerichtet, die eine Seite für Männer und die andere für Frauen. Die Pavillons $U$ und $V$ dienten als Beobachtungsstation für Choleraverdächtige ( $U$ für Frauen, $V$ für Männer).

Das Auffinden der mit verdächtigen Symptomen behafteten Kranken war anfangs nicht ohne Schwierigkeit, da die Geisteskranken aus eigenem Antriebe sich meistens nicht krank meldeten und dem Wartepersonal nur die gröberen Terdauungsstörungen auffielen. Infolgedessen wurde die in Hamburg unter ähnlichen Verhältnissen sehr bewährt gefundene Einrichtung getroffen, daß alle, auch die anscheinend gesunden Pfleglinge nur noch Nachtstühle benutzen durften. Auf diese Weise entgingen auch die leichtesten Durchfälle nicht mehr der Beobachtung. Natürlich mußten auch solche als verdächtig erscheinen und es füllten sich, da ihre Zahl nicht gering war, die Beobachtungsstationen bald in besorgniserregendem Maße. In Hamburg wurden die Verdächtigen immer sofort bakteriologisch untersucht und die mit nicht Cholera Behafteten möglichst bald entlassen, wodurch eine zu starke Ansammlung von Menschen in der Beobachtungsstation leicht zu vermeiden ist. In Nietleben ließ sich die bakteriologische Untersuchung aber anfangs wegen Mangel an Apparaten und Hilfskräften nicht durchführen. Erst vom 1. Februar ab trat ein für diesen Zweck mit größter Beschleunigung in der Anstalt eingerichtetes bakteriologisches Laboratorium in Tätigkeit und es konnten regelmäßig alle verdächtigen Dejektionen untersucht werden. Alle Kranken der Beobachtungsstation, deren Dejektionen frei von Cholerabakterien waren, kamen zunächst noch auf einige Tage in eine Zwischenstation und erst nachdem sie auch hier gesund geblieben waren, in ihre eigentliche Abteilung zurück. Die bakteriologische U'ntersuchung bewirkte auch in Nietleben sehr bald, daß die Beobachtungsstationen leer wurden, und sie verschafften außerdem die so wünschenswerte sichere Kenntnis über den eigentlichen Stand der Epidemie. Während vorher die große Zahl der Verdächtigen eine nicht geringe Beunruhigung veranlaßte, ließ sich vom 1. Februar ab der weitere Gang der Epidemie übersehen, was gerade gegen Ende der Epidemie von besonderer Wichtigkeit ist.

Auch in Nietleben sind ebenso wie gelegentlich der Hamburger Nachepidemie bei der bakteriologischen Untersuchung mehrere Cholerafälle aufgefunden, welche zwar nicht zu den leichtesten aber doch zu denjenigen zu rechnen sind, welche wegen des nur geringfügigen Durchfalls klinisch nicht mit Sicherheit zur Cholera gerechnet wären, höchstens hätte man sie als leichte Cholerine bezeichnen können. Ferner ist bemerkenswert, daß bei zwei Rekonvaleszenten noch etwa drei Wochen nach dem Beginn der Erkrankung Cholerabakterien in den Ausleerungen nachgewiesen werden konnten. Leider sind beide Fälle nicht von Anfang an bakteriologisch untersucht, so daß die Zeitdauer, bis zu welcher die Cholerabakterien im Darm sich halten können, bei ihnen nicht auf den Tag angegeben werden kann. Sie bestätigen aber die prophylaktisch so wichtige auch anderweitig gemachte Beobachtung and lehren, daß die Infektionsgefahr nicht immer mit dem Ablauf des eigentlichen Choleraanfalls verschwunden ist.

Außer der Isolierung der Erkrankten wurde auch gleich von Anfang die Desinfektion der Ausleerungen und aller damit beschmutzter Gegenstände nach Kräften durchgeführt. Die Desinfektion der Wäsche und Kleider geschah in Dampfapparaten, die flüssigen Abgänge wurden teils durch Karbol-Seifenlösungen, teils durch Ätzkalk desinfiziert.

Gegen Ende der Epidemie, als die Fälle nur noch vereinzelt auftraten, konnte man auch an die Desinfektion der Krankenräume gehen. Es wurden zu diesem Zwecke 
die einzelnen Zimmer oder ganze Abteilungen von Kranken evakuiert, die Wände und Fußböden, Bettstellen usw. mit desinfizierender Flüssigkeit abgewaschen, reichlich gelüftet und alsdann wieder mit den inzwischen gebadeten und mit desinfizierter Wäsche, Kleidern, Betten versehenen Kranken belegt. Ereignete sich trotzdem ein neuer Fall, wie beispielsweise die früher beschriebenen Erkrankungen am 5. und 10. Februar, dann wurde die gesamte Prozedur wiederholt.

Besondere Beachtung erforderten noch die Wasserleitung und die Rieselfelder. Da man noch nicht weiß, wie lange Zeit die Cholerabakterien im Wasser oder auf dem Boden, selbst im Winter, sich lebensfähig halten können, so durfte die Wasserleitung nicht ohne vorgängige Desinfektion wieder in Gebrauch genommen werden. Auch für die Rieselfelder schien eine Desinfektion erforderlich, denn es waren auf demselben wiederholt und an verschiedenen Stellen die Cholerabakterien nachgewiesen und es war zu befürchten, daß letztere bei eintretendem Tauwetter mit dem Schmelzwasser in größeren Mengen in die Saale gespült würden.

Die Desinfektion der Leitung bot keine allzu großen Schwierigkeiten. Man hätte dafür verdünnte Kalkmilch, Karbollösung oder eine Mineralsäure verwenden können. Man entschied sich für Karbolsäure, und es wurde eine 3prozentige Lösung derselben von dem Pumpschachte aus in alle Teile der Leitung getrieben, 24 Stunden darin gelassen und dann mit Halleschem Wasser wieder ausgespült. Man darf wohl annehmen, daß dadurch eine zuverläßige Desinfektion bewirkt ist. Als ein Übelstand bei diesem Verfahren könnte bezeichnet werden, daß das Leitungswasser noch längere Zeit nachher einen unangenehmen Karbolgeschmack hatte. Aber vor den beiden anderen erwähnten Desinfektionsmitteln hat die Karbolsäure den Vorteil, daß eine Verschlammung der Röhre, wie sie bei Anwendung von Kalkmilch befürchtet wurde, mit Sicherheit zu vermeiden war, ebenso eine Beschädigung der Innenwand der Röhren, welche durch Mineralsäuren hätte entstehen können.

Viel schwieriger war die Desinfektion der Rieselfelder. An eine Desinfelstion der ganzen Fläche konnte man wegen der außerordentlichen Mengen der dazu erforderlichen Desinfektionsmittel nicht denken. Dieselbe war aber auch nicht notwendig, da die Rieselflüssigkeit sich nicht über das ganze Feld ausgebreitet hatte, sondern nur in bestimmten: schmalen Rinnen geflossen war. Es wurde deswegen die Desinfektion in der Weise zu erreichen gesucht, daß Kalkmilch dem Rieselwasser in großen Mengen und so lange zugesetzt wurde, bis die am unteren Ende des Rieselfeldes in dem Hauptabzugsrohr zum Vorschein kommende Flüssigkeit stark alkalisch reagierte. Einige Zeit darauf, als die Rieselfelder wieder auf Cholerabakterien untersucht wurden, konnten letztere nicht mehr aufgefunden werden. Sie waren verschwunden, ob es nun infolge des Desinfektionsverfahrens, oder, was mir wahrscheinlicher ist, infolge der klimatischen Einflüsse, mag dahingestellt bleiben.

Obwohl so frühzeitig als möglich alle Abgänge der Kranken desinfiziert wurden, so mußten doch schon ganz zu Anfang der Epidemie undesinfizierte Dejektionen in die Schmutzwässer und mit diesen in die Saale geflossen sein. Außerdem war es fraglich, ob durch die Desinfektion auch wohl sämtlicher Infektionsstoff zuverlässig vernichtet würde und ob nicht auch später noch Cholerabakterien in die Saale geraten könnten. Wenn diese Befürchtungen zutrafen, dann war es nicht unmöglich, daß durch die Saale der Infektionsstoff weiter fortgetragen wurde und daß Choleraausbrüche in den flußabwärts an der Saale gelegenen Ortschaften sich entwickelten. Einer auf diesem Wege entstehenden Weiterverbreitung der Seuche mußte so frühzeitig als möglich entgegengetreten werden. Wie berechtigt diese Voraussetzungen waren, zeigten sehr bald das fast gleichzeitige Auftreten der Cholera in mehreren Ortschaften an der Saale und der 
Nachweis der Cholerabakterien auf den Rieselfeldern und im Wasser der Saale unterhalb von Nietleben.

Aber in welcher Weise sollte die Weiterverbreitung der Cholera durch das Saalewasser verhütet werden?

Flüsse kann man nicht desinfizieren, man kann höchstens die Uferberölkerung auf die Gefahren, welche mit der Benutzung des Flußwassers verbunden sind, aufmerksam machen. Dies geschah denn auch in eindringlichster Weise; es wurde nicht nur durch die betreffenden Behörden vor dem Gebrauch des Saalewassers gewarnt, sondern die Verwendung desselben wurde geradezu verboten. Allerdings verhehlte man sich nicht, daß das Verbot in Wirklichkeit nicht durchzuführen sei und daß seine Wirkung eigentlich nur darin bestand, der Bevölkerung die vorhandene Gefahr als eine besonders ernste erscheinen zu lassen. Der größte Wert wurde denn auch nicht auf die Vermeidung der Infelition, die sich ja nicht durchführen ließ, gelegt, sondern darauf, daß nach zustande gekommener Infektion alles geschah, um neu entstandene Seuchenherde so schnell als möglich unschädlich zu machen. Zu diesem Zwecke wurden Arzte, Geistliche, Lehrer, Gemeindevorsteher und Gendarmen, kurz alle Personen, bei denen man ein gewisses Interesse und namentlich auch Verständnis voraussetzen konnte, durch eine für alle Ortschaften an der Saale geltende Verordnung der Regierung von Merseburg aufgefordert, jeden irgendwie verdächtigen Cholerafall zu melden.

Sehr bald nach der Veröffentlichung der Verordnung liefen solche Meldungen ein und jeder Fall wurde sofort durch den Physikus des Saalekreises an Ort und Stelle und bakteriologisch im hygienischen Institut zu Halle untersucht, um möglichst schnell die wirklichen Cholerafälle herauszufinden. Dies ist auch, wie man annehmen darf, überall gelungen und damit die Möglichkeit gewonnen, gegen die eben im Entstehen begriffenen Choleraherde mit allen Mitteln energisch vorzugehen.

Zuerst zeigte sich Cholera in der Ortschaft Trotha, am rechten Saaleufer gelegen, $5 \mathrm{~km}$ unterhalb von Halle. Hier erkrankten am 24. Januar 3 Personen an Cholera, von denen eine starb. Daran schloß sich infolge von Sekundärinfektion noch ein Fall am 29. Januar.

Dann wurde die Cholera nachgewiesen am 28. Januar in Wettin, $20 \mathrm{~km}$ unterhalb Halle am rechten Saaleufer, bei einer Frau, welche einige Tage später starb. Diese Frau war anscheinend bereits am 24. Januar erkrankt, hatte aber erst am 28., als sich ihr Zustand verschlimmerte, einen Arzt zugezogen. Die weiteren in Wettin angestellten Nachforschungen haben nicht zur Entdeckung von sonstigen unzweifelhaften Cholerafällen geführt. Von einem Falle, welcher dringend verdächtig erschien, waren keine Ausleerungen mehr zur bakteriologischen Untersuchung zu erhalten gewesen.

In dem Dorfe Cröllwitz am linken Saaleufer, 2 bis $3 \mathrm{~km}$ unterhalb von Nietleben, wurde am 30. Januar eine verdächtige Erkrankung gemeldet und noch am selben Tage als Cholera konstatiert. Hier kam es zu 6 Erkrankungen mit 2 Todesfällen. Da 5 Fälle die Mitglieder einer einzigen Familie betrafen, welche auch nicht gleichzeitig, sondern in Abständen von mehreren Tagen erkrankten, so werden dieselben zum Teil durch Sekundärinfektion entstanden sein.

Schließlich wurde noch in einem zweiten auf dem linken Saaleufer gelegenen Dorfe, Lettin ( 6 bis $7 \mathrm{~km}$ unterhalb Nietleben) die Cholera bei drei Personen in der Zeit vom 2. bis 4 . Februar nachgewiesen, von denen eine starb.

Wenn man die angeführten Ortschaften auf dem Plan Fig. 2 (sie sind durch Unterstreichung kenntlich gemacht) aufsucht, dann fällt sofort auf, daß sie sämtlich unterhalb von Nietleben liegen und sich regellos auf beide Ufer der Saale verteilen. Sie sind nicht durch Verkehrsstraßen miteinander verbunden, haben auch erwiesenermaßen untereinander 
nicht den geringsten Verkehr. Die einzige bestehende Verkehrsmöglichkeit, die Schifffahrt auf der Saale, war vollkommen ausgeschlossen, weil der Fluß mit Ausnahme einiger Stellen, wo die Strömung besonders stark ist, mit dickem Eis bedeckt war. Irgendwelche Beziehungen zur Irrenanstalt Nietleben hatte keine dieser Ortschaften. Das einzige, was ihnen gemeinschaftlich ist, ist die Benutzung des Saalewassers und diese hatte trotz des früher erwähnten strengen Verbots in allen Fällen stattgefunden, sie konnte in jedem der befallenen Orte mit Leichtigkeit nachgewiesen werden.

In Wettin hatte man vor den an der Saale gelegenen Häusern Löcher durch das Eis geschlagen, um an das Wasser kommen zu können und es war schließlich nur clurch polizeiliche Bewachung des Saaleufers zu erreichen, daß die Bevölkerung nicht immer von neuem das Saalewasser in die Häuser holte.

In Cröllwitz mußten aus demselben Grunde die zugänglichen Stellen des Flusses durch Bretterzäune abgeschlossen werden. Die in diesen beiden Ortschaften erkrankten Personen gaben auch ohne weiteres $\mathrm{zu}$, daß sie Saalewasser im Haushalt benutzt hatten.

In Trotha und auch in Lettin wurde dagegen behauptet, daß das Verbot streng durchgeführt sei und niemand Wasser aus der Saale entnommen habe. Und dennoch war in beiden Orten das Saalewasser im Spiele gewesen. Man hatte zwar nicht das Wasser aus dem Flusse direkt geholt, aber die Erkrankten hatten nachweislich aus Wasserleitungen getrunken, die Saalewasser zur Tränkung von Vieh herbeiführten. In Lettin bestand eine solche Wasserleitung für die Schäferei der Domäne; aus dieser hatten der Schäfer und ein Knecht getrunken, welche beide an Cholera erkrankten. In der Wohnung des Schäfers, dessen Krankheit schnell tödlich verlief, wurde noch ein Kind desselben offenbar direkt infiziert.

Ganz besonders interessant gestaltete sich der. Choleraausbruch in Trotha. Die Krankheit beschränkte sich hier vollständig auf ein Haus. Aber dieses Haus war eine Art von Arbeiterkaserne; es wohnten darin 14 Familien mit 62 Personen. Jede Familie hatte einen oder höchstens zwei Räume zur Verfügung. Das Auftreten der Cholera in dieser dicht zusammengedrängten, unter den ungünstigsten hygienischen Verhältnissen lebenden Menschenmase mußte um so bedenklicher erscheinen, als in einer früheren Epidemie (1866) dieses selbe Haus in der schwersten Weise von Cholera heimgesucht war. Es sollen damals viele Choleraleichen (16 bis 18, eine zuverlässige Zahl konnte ich nicht in Erfahrung bringen) aus demselben beerdigt sein. Gleich bei der ersten Untersuchung fiel es nun aber auf, daß von den zahlreichen Bewohnern drei Menschen an ganz verschiedenen Stellen des Hauses, einer im Erdgeschoß, einer im mittleren und einer im oberen Stock erkrankt waren und daß die Erkrankten Männer waren; Frauen und Kinder blieben zunächst vollkommen verschont. Die weitere Untersuchung ergab nun folgendes. Die Arbeiterfamilien, zum größten Teil aus Oberschlesien stammend, lebten ganz für sich und hatten mit der Stadt Halle oder der Anstalt Nietleben gar keinen Verkehr, selbst mit den übrigen Dorfbewohnern verkehrten sie wenig. Die erkrankten Männer waren in einer Zuckerfabrik, zu welcher die Arbeiterkaserne gehörte, mit der Fütterung des Mastviehs beschäftigt und zu den Viehställen führte auch hier eine SaaleWasserleitung. Allerdings ging ein Zweigrohr der Leitung auch in die Arbeiterkaserne und für gewöhnlich benutzten sämtliche Bewohner derselben das Saalewasser. Aber gerade zu dieser Zeit war das Zweigrohr eingefroren und nur in die Viehställe kam noch das Saalewasser. Die Frauen und Kinder des Hauses mußten sich deswegen mit dem Wasser aus den benachbarten Brunnen behelfen, während die Männer, wie sie selbst erzählten, das Leitungswasser im Stalle getrunken hatten. Insbesondere soll der am schwersten Erkrankte und an der Cholera Gestorbene, nachdem er viel Pferdewurst gegessen hatte, reichlich Wasser getrunken haben. 
Das, was hier über die Cholera in den Ortschaften an der Saale berichtet ist und namentlich die Art und Weise, wie sie sich in den einzelnen Fällen, z. B. in Trotha, verhalten hat, läßt keine andere Deutung zu, als daß der Cholerainfektionsstoff, mag man sich ihn nun vorstellen, wie man will, durch das Wasser verschleppt rurde. Wie hätte sonst mitten im harten Winter unmittelbar nach dem Choleraausbruch in Nietleben die Seuche ihren Weg in abgelegene, weder untereinander noch mit dem C'holeraherd selbst in einer anderen Weise verbundene Ortschaften finden und sich überdies nur auf die am Flusse gelegenen Ortschaften beschränken sollen? Wer hier noch leugnen will, daß das Wasser der Träger des Cholerainfektionsstoffes sein kann, der ist für die Logik der Tatsachen überhaupt nicht zugänglich.

Daraus, daß die Cholera in Wettin, also drei Meilen von dem Ausgangsherd entfernt, ihr Ende erreichte, könnte man vielleicht schließen, daß die Cholerabakterien, wenigstens im Winter, nicht auf größere Entfernungen in lebensfähigem Zustande geschwemmt werden können, aber im vorliegenden Falle wird sich diese Frage doch nicht entscheiden lassen und zwar aus folgendem Grunde. Wenige Kilometer unterhalb von Wettin mündet bei Friedeburg ein von Westen herkommendes Flüßchen, die Schlenze, in die Saale. Dieselbe führt die aus den Mansfelder Gruben mit dem Schlüsselstollen kommenden Grubenwässer der Saale zu. Seit einiger Zeit haben die Grubenwässer wahrscheinlich durch Auslaugung von unterirdischen Salzlagern einen so hohen Salzgehalt angenommen, daß das Wasser der Schlenze beim Einfluß in die Saale etwa 10 Prozent Kochsalz hat. Infolgedessen ist das Saalewasser unterhalb Friedeburg so salzig, daß es zu keinem Gebrauch, wenigstens für häusliche Zwecke, mehr zu verwenden ist. Hier ist es nicht mehr erforderlich, Gendarmen am Ufer aufzustellen, oder Zäune zu ziehen, um die Bevölkerung vom Fluß abzuhalten. Von hier ab verbietet sich der Gebrauch des Wassers von selbst und es ist sehr wahrscheinlich, daß das Verschontbleiben der unterhalb Friedeburg gelegenen Flußstrecke vielmehr diesem L'mstande, als dem Absterben der Cholerabakterien zuzuschreiben ist.

In den Choleraorten an der Saale wurden überall die im Vorjahr so bewährt gefundenen Maßregeln energisch durchgeführt. Die Erkrankten wurden isoliert, ihre Angehörigen und sonst der Infektion Verdächtige mehrere Tage sorgfältig beobachtet und bei den geringsten Verdauungsstörungen bakteriologisch untersucht, die Abgänge der Kranken, ihre Wäsche und die Krankenräume desinfiziert.

Besonders schwierig gestalteten sich die Verhältnisse in Trotha, wo Hals über Kopf für etwa 50 Menschen, die man unmöglich länger in der Arbeiterkaserne zusammengepfropft lassen konnte, eine Unterkunft geschaffen werden mußte. Es blieb hier nichts weiter übrig, als das Schulhaus für diesen Zweck herzurichten, was auch in kürzester Frist ausgeführt wurde. Nur die Erkrarkten und deren Familien blieben in dem Hause. Unter den letzteren kam dann auch nur noch eine Erkrankung bei einem Knaben vor, der sich offenbar gleich zu Anfang infiziert hatte, als er noch bei der Pflege des schwererkrankten Vaters in einer engen schmutzigen Kammer behilflich gewesen war. Unter den übrigen nach dem Schulhaus evakuierten Personen ist kein einziger Cholerafall vorgekommen.

Dank den allseitigen und unermüdlichen Anstrengungen, unter denen ganz besonders die aufopfernde Tätigkeit des Landrats und des Physikus des Saalekreises hervorzuheben ist, gelang es uiberall, die neuenstandenen Choleraherde im Keime zu ersticken und zu verhüten, daß die Cholera sich von Nietleben aus zunächst an der Saale abwärts und, wie es ohne diese Bemühungen wohl nicht anders zu erwarten war, über weitere Teile der Provinz Sachsen verbreitete. 
Wenn man sich mit der Nietlebener Cholera-Epidemie zu beschäftigen hat, dann drängt sich unwillkürlich die Frage auf, ob denn dies Unglück, das einer nicht unbeträchtlichen Zahl von Menschen das Leben gekostet hat, nicht zu verhüten gewesen wäre. Gewiß war es zu verhüten. Es hätte nur Sorge dafür getragen werden müssen, daß die an und für sich zweckmäßigen sanitären Einrichtungen der Anstalt, das Wasserwerk mit den Filtern und die Kanalisation mit den Rieselfeldern, richtig funktionierten. Ich möchte von vornherein Einsprache dagegen erheben, wenn etwa der Versuch gemacht werden sollte, aus dem Versagen der Filter und der Rieselfelder von Nietleben Gründe gegen die Zweckmäßigkeit dieser Einrichtungen im allgemeinen abzuleiten. Wie man in Zukunft über die Wasserfiltration mit Rücksicht auf die letzten Choleraerfahrungen zu urteilen hat, darüber habe ich mich bereits in der Abhandlung über „Wasserfiltration und Cholera" ausgesprochen und bezüglich des Rieselverfahrens möchte ich mich dahin äußern, daß ich die Behandlung der Schmutzwässer durch Berieselung, wenn sie sachgemäß ausgeführt wird, auch jetzt noch für das beste Reinigungsverfahren halte, welches wir zur Zeit besitzen. Es lag, wie gesagt, nicht an den Einrichtungen selbst, sondern an der fehlerhaften Behandlung derselben, daß sie den auf sie gesetzten Erwartungen nicht entsprochen haben. Also müßten wohl diejenigen, unter deren Leitung und Aufsicht die sanitären Einrichtungen der Anstalt standen, verantwortlich gemacht werden. Ich glaube, daß man auch dazu nicht das Recht hat. Nicht einzelne Personen sind hier zu beschuldigen, sondern die Verhältnisse, unter denen wir uns heutzutage befinden.

Man kann doch unmöglich verlangen, da $\beta$ der ärztliche Direktor einer Irrenanstalt oder der technische Beamte der Regierung neben ihren Spezialkenntnissen auch noch bessere Hygieniker sein sollen, als es manche Professoren der Hygiene sind, denen es auch noch an dem genügenden Verständnis für die feineren Vorgänge beim Filtrationsprozeß in Sandfiltern und im Boden fehlt. Überhaupt darf in den Anforderungen an die hygienische Verantwortlichkeit der ärztlichen Anstaltsdirektoren nicht zu weit gegangen werden. Es gibt gewisse Kenntnisse, die man sich nicht mit dem gewöhnlichen für praktische Ärzte berechneten hygienischen Studium aneignet und die auch nicht aus Büchern zu erwerben sind, sondern nur durch Spezialstudien und durch die in der Praxis gemachten Erfahrungen erlangt werden. Auf diesem Gebiet hört die Verantwortlichkeit der mit gewöhnlicher hygienischer Vorbildung ausgerüsteten Ärzte auf und ebensowenig wie man einen Anstaltsdirektor dafür zur Verantwortung ziehen wird, daß in seiner Anstalt ein Dampfkessel wegen eines leicht zu erkennenden und zu vermeidenden Fehlers explodiert ist, ebensowenig soll man denselben auch wegen einer Choleraexplosion infolge von Fehlern, die bei der Wasserfiltration und bei der Berieselung gemacht sind, zur Rechenschaft ziehen.

Hier gibt es nur ein Auskunftsmittel, auf das ich bereits früher hingewiesen habe und an dieser Stelle nochmals so dringend als möglich befürworten möchte, das ist die staatliche Überwachung derartiger Anlagen durch Spezial-Sachverständige, die mit den einschlägigen Verhältnissen vertraut sind und, mitten in der Praxis stehend, sich die erforderlichen Erfahrungen angeeignet haben.

Aber wird sich der Staat hierzu verstehen? Soweit ich die Verhältnisse zu übersehen vermag, glaube ich nicht, daß er dies schon bald tun wird. Einmal wird man sich bestimmt dazu entschließen müssen; aber vorläufig hält man die ganze Frage noch nicht für spruchreif. Immer wieder begegnet man in den maßgebenden Kreisen der Ansicht, daß die Gelehrten ja unter sich noch nicht einig seien und daß man deswegen noch damit warten müsse, bestimmte Stellung zu dieser Frage zu nehmen. Von bakteriologischer Seite werde zwar behauptet, daß Cholera und Typhus durch Wasser verbreitet werden könnten, aber von anderer nicht minder autoritativer Seite werde das bestritten, und 
man wisse ja überhaupt noch nicht, ob die Cholerabakterien auch wirklich die Ursache der Cholera seien, und ob sie verdienten, bei der Bekämpfung der Cholera so berücksichtigt zu werden, wie von den Bakteriologen angeraten werde. Wie tief derartige Anschauungen eingewurzelt sind, geht am besten daraus herror, daß vor noch nicht so langer Zeit der Grundsatz aufgestellt wurde, daß die Lehrstühle der Hygiene abwechselnd zu besetzen seien mit einem Hygieniker, welcher zugleich Bakteriologe sei, und mit einem solchen, der der entgegengesetzten Richtung angehöre, das heißt doch wohl, der von Bakteriologie nichts hält.

Wer sind denn nun aber die Gelehrten, welche über die Bedeutung der Cholerabakterien nicht einig sein sollen? Selbstverständlich können dies doch nur Leute sein, welche sich selbst mit Bakteriologie beschäftigt haben, also die sogenannten Bakteriologen. Nun kann ich mit Bestimmtheit behaupten, daß wohl kein namhafter Bakteriologe " existiert, welcher nicht die Cholerabakterien als die nächste Ursache der Cholera gelten läßt. Selbst die Münchener Schule, welche am längsten opponiert hat, mußte sich ganz allmählich dazu verstehen, ihm wenigstens die Rolle des $\mathrm{X}$ in der bekannten Gleichung mit drei Unbekannten einzuräumen. Der einzige Meinungsunterschied unter den in dieser Frage allein kompetenten Gelehrten besteht noch darin, welche weiteren in und außerhalb des Menschen wirkenden Hilfsmomente und in welchem Lmfange solche anzunehmen sind. Aber über die eigentliche Hauptfrage sind die Gelehrten rollkommen einig.

Diejenigen Gelehrten, welche ron den Cholerabakterien nichts wissen wollen, sind also keine Bakteriologen, ihre Gelehrsamkeit wurzelt auf einem anderem Gebiete. Aber sie haben in der Diskussion über die Cholerafrage einen großen Torteil. Sie machen es nämlich ebenso, wie andere Leute, die von einer Sache nichts verstehen; sie reden darüber mit einer Bestimmtheit und Sicherheit, welche dem Laien, in diesem Falle also dem NichtBakteriologen, imponieren muß und bisher auch noch immer imponiert hat. Ton dem ärztlichen Publikum und von den Behörden, welche mit Choleraangelegenheiten zu tun haben, werden sie deshalb als Autoritäten, als ,Gelehrte" , angesehen, die mit den anderen Gelehrten noch nicht einig geworden sind.

Dafür, daß die Nicht-Bakteriologen aufhören würden, in diese Fragen hineinzureden und immer vom neuem dem großen Publikum den Sinn zu verwirren, liegen bis jetzt noch keine Anzeichen vor. Wenigstens hat $v$. P et t e n k of e r, welcher doch, wie er selbst bei jeder Gelegenheit hervorhebt, sich nicht mit Bakteriologie beschäftigt hat, noch in seiner letzten Publikation sich gegen den jetzt von allen Bakteriologen und selbst von seinen eigenen Schülern ${ }^{1}$ ) eingenommenen Standpunkt erklärt und sich mit der bakteriologischen Seite der Cholerafrage mit Scherzen über den „,Bazillenfang“ und über die „Unmöglichkeit, den Verkehr pilzdicht zu machen" abgefunden, obwohl er doch recht gut wissen sollte, daß das Prinzip der jetzt zur Anwendung kommenden Choleramaßregeln nicht darin beruht, den Verkehr pilzdicht zu machen. Hoffentlich wird er sich nach den Erfahrungen, welche in der letzten Epidemie mit den von ihm so hartnäckig bekämpften Maßregeln ${ }^{2}$ ) gemacht sind, schon überzeugt haben, daß dieselben denn doch nicht so schlecht sind, als er sich vorgestellt hat.

Wenn v. Petten $\mathrm{k}$ of er trotz alledem auch ferner auf seinem ablehnenden Standpunkt beharren sollte, so würde ich das zwar nicht vom wissenschaftlichen, jedoch

1) Emmerich, welcher mit v. Petten $\mathrm{k}$ of er zusammen den bekannten Versuch mit. dem Verschlucken von Cholerabakterien machte, hat in einer vor kurzem erschienenen Arbeit die Cholerabakterien ebenfalls als die Uxsache der Cholera anerkannt.

2) Ich meine hier selbstverständlich nur diejenigen Maßregeln, welche von ärztlicher Seite angeraten wurden, und nicht diejenigen, welche von einzelnen Behörden in ihrem Übereifer darüber hinaus angeordnet wurden. Über letztere urteile ich ebenso wie v. Petten $\mathrm{k}$ ofer. 
vom menschlichen Standpunkt begreifen. Es muß ihm, der mit seinen viele Jahre hindurch mit dem größten Aufwand von Genie und. Scharfsinn vertretenen Ansichten verwachsen und mit ihnen alt geworden ist, außerordentlich schwer werden, sich davon, wenigstens teilweise, zu trennen. Aber unbegreiflich ist es mir, daß ein Mann wie L i e b$\mathrm{r}$ e i $\mathrm{ch}$, welcher sich auch nicht mit Bakteriologie beschäftigt hat und wie fast jeder Satz in seinem kürzlich vor der Berliner Medizinischen Gesellschaft gehaltenen Vortrage $^{1}$ ) beweist, von Bakteriologie tatsächlich nichts versteht, außerdem offenbar auch nicht ein einziges Mal eine Choleradejektion bakteriologisch selbst untersucht hat, es unternehmen kann, über die bakteriologische Choleradiagnostik im besonderen und über die Bakteriologie mit ihren bisherigen Leistungen im allgemeinen den Stab zu brechen. Was soll wohl daraus werden, wenn auf der einen Seite die Gelehrten der Bakteriologie sich alle erdenkliche Mühe geben, um nachzuweisen, daß filtriertes Wasser auf seine Reinheit bakteriologisch geprüft werden muß, und auf der anderen Seite der Gelehrte Lie b r e i c h erklärt: „In bezug auf die Wasserfrage hat die Bakteriologie nichts Neues gebracht; gutes Wasser wurde schon früher verlangt; daß fauliges Wasser krank macht, wußten wir lange schon." Heißt das nicht mit aller Gewalt Verwirrung anrichten?

Ich fürchte, daß man, so lange solche Reden geführt werden, an maßgebender Stelle immer wieder sagen wird: Die Gelehrten sind noch nicht einig und es muß vorläufig alles beim Alten bleiben. Wenn uns dann aber, wie ich ebenfalls fürchte, solche Katastrophen, wie in Hamburg und Nietleben auch in Zukunft nicht erspart bleiben, dann möge man sich auch an diejenigen "Gelehrten" halten, welche sich das höchst verantwortliche Amt vindizieren, über Dinge zu reden, von denen sie nichts verstehen.

1) Deutsche Medizinische Wochenschrift, 1893, Nr. 26. 